\title{
WestVirginiaUniversity
}

THE RESEARCH REPOSITORY @ WVU

Graduate Theses, Dissertations, and Problem Reports

2005

\section{Suicide and socioeconomic context in the Appalachian region}

Joel A. Halverson

West Virginia University

Follow this and additional works at: https://researchrepository.wvu.edu/etd

\section{Recommended Citation}

Halverson, Joel A., "Suicide and socioeconomic context in the Appalachian region" (2005). Graduate Theses, Dissertations, and Problem Reports. 4154.

https://researchrepository.wvu.edu/etd/4154

This Dissertation is protected by copyright and/or related rights. It has been brought to you by the The Research Repository @ WVU with permission from the rights-holder(s). You are free to use this Dissertation in any way that is permitted by the copyright and related rights legislation that applies to your use. For other uses you must obtain permission from the rights-holder(s) directly, unless additional rights are indicated by a Creative Commons license in the record and/ or on the work itself. This Dissertation has been accepted for inclusion in WVU Graduate Theses, Dissertations, and Problem Reports collection by an authorized administrator of The Research Repository @ WVU.

For more information, please contact researchrepository@mail.wvu.edu. 


\title{
Suicide and Socioeconomic Context in the Appalachian Region
}

Joel A. Halverson

Dissertation Submitted to the Eberly College of Arts and Sciences at West Virginia University in Partial Fulfillment of the Requirements for the degree of

\section{Doctor of Philosophy}

in

\section{Geography}

\author{
Committee: \\ Robert Q. Hanham, Ph.D., Chair \\ Elizabeth Barnett, Ph.D. \\ Kobena Hanson, Ph.D. \\ Ken Martis, PhD. \\ Irene Tessaro, Dr.PH. \\ Morgantown, West Virginia \\ 2005
}

Keywords: suicide rates, suicide trends, socioeconomic context, industrial change, Appalachia 


\section{ABSTRACT \\ Suicide and Socioeconomic Context in the Appalachian Region}

Joel A. Halverson

Significant economic changes have occurred over the past thirty years that have altered the geoeconomic landscape of the United States. Although a considerable literature examines economic impacts that have resulted from these changes, there has been less work devoted to understanding the extraeconomic affects of economic change. Many places in the U.S.have experienced large-scale employment and industry losses over the past thirty years. At the same time some places have experienced rapid industrial and employment growth. Together these events represent the continued process of geographic uneven development and provide the context for examining potential affects that economic conditions and elements of change may have on local populations.

Some of the potential extraeconomic affects of large-scale economic changes include increasing levels of stress, anxiety, depression, and generally poor mental health among populations who suffer adversity from these changes. Increasing incidence of suicide is a possible outcome of these processes of economic change. This dissertation examines geographic variability in rates and trends in suicide for two distinct time periods 19801990 and 1990-2000 in the Appalachian region. Over the period 1980 through 2000 a number of broad swings have occurred in the U.S. economy; an economic recession in the early 1980s, post-recession structural adjustment in the mid-to-late 1980s, another economic recession in the early 1990s, followed by several years of economic growth through the end of the 1990s.

Associations between aggregate rates of suicide, trends in suicide, socioeconomic setting (context), and industrial changes are examined among labor market areas in the Appalachian region. The first part of the analysis identifies and describes geographic variability in rates and trends of suicide along with corresponding measures of socioeconomic context and industrial change. The second part of the analysis examines 
statistical associations between aggregate rates of suicide, trends in suicide, and measures of socioeconomic and industrial change.

The results suggest that there are persistent, positive associations between rurality (measured by percent urban population and population density) and aggregate rates of suicide for both age-groups and time-periods. The models for suicide trends also suggest a persistent association with measures of rurality, although the changing direction of the association is more difficult to assess and may be complicated by suggestions that decreases in rates of suicide in the 1990s were influenced by increased use of antidepressant medications. The models used in this analysis, in general perform poorly, in terms of identifying associations between specific measures of socioeconomic context, industrial change, aggregate suicide rates, and trends in suicide. 


\section{ACKNOWLEDGEMENTS}

I would like to thank members of my committee for their guidance and incredible patience during the time I have spent working towards the completion of this dissertation. I would particularly like to thank Robert Hanham and Elizabeth Barnett for their support and guidance in the development of this dissertation and my academic career in general. I am also grateful to the West Virginia University Prevention Research Center for providing support for the initial analysis that led to this dissertation.

A sincere thanks to numerous colleagues and friends I have interacted with in the Department of Geology and Geography and the Department of Community Medicine over the last twenty five years for their inspiration, guidance, and friendship. Special thanks to Frank Calzonnetti, who was largely responsible for starting me on this path.

I would also like to thank my family for their tolerance of my time away from them over the years in this effort. 


\section{TABLE OF CONTENTS}

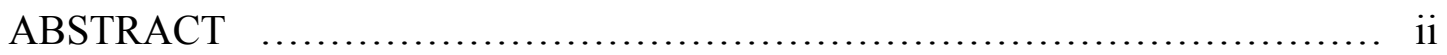



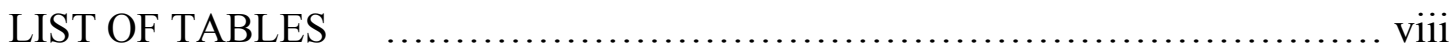

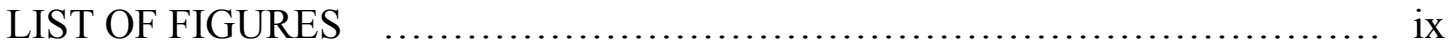

CHAPTER 1 INTRODUCTION $\quad$.......................................... 1

CHAPTER 2 CONCEPTUAL FRAMEWORK AND LITERATURE REVIEW .... 6

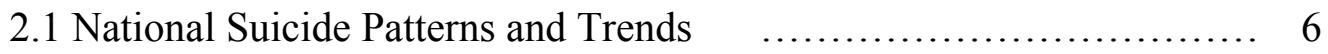

2.2 Suicide and Socioeconomic Context $\quad$............................ 9

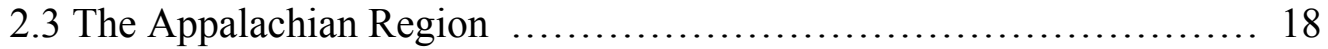

2.4 Conclusion $\quad$............................................... 21

CHAPTER 3 REARCH DESIGN $\quad$......................................... 22

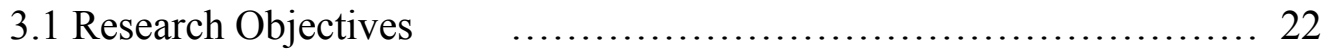

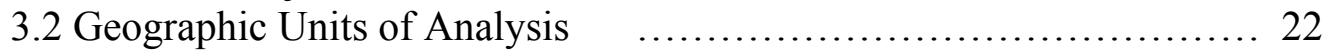

3.3 Measures of Suicide $\quad$........................................ 25

3.3.1 Measuring Aggregate Rates of Suicide $\quad$.................... 25

3.3.2 Measuring Temporal Trends in Suicide …................ 26

3.4 Models of Suicide $\quad$.......................................... 27

3.5 Measures of Socioeconomic Context …....................... 28

3.5.1 Population …...................................... 30

3.5.1.1 Population Distribution $\quad$......................... 30

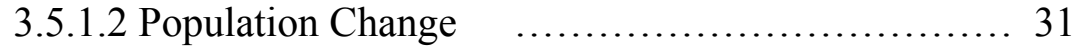

3.5.2 Industrial Structure $\quad$................................... 31

3.5.2.1 Sector Share of Total Employment $\quad$............... 31

3.5.2.2 Change in Sector Share of Total Employment ..... 31

3.5.2.3 Industrial Dominance $\quad$............................ 32

3.5.3 Economic Change $\quad$................................... 32

3.5.3.1 Change in Employment $\quad$..................... 32

3.5.3.2 Volatility in Employment $\quad$...................... 32



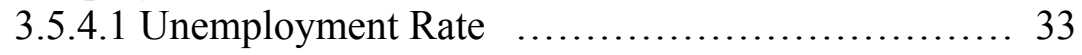

3.5.4.2 Change in Unemployment Rate $\quad$.................. 33

3.5.4.3 Volatility in Rate of Unemployment $\quad$............. 33 


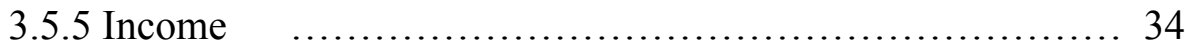

3.5.5.1 Median Family Income $\quad$......................... 34

3.5.5.2 Changes in Median Family Income $\quad$................. 34

3.5.5.3 Percent of Persons Living in Poverty $\quad$.............. 35

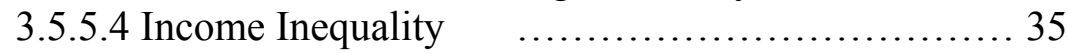

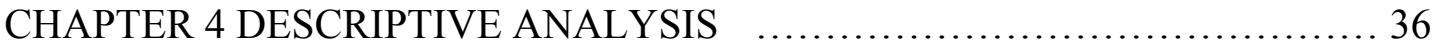

4.1 Measures of Suicide $\quad$......................................... 36

4.1.1 Suicide Rates Among Appalachian Labor Market Areas .... 36

4.1.2 Trends in Rates of Suicide 1980-1990 and 1990-2000 _.... 42

4.2 Measures of Socioeconomic Context $\quad$............................ 45

4.2.1 Population Distribution $\quad$.............................. 45

4.2.2 Population Change …................................ 47

4.2.3 Sector Share of Total Employment $\quad$...................... 48

4.2.4 Change in Sector Share of Total Employment by Industry $\quad \ldots \quad 51$

4.2.5 Volatility in Employment $\quad$................................. 54

4.2.6 Unemployment Rate $\quad$.................................. 57

4.2.7 Income $\quad$........................................ 60

4.2.7.1 Median Family Income $\quad$...................... 60

4.2.7.2 Percent of Persons Living in Poverty ................ 61

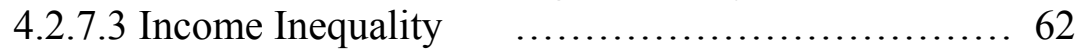

4.3 Conclusion $\quad$............................................... 64



5.1 Models of Suicide $\quad$......................................... 65

5.2 Expanded Models of Suicide $\quad$................................. 67

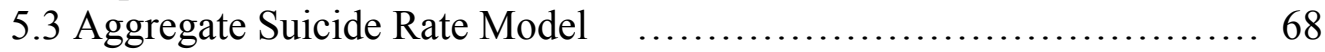

5.3.1 Suicide Rates Among Persons Aged 25 to 44 for the Period .. 68 1980-1990

5.3.2 Suicide Rates Among Persons Aged 25 to 44 for the Period .. 70 1990-2000

5.3.3 Suicide Rates Among Persons Aged 45 to 64 for the Period .. 72 1980-1990

5.3.4 Suicide Rates Among Persons Aged 45 to 64 for the Period .. 75 1990-2000

5.4 Suicide Trend Model $\quad$......................................... 76

5.4.1 Suicide Trends Among Persons Aged 25 to 44 for the Period .. 76 1980-1990

5.4.2 Suicide Trends Among Persons Aged 25 to 44 for the Period .. 78 1990-2000

5.4.3 Suicide Trends Among Persons Aged 45 to 64 for the Period .. 79 1980-1990 
5.4.4 Suicide Trends Among Persons Aged 45 to 64 for the Period .. 81 1980-1990

5.5 Conclusion 83



APPENDIX A3






\section{LIST OF TABLES}

Table 3-1. Measures of Suicide 25

Table 3-2. Measures of Socioeconomic Context 29 


\section{LIST OF FIGURES}

Figure 2-1. United States Suicide Trend 1981-2002 …................... 7

Figure 2-2. State Suicide Rates, 1990-1994, 1998, $2002 \quad$ …............... 8

Figure 3-1. Labor Market Areas containing at least one Appalachian county ... 24

Figure 4-1 Numbered Appalachian Labor Market Areas $1990 \quad$ …............. 37

Figure 4-2. Age-Adjusted Suicide Rates 1980-1990- Appalachian Labor

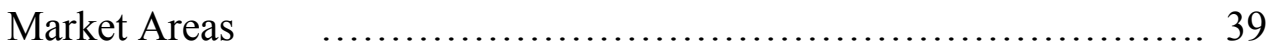

Figure 4-3. Age-Adjusted Suicide Rates 1990-20000- Appalachian Labor

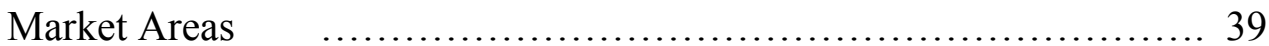

Figure 4-4. Distribution of Suicide Rates Among Appalachian LMAs,

Persons 25 to 44, 1980-1990 and 1990-2000 …............... 40

Figure 4-5. Distribution of Suicide Rates Among Appalachian LMAs,

Persons 45 to $64,1980-1990$ and 1990-2000 …................. 40

Figure 4-6. Rank Difference in Suicide Rates $\quad$.......................... 41

Figure 4-7. Average Percent Change in Suicide Rates 1980-2000,

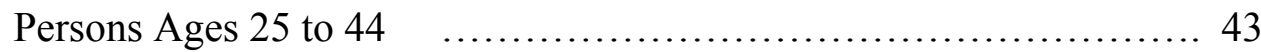

Figure 4-8. Average Percent Change in Suicide Rates 1980-2000,

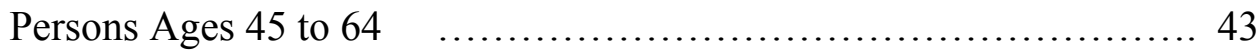

Figure 4-9. Distribution of Suicide Trend Values Among Appalachian LMAs, Ages 25 to 44, 1980-1990 and 1990-2000 ….............. 44

Figure 4-10. Distribution of Suicide Trend Values Among Appalachian LMAs, Ages 45 to 64, 1980-1990 and 1990-2000 …............... 44

Figure 4-11. Percent Urban Population - 1980,1990,2000 .................. 46

Figure 4-12. Population per Square Mile - 1980,1990,2000 …............... 47

Figure 4-13. Percent Change in Population 1980-1990, 1990-2000 .............. 48

Figure 4-14. Mining Sector Share of Total Employment, 1980-1990 and 1990-2000 _.............................. 49

Figure 4-15. Manufacturing Sector Share of Total Employment, 1980-1990 and 1990-2000 


\section{LIST OF FIGURES (continued)}

Figure 4-16. Service Sector Share of Total Employment, 1980-1990 and 1990-2000 50

Figure 4-17. Retail Trade Sector Share of Total Employment, 1980-1990 and 1990-2000 50

Figure 4-18. Percent Difference in Mining Employment, 1980-1990 and 1990-2000 52

Figure 4-19. Percent Difference in Manufacturing Employment, 1980-1990 and 1990-2000 52

Figure 4-20. Percent Difference in Service Sector Employment, 1980-1990 and 1990-2000 53

Figure 4-21. Percent Difference in Retail Trade Employment, 1980-1990 and 1990-2000 53

Figure 4-22. Mining Employment Volatility, 1980-1990 and 1990-2000 55

Figure 4-23. Manufacturing Employment Volatility, 1980-1990 and 1990-2000 55

Figure 4-24. Service Employment Volatility, 1980-1990 and 1990-2000 ….... 56

Figure 4-25. Retail Trade Employment Volatility 1980-1990 and 1990-2000 _... 56

Figure 4-26. Unemployment Rates Among Appalachian Labor Market Areas, 1980,1990 , and 2000 58

Figure 4-27 Volatility in Rates of Unemployment Between 1980-1990 and 1990-2000 59

Figure 4-28 Annual Rates of Unemployment Between 1980 and 1990 for LMAs 51 and 91 59

Figure 4-29 Annual Rates of Unemployment Between 1990 and 2000 for LMAs 46 and 129 59

Figure 4-30. Median Family Income Among Appalachian Labor Market Areas, 1979, 1989, and 2000 61

Figure 4-31. Percent of Persons Living Below the Poverty Level, $1979,1990,2000$ 


\section{LIST OF FIGURES (continued)}

Figure 4-32. Income Inequality Among Appalachian Labor Market Areas, 1990 and 2000

Figure 5-1. Scatterplot of AGGSUICIDERATE $\mathrm{i}_{\mathrm{i}, 25-44,1980-1990}$ against URBAN for Appalachian Labor Market Areas

Figure 5-2. Scatterplot of AGGSUICIDERATE $\mathrm{i}_{1,25-44,1990-2000}$ against URBAN for Appalachian Labor Market Areas

Figure 5-3. Scatterplot of AGGSUICIDERATE $\mathrm{i}_{\mathrm{i}, 25-44,1990-2000}$ against UNEMCHANGE for Appalachian Labor Market Areas

Figure 5-4. Scatterplot of AGGSUICIDERATE ${ }_{i, 45-64,1980-1990}$ against URBAN for Appalachian Labor Market Areas

Figure 5-5. Scatterplot of AGGSUICIDERATE $\mathrm{i}_{1,45-64,1980-1990}$ against ALLEMPVOLATILE for Appalachian Labor Market Areas

Figure 5-6. Scatterplot of AGGSUICIDERATE $\mathrm{i}_{\mathrm{i}, 45-64,1980-1990}$ against MAN*UNEM for Appalachian Labor Market Areas

Figure 5-7. Scatterplot of AGGSUICIDERATE $\mathrm{i}_{1,45-64,1990-2000}$ against URBAN for Appalachian Labor Market Areas

Figure 5-8. Scatterplot of SUICIDETREND ${ }_{i, 25-44,1980-1990}$ against DENSITY for Appalachian Labor Market Areas

Figure 5-9. Scatterplot of SUICIDETREND ${ }_{i, 25-44,1990-2000}$ against DENSITY for Appalachian Labor Market Areas

Figure 5-10. Scatterplot of SUICIDETREND ${ }_{\mathrm{i}, 45-64,1980-1990}$ against DENSITY for Appalachian Labor Market Areas

Figure 5-11. Scatterplot of SUICIDETREND ${ }_{\mathrm{i}, 45-64,1990-2000}$ against DENSITY for Appalachian Labor Market Areas 82

Figure 5-12. Scatterplot of SUICIDETREND ${ }_{i, 45-64,1990-2000}$ against MANSHARE for Appalachian Labor Market Areas

Figure 5-13. Scatterplot of SUICIDETREND ${ }_{i, 45-64,1990-2000}$ against

MANSHARECHANGE for Appalachian labor Market Areas 


\title{
Chapter One \\ INTRODUCTION
}

\begin{abstract}
"It is a narrow and misleading optic which restricts the term self-destructive to immediately suicidal acts and associates them in turn with aberrant forms of risk-taking or the extremes of despair. This approach misses the true dimensions of the problem, renders alien the act, and estranges the actor from the field of common experience. It makes bizarre and pathetic what in its more attenuated forms is a routine, even enthusiastic pursuit: the 'willing' engagement of people in patterns of behavior that are patently ruinous. Whether it be overeating, smoking, overdrinking, atomized living arrangements, fiercely competitive work, or tolerance for publicly proclaimed unhealthy levels of pollution - all serve to underscore the ordinariness of daily risk, the ease with which habits of self-destruction are incorporated within an economy of waste. It is the banality of self-destructiveness, its ubiquitousness, that needs explaining, and not simply the odd leap from the Brooklyn Bridge" (Hopper and Guttmacher, 1979, pp. 434-435).
\end{abstract}

The influence of place and location on the health and well-being of populations and individuals has long been recognized. Specific diseases often occur in some places while not in others and the magnitude in incidence of more common human afflictions often varies substantially from place to place. Understanding the nature of geographic differences in the prevalence of health outcomes and, particularly, the geographically variable factors that affect the health and well-being of individuals and populations is one of the challenges of medical geography and related disciplines such as epidemiology and sociology. 
The economy is a critical part of social organization and crucial to population health and well-being. Economic viability translates into individual opportunities for income generation and into the development and maintenance of social infrastructures, which generally serve to maintain and enhance the public 'quality-of life'. Much of what defines a place has been constructed around social relations that are related to economic activity and the productive process and the nature of these socioeconomic relations is manifested in a variety of forms across different geographies (Massey, 1995).

For individuals, economic viability often means a stable income, sufficient to maintain life's essentials of food, clothing, housing, medical care, and leisure activities. For nations, regions, and local areas, economic viability and stability translate into tax bases that are essential for maintaining public infrastructures such as schools, roads, law enforcement, social services, parks, etc. In addition, viable and stable economies are able to support a number of service and retail related industries (grocery stores, gas stations, department stores, restaurants etc.) which serve to further enhance the public 'quality-oflife'. Adverse changes in local economies in the form of business closures and resulting unemployment leads to economic adversity for individuals and local populations and disrupts established social relationships and social infrastructures. Conversely, rapid economic growth may place additional burdens on local social infrastructures that may reduce the effectiveness of these infrastructures in assuring local well-being.

There is a great deal of literature that examines contemporary changes in global, national, and regional economies. Much of this literature is concerned more with the direct outcomes of economic change e.g. the number of firms lost or gained, changes in employment/unemployment, and variations in incomes. A number of contemporary processes have dominated geographic literature on economic change; post-Fordism as a stage of capitalism, the geography of uneven development, and economic globalization. Well-documented shifts from manufacturing to service sector employment, large-scale lay-offs and business closures, and conversely, rapid economic development in some areas have contributed to significant changes in the geoeconomic landscape over the past thirty years. These economic changes, in part, represent the continued process of 
geographic uneven development. Uneven development is reflected in fluctuations in the geography of economic development and is a necessary part of capitalist production due to capital's constant search for increased rates of profit (Smith, 1990). Contemporary economic 'globalization' has facilitated the frequency, speed, and scales at which these fluctuations occur. One result of these processes is an increasing disconnect between the scales at which socioeconomic relationships are realized and the scales at which economic relationships are established and maintained.

Despite clear indications of potential social consequences that result from these types of economic changes, much less attention has been paid to the effects economic changes have on physical and mental health outcomes and other important aspects of social wellbeing (Lobao \& Rulli, 1996). Due to the geographic nature of many economic changes, place becomes an important consideration in determining the affects of economic change on physical and mental health outcomes. Geographic changes in local economies over the past thirty years provide a framework with which to examine potential impacts on population health at the local level.

One potential consequence of contemporary economic change is an increased level of social anxiety and stress that may adversely impact the mental health of individuals who are collectively affected by these changes. Suicide may be the most valid and reliable indicator of collective mental health (Weyerer and Wiedenmann, 1995) and may reflect one of many potential extraeconomic effects of economic change.

This dissertation contributes to the development of the political economy literature in geography on the social consequences of economic change. It examines the impact of local socioeconomic conditions and industrial changes on local rates of suicide in the Appalachian region between 1980 and 2000. Over the period 1980 through 2000 a number of broad swings have occurred in the U.S. economy; an economic recession in the early 1980s, post-recession structural adjustment in the mid-to-late 1980s, another economic recession in the early 1990s, followed by several years of economic growth through the end of the 1990s. 
The Appalachian region has always economically 'lagged' other regions of the U.S. Relatively high levels of unemployment, low regional incomes, and educational deficits continue to contribute to a lower standard of living than enjoyed in many areas of the U.S. (Isserman, 1997). However, there are significant levels of socioeconomic diversity within Appalachia. For example, metropolitan areas in the region have more diversified economies, higher per capita incomes, and more well-developed social infrastructures than non-metropolitan areas (Barnett et. al., 1998). The Appalachian region also subsumes a number of key economic regions of the country ( the 'rust belt' in the Northeastern U.S., the coal mining region in Central, Mid-Atlantic states of Appalachia, and area of significant economic growth in the south), making the region a good setting for examining economic change.

Examination of the social consequences of economic change is critical during a time of growing income inequality and decreased levels of employment stability/security. It is particularly important to examine potential consequences of economic change during a time when the prevailing political view treats economic hardship as an individual-level problem, greeted with self-blame rather than system-blame. This view assumes economic hardship to be the justifiable outcome "of a system which grants all similar footing to succeed, regardless of class, race and ethnicity, gender, and other social structural impediments" (Lobao and Rulli, 1996, p. 607).

Change is an inevitable part of society. Places continually evolve and transform, responding to economic and cultural shifts that coincide with regional, national and global changes. The nature, direction, and pace of change may result from many complex factors including levels of social and economic infrastructure and/or local cultural beliefs and practices. There may be no more powerful mechanism of change, however, than the economy. Economic conditions provide the foundation for social organization as well as individual well being. Economic change, particularly rapid change, may lead to incompatibilities between historical socioeconomic relationships and the demands and expectations of the new social situations. Local susceptibility or resilience to economic 
change may largely depend on the historical nature of local and regional economic situations.

Populations in places which experience adverse economic conditions and changes confront not only economic adversity, but potentially a wide range of cascading affects resulting from unemployment, loss of revenue to support public infrastructure, fragmentation and disintegration of social linkages and networks and many others. All of these consequences may increase levels of anxiety and stress in local populations. In turn this may also lead to increased incidence of depression and ultimately suicide. Although there are numerous individual expressions of stress, anxiety, and despair (as well as apathy) that don't involve sudden death, as Hopper and Guttmacher (1979) had pointed out, perhaps no other collective measure is as amenable for study as suicide.

This dissertation is organized as follows. Chapter two describes contemporary patterns and trends in suicide for the coterminous United States, and reviews the literature which addresses risk factors and socioeconomic conditions typically associated with suicide. Chapter three describes the research design, methods, and variables used in the analyses. Chapter four examines the geographic distributions of suicide rates and measures of socioeconomic context in the Appalachian region. Chapter five presents the results of regression analyses which examine associations between suicide rates and measures of socioeconomic context. Chapter six provides concluding remarks, including avenues for further research. 


\section{Chapter Two CONCEPTUAL FRAMEWORK AND LITERATURE REVIEW}

This chapter first develops a conceptual framework for examining suicide in relation to socioeconomic context by examining contemporary conditions of suicide rates in the contiguous United States. This is followed by a review of the literature which examines individual and social dimensions of suicide. The chapter concludes with a description of the Appalachian region.

The conceptual framework developed in this dissertation draws upon theoretical foundations developed by Emile Durkheim in Suicide which was published in 1897 (Berkman et al, 2000). Durkheim, a french sociologist, theorized suicide as a social problem rather than an individual problem, a product of decreasing levels of social integration that result from societal changes, particularly economic crises. Although there is a broad range of factors that affect individual mental health outcomes, suicide may be the most valid and reliable indicator of collective mental health (Weyerer and Wiedenmann, 1995).

\subsection{National Suicide Patterns and Trends}

Suicide is a serious public health problem. In the U.S. in 2002, suicide was the eleventh leading cause of death overall and the eighth leading cause of death for men (Kochanek, et al 2002). Although accounting for a relatively small percentage of total deaths in the U.S. (1.3\%), suicides in 2002 outnumbered homicides by five to three and deaths due to AIDS by two to one. National rates of suicide vary significantly among gender, age, and race/ethnicity. More men than women die from suicide by a ratio of four to one. In 1999, white men and women accounted for 90 percent of all suicides and white men accounted for 72 percent of all suicides. National rates of suicide are higher for persons aged 65 years and older and suicide is the third leading cause of death for young people ages 15 to 24 , after unintentional injury and homicide. In addition to an annual average of approximately 30,000 suicide deaths, around 500,000 people receive hospital treatment for attempted suicide each year. Along with placing a considerable burden on the public 
health infrastructure, suicide and attempted suicide adversely affects thousands of people who have had friends or family members commit suicide.

U.S. suicide trends indicate a general decline beginning in the late 1980s after a continuous increase in the early 1980s. (Figure 2-1) Disturbingly, there appears to be an increasing trend in suicide rates beginning in 2000. Although declining aggregate suicide rates in the U.S. represent a positive outcome, there is considerable geographic variability in the rate of decline and some geographic areas have experienced increasing rates of suicide. A number of studies have documented increasing trends in mortality among substate geographic units in the face of declining aggregate trends (Barnett and Halverson, 2000; Halverson et al, 2004).

Figure 2-1. United States Suicide Trend 1981-2002

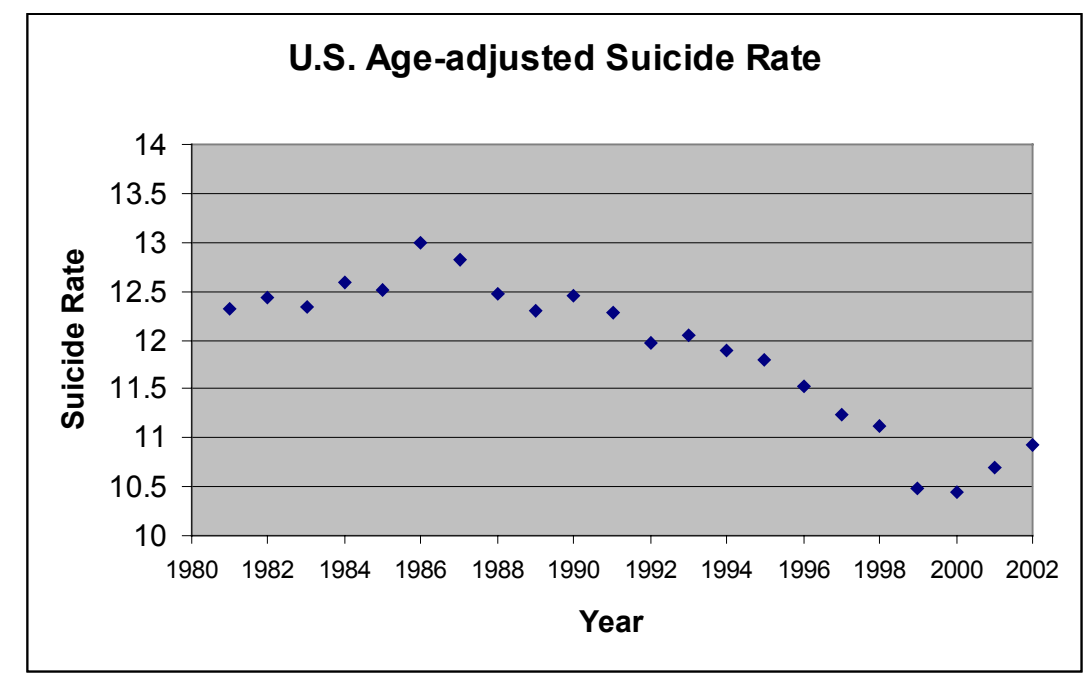

Source: National Center for Health Statistics, Mortality detail 1980-2002.

Substantial geographic variability in suicide rates has also been documented.

A report published by the Centers for Disease Control and Prevention documented significant regional disparities in suicide rates among U.S. states over the period 19901994. (U.S. DHHS/CDC, 1997) States in the western U.S. exhibit substantially higher rates of suicide than states in the South, Midwest, and Northeastern portions of the country, although the reasons for these disparities are unknown. More recent data suggest 
relative shifts in the predominance of suicide rates among many U.S. states. Figure 2-2 depicts the geographic distribution of state-based suicide rates for three periods 19901994, 1998 and 2002. Changes in the relative predominance of suicide rates are perhaps most notable in California, Vermont, and West Virginia (the only state completely with the Appalachian region). Understanding geographic disparities in rates of suicide may help identify factors that contribute to poor mental health, and aid in developing theory that links social and socioeconomic factors to mental health outcomes.

Figure 2-2. State Suicide Rates, 1990-1994, 1998, 2002.

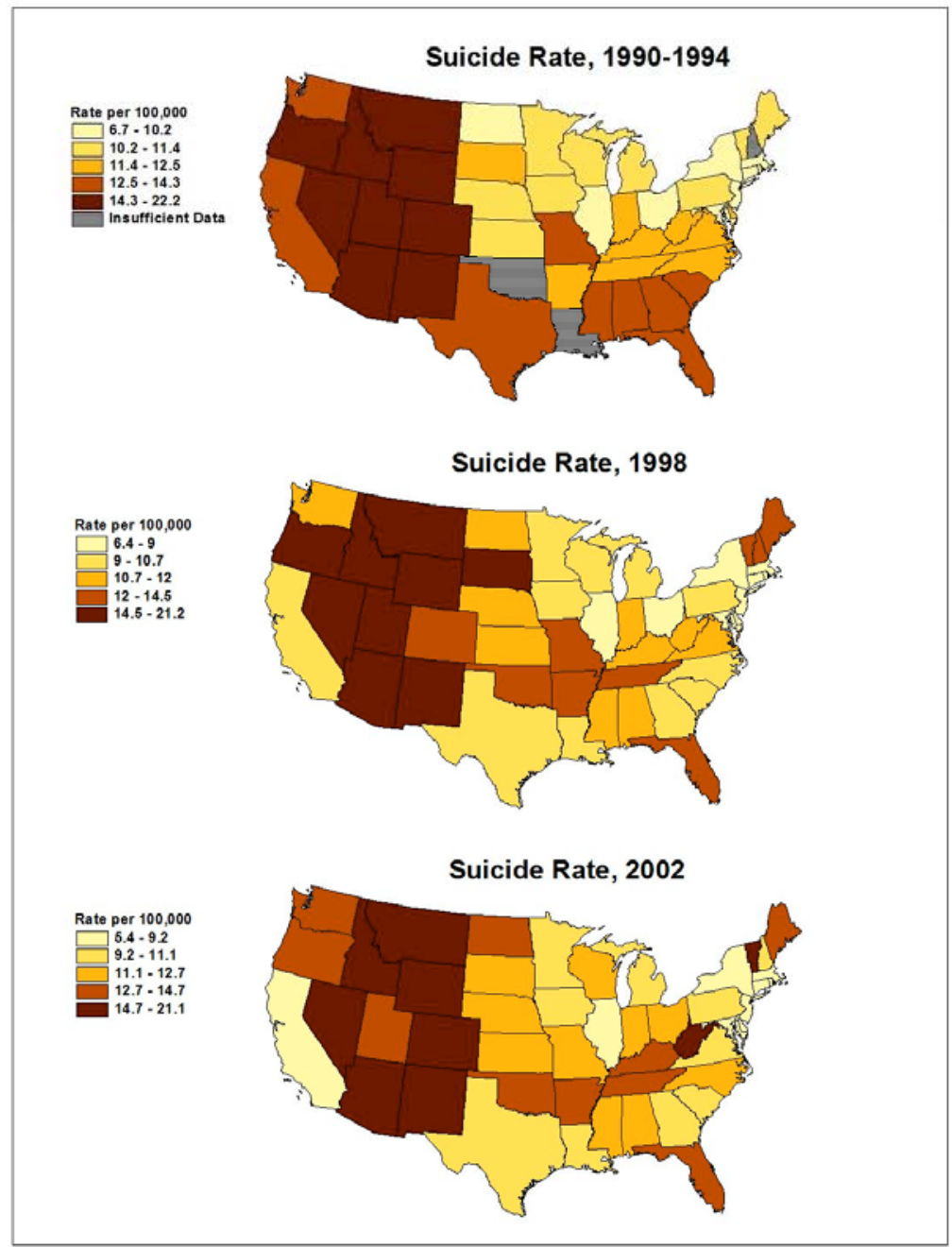

Sources: U.S. Department of Health and Human Services, Centers for Disease Control. (1997); Kochanek, K. D., Murphy, S. L., Anderson, R. N., \& Scott, C. (2004) 


\subsection{Suicide and Socioeconomic Context}

The events that lead individuals to commit suicide are varied and complex. However, almost all suicides have been linked to some level of mental illness, depression, and/or substance abuse disorder (National Institute of Mental Health, 2001; Proenca, 2001). Major, or clinical, depression is the most typical form of depressive illness, although most people suffering from depression do not kill themselves. According to Bell (2001), "It is estimated that $25 \%$ of sufferers will attempt suicide within five years of a depressive episode, and that about $15 \%$ of those who suffer from major depressive disorder will ultimately die by suicide".

Although the specific causes of depression are highly variable, two major reasons people become depressed are, loss of control over life situations and feelings of hopelessness about the future (National Institute of Mental Health, 2001; Proenca, 2001; Preti and Miotto, 2000). The specific events which trigger these feelings are highly variable and may include loss of a job or vocation, loss of a spouse or loved one, illness or disability. Suicide is generally considered a possible complication of depression in combination with other risk factors. Although clinical mental disorders such as bi-polar disorder and schizophrenia are highly correlated with suicide, the concentration of high suicide rates in some areas while not in others suggests locally variable social, economic, political, and cultural conditions (socioeconomic contexts) may contribute to collective mental health outcomes of local areas.

Two conceptual frameworks are commonly employed in the study of suicide; compositional and contextual. Compositional approaches focus on the characteristics of individuals who have killed themselves such as age, race, marital status, employment status, income status, and educational attainment. Compositional approaches are useful for identifying individual risk factors that may contribute to suicide incidence. A number of studies have examined the compositional aspects of suicide. 
Kposowa (1999) found that people who were divorced or separated had more than double the risk of suicide when compared to their married counterparts; however men were more affected by divorce and separation than women. Persons 55 to 64 years old are at a $41 \%$ greater risk of suicide than people aged 15 to 24 . African Americans had a $61 \%$ lower risk of suicide than whites. Low levels of educational attainment and income were also shown to increase the risk of suicide. Johansson and Sundquist (1997) found, in a sample of Swedish adults ages 20-64, that people who self-reported poor health had the highest relative risk of suicide. They also reported increased risk of suicide associated with unemployment and living alone. Olfson et al (2000) report symptoms of 'social anxiety' (a suicide risk factor) are more common among those persons with less formal education and the unemployed. Persons with social anxiety were also more likely to reside in a small town or rural area. Social anxiety was found to be strongly associated with feelings of social isolation and resulted in a 1.4 times greater risk of suicidal ideation. Low socioeconomic status is commonly associated with suicide risk. Hopper and Guttmacher (1979) report that "low socioeconomic status (whether through birth or downward mobility) is disproportionately found among suicides in places as diverse as Chicago, New Orleans, Seattle, and Hong Kong” p. 428. Eyer (1976) suggests that the prevalence of mental illness increases with declining socioeconomic status, stating that "the degree of mental illness is proportional to the frequency of life stresses, which are both more intense and more frequent to the lower class" p. 139. Farber (1968) suggests that "psychological damaged personalities confronted by deprivational situations are most likely to commit suicide" p. 11. However, the relationship between low socioeconomic status and suicide may be mediated by the context(s) within which the relationship is situated. For example, deprivation may be relative to individual experience, expectations, and aspirations. In this light, deprivation is clearly not limited to only those of low socioeconomic status. Durkheim had hypothesized that poverty was actually a protective factor for suicide because it kept expectations low and that suicide was "exceptionally frequent" among members of higher social class (Hopper and Guttmacher, 1979). The relationship between socioeconomic status and suicide is unclear. In the U.S., for example, states that suffer more adverse socioeconomic conditions generally do not exhibit higher rates of suicide (see Figure 2-2). 
Unemployment is commonly associated with the incidence of suicide. Rates of unemployment have been shown to be highly correlated with rates of suicide in a number of studies (Preti and Miotto, 1999; Weyerer and Wiedenmann, 1995; Leenaars et. al., 1993). Theoretically, unemployment may result in individual economic hardship and also initiate feelings of inadequacy, which may in turn lead to depression and ultimately suicide. Ostamo et al, (2001) found that among all suicide attempters in Helsinki, Finland that were admitted to emergency health care, the highest attempted suicide rates were found among the unemployed. However, they also found that unemployment did not always precede the suicide attempt and suggested that unemployment may be "a marker of problems among some persons in a society where employment is very common" $p$. 1747.

The affect that individual unemployment may have on individual incidence of suicide is not entirely clear. However, rates of unemployment for geographic areas are a partial reflection of overall socioeconomic conditions in those areas. When local areas experience large-scale unemployment events, such as massive layoffs or business closures, collective financial and emotional hardships are magnified for both individuals and communities. Social networks and infrastructures fragment and disintegrate, further exacerbating the problem and may lead to increased levels of depression and ultimately increased levels of suicide.

There is an increasing awareness that both individual and population health (physical and mental) are affected by individual risks as well as "exposure to factors in the environment that effect all those who share this environment" (Berkman et. al., 2000, Crawford and Prince, 1999, p. 1419). Although compositional studies have identified individual risk factors for suicide, they have failed to account for regional disparities in rates of suicide in the U.S. (U.S. DHHS/CDC, 1997). Individuals are affected by a broad range of unique phenomenon that may influence their physical and mental well being. However individuals are also collectively affected by the social, economic, and political milieus in which they live and work; social contexts or social environments. Geographic variability in rates of suicide, together with a variable landscape of social environments, suggests 
potential linkages between local social context (in addition to individual risks) and mental health outcomes.

Contextual approaches examine the social conditions (contexts) that affect those who share a particular environment. The social contexts of local areas are largely defined by socioeconomic conditions that exist in these areas. Socioeconomic conditions are tied to forms of social organization, the productive process, which are important factors influencing the collective social, physical, and mental well-being of populations. There is an inherent relationship between the quality-of-life of places and economic issues of those places. The nature of local economies (industrial structure), together with their relationship to regional and national economies, have helped to define occupational and income opportunities, labor relations, social relationships and community infrastructure, local cultural practices and values, and overall levels of individual and community wellbeing. Although many risk factors may collectively impact a population, economic conditions provide a fundamental basis for local social context.

The notion of suicide as a social rather than individual problem was first proposed by Emile Durkheim in the late 1880's. Durkheim, a French sociologist, had theorized that suicide was related to "large scale societal crisis of an economic or political nature often occurring during times of rapid social change and turbulence" (Berkman et al, 2000, p. 844). He suggested that in situations of social crises, social norms are weakened which "serve to deregulate values, beliefs, and general norms and fail to rein-in or guide individual aspirations" p. 844. Gibbs and Martin (1964), suggest that "the suicide rate of a population varies inversely with the stability and durability of social relations within that population" p. 17. The effects of economic hardship, unemployment and social disintegration are believed to contribute to suicide incidence in an initiatory or exacerbatory capacity, for those suffering from psychiatric vulnerability or existing mental illness.

Changes in local economic conditions, particularly adverse changes, often represent forms of social crises, resulting in unemployment, loss and fragmentation of social 
infrastructures, and individual stresses that result from these events. Conversely, rapid economic growth may place additional burdens on local social infrastructures that may reduce the effectiveness of these infrastructures in assuring local well-being. Within local socioeconomic relationships, certain dependencies on local infrastructures develop ('local dependence') along a number of dimensions and within and among specific groups in each locality (Cox and Mair, 1988). The nature of these local dependencies will influence the production and reproduction of local socioeconomic relationships, and the ability to maintain economic and cultural lifestyles. Individuals and groups are likely to be locally dependent on socioeconomic milieus that are predictable and reinforce confidence. According to Cox and Mair (1988), "Traditional social relations, those of family, ethnicity, religion, etc., define not simply a sphere of predictability and confidence, but also sources of self-identification, means through which the individual achieves selfunderstanding" p. 312.

Much of the contemporary literature that examines social context and health outcomes focuses on collective conditions related to income, social class, employment status, and rurality/urbanicity. Individual and social stress is a theme common to literature that relates suicide to individual economic conditions, socioeconomic context, and economic change. Dooley and Catalano (1984) provide a review of research that attempts to link economic stress, resulting primarily from job loss, to psychiatric disorders and suicide. They suggest that "the impact of such aggregate economic change can affect very many more people in more subtle and more gradual ways. For example, the spouses and children of job-losers may pay a price in conflict or abuse. Workers dislocated from one job may pay a price in conflict or abuse. Workers from one job may immediately find reemployment in another but at a psychological cost of physical relocation or of retraining and may well slip down the status ladder" p. 396. When or where unemployment is high, individuals who have managed to retain a job "may suffer the anxiety anticipating job loss and may remain in unsatisfactory working conditions because no alternate jobs can be found. Organized labor has learned that its bargaining position for better wages and working conditions is undermined by high unemployment 
rates" p. 396 Unemployment, resulting income loss, and perhaps feelings of inadequacy are powerful sources of social stress.

In capitalist societies the free enterprise system is constantly seeking to maximize productivity, often requiring the reallocation of economic resources to more profitable uses. The assumption is that the freedom to reallocate capital will ultimately improve every one's standard of living, despite short-term costs associated with dislocated workers who must adapt to job loss, relocate, or retrain for alternate employment. It is assumed that "such an adaptation, if not pleasant, can reasonably be achieved within the normal person's resources" (Dooley and Catalano, 1984, p. 390).

There are a number of themes in the geographical literature that provide theoretical guidance for understanding the relationships between economic conditions, economic change, and implications for social well-being. Central to this study is the realization that economic change and fluctuations in the geography of economic development (uneven development) are a necessary part of capitalist production due to capital's constant search for increased rates of profit (Smith, 1990). Local areas are under constant threat of capital relocation, and contemporary conditions (economic globalization) have enabled this to occur with increasing speed and frequency. The levels of local economic uncertainty that results from the 'inconstant geography of capital' that are realized in local areas both constrain and facilitate local efforts to develop strategies to maintain local interests (Storper and Walker, 1989).

The degree to which this threat is realized is contingent on a number of conditions including levels of fixed vs. mobile capital within local areas or regions, the degree and nature of local economic dependence (spaces of dependence), and the scales at which local agents are engaged to promote and secure local interests (spaces of engagement) (Cox and Mair, 1988; Cox, 1998). With the 'globalization' of the economy there is an increasing necessity to establish geographically expanded networks to maintain spaces of dependence. The ability of local areas to respond to economic change in the contemporary global climate may depend to a large extent on historical economic 
development patterns and local dependence on these patterns. Places which have diversified economies may be more likely to have well-established linkages to a greater number of potential spaces of engagement. Therefore economic diversity may increase the ability of local agents to respond to economic crises. Many areas in the Appalachian region, for example, lack economic diversity and have historically been dependent on specific industries for the maintenance of spaces of dependence. The region, in general, may therefore be susceptible to economic crises that result from contemporary economic conditions and changes.

A local economy can be viewed as a collection of industries (and social relations related to those industries), each under constant threat of losing economic viability. Local industries may experience economic volatility resulting from systematic sources such as national economic conditions or seasonal fluctuations in demand for products and services. Although some forms of volatility can be anticipated, changes in national economic conditions may make economic diversification less effective in influencing positive responses to local economic crises.

In addition to local economic dependence, people may be locally dependent on social environments and relations that rely on local economic vitality (Cox and Mair, 1988). When the conditions of employment change (job loss, change in working conditions, and 'downward mobility' in level of employment and wage), for individuals and communities, social relations and social infrastructures supporting those relationships are disrupted. These types of events lead to personal and community stresses that may contribute to poor individual and collective community physical and mental health. The degree to which these types of events impact individual and community health and well-being will depend on a number of factors including the historical context in which local economic relationships are situated, diversity and nature of local employment opportunities, and social support.

Although research suggests a strong relationship between rates of unemployment and rates of suicide, most of this research has been conducted at state, national, and 
international geographic scales. When disaggregated to finer geographic scales of analysis the relationships between unemployment and suicide becomes less consistent between regions, suggesting that other socioeconomic processes maybe operating that may either mediate or exacerbate the collective mental health impact of unemployment.

Well-documented shifts from manufacturing to service sector employment, large-scale lay-offs and business closures, as well as rapid development in other areas provide a framework with which to examine potential impacts of economic changes on the incidence of suicide. Contemporary economic 'globalization' has facilitated the frequency, speed, and scales at which geographically uneven development occurs. One result of these processes is an increasing disconnect between the scales at which socioeconomic relationships are realized and the scales at which economic relationships are established and maintained. A potential implication of these circumstances is an increased level of social anxiety and stress that may adversely impact the mental health of individuals who are collectively affected by these changes. Suicide incidence may be an indicator of these processes and reflect one of many potential extraeconomic affects of economic change.

When widespread and rapid changes occur in major sources of local employment, individual well-being and community infrastructures are threatened. Analysis at a number of geographic scales has revealed associations between the unemployment experiences of nations, regions, and localities with their health experiences (Brenner, 1987; Bartley and Owen, 1996; Ferrie et. al., 1998). However, absolute measures of employment/unemployment may skew the relationship of economic change to health because the underlying assumption that employment implies well being may be untenable (Matsuoka and Benson, 1996). The nature of employment, issues of relating to job status, income, and security, may be more appropriate measures linking employment to wellbeing. Communities are affected by these processes of economic change, not only in terms of losses (or gains) in employment, but also in terms of overall changes in economic and social organization ( ${ }^{\text {Lobao }}$ and Rulli, 1997). Lobao and Rulli (1997) also suggest that where high wage manufacturing is greater, there is likely to be a positive 
'shadow effect' on the population of the community at large and that overall incomes should be higher and more evenly distributed. With the loss of this economic activity, we should also expect a negative 'shadow effect' on the affected community, e.g. increased levels of income inequality.

Levels of income inequality have been shown to influence health and well being of local communities. Kennedy et al. (1998) suggest that “..inequalities in income may have extraindividual or contextual effects that structure the social environment in ways that affect the health of a population" p. 917. Waitzman and Smith (1998) suggest that “...higher levels of income inequalities lead to a deterioration of community attachment and involvement, resulting in deleterious psychosocial and material consequences". Dooley and Catalano (1984) suggest that economic change, particularly job loss, results in 'psychological disorders' which increase the likelihood of suicide and admission to psychiatric facilities. Kearns and Joseph (1993) quoting Kobayashi and Mackenzie (1989) suggest that: "a continuous restructuring of economic and social conditions seems to restrict options... we seem to have few choices and less space in which to create them...(yet) there appear to be more places, more parts of our lives, in which we can deliberately act and exercise control" p. 714.

The processes of economic change operate differentially, some areas are being adversely affected, some areas experience rapid economic development, and the fortunes of other areas fluctuate dramatically. Sclar (1980) suggests that health impacts resulting from job losses vary greatly with the conditions of unemployment and reemployment, dependent on the economic structure of a community, and how this structure changes with the economy. At the local level, changes in economic structure can result in a number of socioeconomic changes including, increases/decreases in income and cost of living, resource utilization, infrastructural components of the community (e.g. social services, schools, transportation), and the overall economic and social organization of communities (Matsuoka and Benson, 1996; Lobao and Rulli, 1997). These fundamental changes may have either beneficial or deleterious effects on local populations. Understanding the linkages between economic structure and local community mental health and well-being 
will aid in understanding conditions which may instigate, exacerbate, or mediate poor mental health. Understanding linkages between economic structure and change will also aid in the formulation of health conscious economic development policies and strategies. Matsuoka \& Benson (1996), for example, are critical of local economic development strategies which ignore the complexity of community relationships, family structures, and dynamics: "decisions promoting economic development are often based on the assumption that employment implies well-being. This assumption is narrow with respect to broader conception of quality-of-life issues" p. 109.

The processes of deindustrialization and industrial restructuring have been primary components of economic change in the U.S. and many parts of the world, particularly over the past thirty years. Often, these processes have resulted in loss of basic industry and have resulted in massive layoffs and closures in many areas of the country. The overall decline in manufacturing sector employment and coincident rise in service sector employment has been well documented in the United States and other countries. Tangentially, new industries and opportunities have often developed as a result of technological innovations that represent new modes of production and may challenge traditional labor relations in some regions. Together these processes have transformed historic employment and social relationships in many regions within the U.S. It is hypothesized that the manner in which these basic industrial changes have taken place will influence the incidence of suicide in many regions of the U.S. and specifically, among local areas in the Appalachian region.

\subsection{The Appalachian Region}

The Appalachian Region is a 200,000-square-mile area in the Eastern U.S. that extends from Southern New York to Northern Mississippi and includes all of West Virginia and parts of twelve other states: Alabama, Georgia, Kentucky, Maryland, Mississippi, New York, North Carolina, Ohio, Pennsylvania, South Carolina, Tennessee, and Virginia. The region derives its name from the most prominent topographical features in the area, the Appalachian Mountains, which extends north-to-south through the region. Rugged 
terrain and limited accessibility are features that are common in much of the region. However the area is more defined as a region which lags behind the rest of the country socially and economically. The region is characterized as a "region apart" with low incomes, lack of urbanization, high unemployment, lack of jobs, educational deficits, and lower standards of living than the rest of the U.S (Isserman, 1997). In 1965 the Appalachian region became a political entity through the Appalachian Regional Development Act.

The Appalachian region includes three broad economic regions; the rust belt in the northern region, a coal region in Central Appalachia, and a largely agricultural region in the south. The northern region has been dubbed the 'rust belt' due to large-scale declines in the manufacturing industries which historically dominated employment among a swath of contiguous states in the Northeast, Mid-Atlantic, and Midwest portions of the country. The coal region of Appalachian centers primarily on West Virginia and includes Eastern Kentucky, Southwestern Pennsylvania, and Southeastern Ohio. In general, the coal industry experiences cyclical and seasonal fluctuations in employment, however, long term decline in mining employment has occurred in the region even before 1980. In contrast, to the overall economic decline in the northern and central regions of Appalachia, the historically agricultural southern portion of the region has, in general, experienced significant economic growth and has realized increases in manufacturing employment since 1980 .

The Appalachian Regional Commission (ARC) is a federal-state partnership established in 1965 by the Appalachian Regional Development Act to promote economic and social development of the Appalachian Region. The Appalachian Region includes, as amended in 2002 , four-hundred and ten counties and is home to approximately 22.8 million people. In 2000, the ARC designated region consisted of four-hundred and six counties. The four-hundred and six county designation has been retained for this study. The ARC designated region includes all of West Virginia and parts of twelve other states and extends more than a thousand miles from the southern tier of New York to Northeast Mississippi. 
In general, the Appalachian region has lagged economically from other parts of the U.S. Relatively high levels of unemployment, low regional incomes, and educational deficits continue to contribute to a lower standard of living than enjoyed in many areas of the U.S. (Isserman, 1997). However, there are significant levels of socioeconomic diversity within Appalachia. For example, metropolitan areas in the region have more diversified economies, higher per capita incomes, and greater access to medical care than nonmetropolitan areas (Barnett et al, 1998). Local socioeconomic differences within the Appalachian region are likely to be key contributors to disparities in health outcomes with those areas having diminished access to social, economic, and medical care resources experiencing more adverse outcomes. However, direct associations are also likely to vary throughout the region.

When the ARC was established, one of three Appalachians lived in poverty, which was fifty percent higher than the national rate. By 2000 , the regional poverty rate had been reduced to 13.6 percent, and the spread between Appalachia and the nation has narrowed to 1.2 percentage points. Over the $1960-1980$ period, the number of economically distressed counties in the region showed a steady decline, falling from two-hundred and twenty-three in 1960 to eighty-four in 1980, but over the next twenty years there was a steady, slow increase with the number rising to one-hundred and twenty-one distressed counties in fiscal year 2003.

Appalachia's population is geographically distributed across the urban-rural spectrum, from large urban areas in metropolitan counties to small, very remote counties lacking even small urban concentrations. Approximately sixty percent of the population lives in metropolitan counties, twenty-five percent lives in counties adjacent to metropolitan counties, while the balance of the population lives in more remote, rural locations. 


\subsection{Conclusion}

This chapter has reviewed contemporary patterns and trends in suicide rates in the contiguous U.S. Suicide continues to be a serious public health problem in this country. However, there is substantial geographic variability in rates of suicide. In addition, although national rates of suicide have been in general decline, it appears that geographic shifts in the relative predominance of high and low rates of suicide have occurred over the period 1990-2002.

The literature has established both theoretical and empirical associations between individual socioeconomic status and the risk of suicide, as well as socioeconomic conditions in place and the collective mental health status measured by suicide rates. Geographically variable patterns of suicide, together with a history of geographically uneven development, may elucidate factors that influence population mental health at the local level. Significant changes in the geo-economic landscape in the U.S over the past thirty years may help to explain shifts in the relative predominance of suicide rates.

The Appalachian region, with a history of economic adversity and diversity, provides a geographic setting to examine the influence that both socioeconomic context and economic change may have on locally variable mental health outcomes. 


\section{Chapter Three \\ RESEARCH DESIGN}

In this chapter the research objectives are first outlined followed by a description of the geographic units of analysis. Next, a description of the measures of suicide used in this research is provided followed by an explanation of the models used to associate aggregate measures of suicide with socioeconomic context as well as suicide trends with economic change. The specific measure of socioeconomic context and economic change are then discussed.

\subsection{Research Objectives}

This dissertation has three objectives:

1. To describe the geographic variation in aggregate rates of suicide and trends in suicide rates for labor market areas in the Appalachian region for two time periods, 1980-1990 and 1990-2000.

2. To assess the association between aggregate rates of suicide and measures of socioeconomic context in Appalachian labor market areas for both time periods.

3. To assess the association between trends in suicide rates and measures of socioeconomic context in Appalachian labor market areas for both time periods.

\subsection{Geographic Units of Analysis}

The areal units of analysis for this dissertation are labor market areas. Labor market areas (LMAs) consist of groups of counties and/or county equivalents, which define small regions in which participants in local labor markets both live and work. LMAs were chosen for this analysis to provide a more theoretical basis for defining communities in the context of socioeconomic setting than would be achievable using counties for other 
county aggregates. A map showing the LMAs that contain Appalachian counties is shown in Figure 3-1.

The LMAs to be used in the following analysis were developed by a team of rural sociologists at Louisiana State University (Tolbert and Sizer-Lillian, 1987), based on empirical journey-to-work and residence data for counties, county equivalents, and the District of Columbia, obtained from the U.S. Census of Population and Housing.

There are three-hundred and ninty-four LMAs defined for the United States and seventynine LMAs which encompass the Appalachian region (as defined by the Appalachian Regional Commission in 2000). LMAs cross state boundaries, which is appropriate given the nature of local labor markets. Each LMA has been constrained to contain at least 100,000 inhabitants. Subsequently, LMAs tend to be much larger in more sparsely populated regions of the U.S. The total area used in this analysis extends, in some cases, well beyond the official boundary of Appalachia as defined by the Appalachian Regional Commission. Some large LMAs contain only a single Appalachian county. However, areas outside of the 'official' Appalachian boundary are theoretically influential in defining economic opportunities in Appalachian counties and therefore contribute to socioeconomic conditions in those counties.

In addition to providing a theoretical foundation for defining geographic units of study within Appalachia, the use of LMAs as geographic units of analysis another advantage. Because LMAs have a minimum population of 100,000, adequate population denominators are assured for constructing stable estimates of suicide mortality. Lastly, the 1990 LMA definitions are used in this study. These were chosen because 1990 represents the mid-point definition for this analysis. 
Figure 3-1 Labor Market Areas containing at least one Appalachian county.

\section{Appalachian Labor Market Areas}

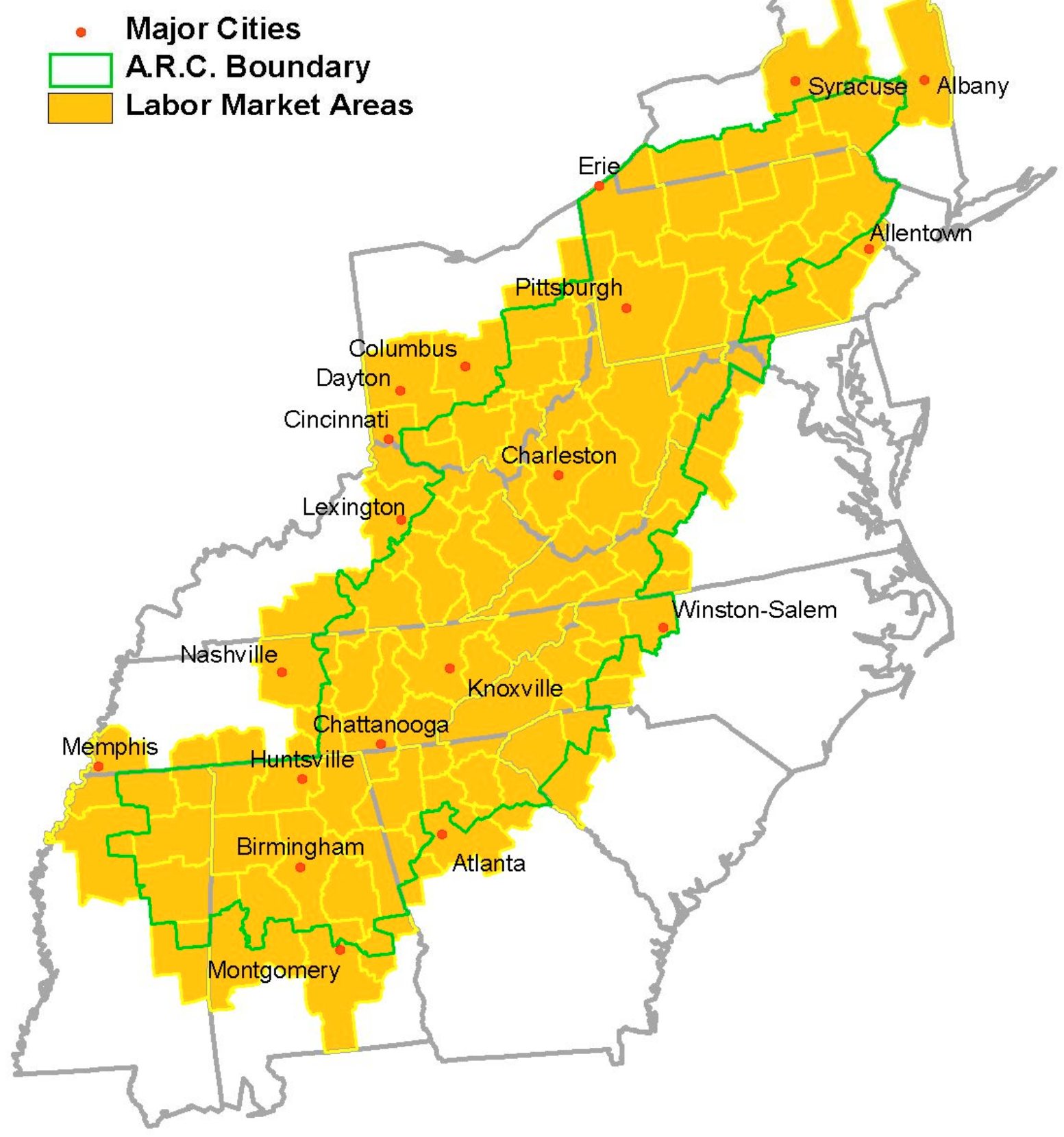




\subsection{Measures of Suicide}

Two measures of suicide are constructed in this analysis which address objective one. The first measure consists of aggregate rates of suicide over two periods of time, 19801990 and 1990-2000. The second measure consists of trends in rates of suicide over each

eleven-year time period. Both aggregate suicide rates and suicide trends were constructed for two age-groups, ages 25 to 44 and 45 to 64 . A complete list of suicide measures used in this research is shown in Table 3-1. Suicide rates and trends for the 79 Appalachian LMAs are provided in Appendix A3.

\section{Table 3-1 Measures of Suicide}

- Suicide Rate, Ages 25-44 1980-1990

- Suicide Rate, Ages 25-44 1990-2000

- Suicide Rate, Ages 45-64 1980-1990

- Suicide Rate, Ages 45-64 1990-2000

- Suicide Trend, Ages 25-44 1980-1990

- Suicide Trend, Ages 25-44 1990-2000

- Suicide Trend, Ages 45-64 1980-1990

- Suicide Trend, Ages 45-64 1990-2000

\subsubsection{Measuring Aggregate Rates of Suicide}

Aggregate rates of suicide were estimated for LMAs in Appalachia for two separate time periods, 1980-1990 and 1990-2000. Aggregate rates were generated by summing consecutive years of data. The resulting rates represent the rates over that entire period of time. Because suicide is relatively rare, especially when examined for small geographic areas, the use of aggregate rates increases the likelihood of generating stable and reliable rates. Mortality resulting from suicide was abstracted from death records from the National Center for Health Statistics for the years 1980-2000. Suicide mortality included all records with an underlying cause-of-death coded E950-E959 using the International Classification of Diseases, Ninth Revision. Population denominators were obtained from the U.S. Bureau of Census for all U.S. counties by 10-year age groups. Both death 
records and population denominators were summed to the LMA level. Age-adjusted rates of aggregate suicide mortality were calculated for two periods 1980-1990 and 19902000 for two sub-populations, all persons 25 to 44 years of age, and all persons 45 to 64 years of age. Age-adjustment was performed using the 2000 standard population weights.

Data for those ages 65 and older and those younger than 25 years of age are excluded from this analysis because the literature suggests that suicide in these age groups is affected by many different factors than those of working age adults (Saunderson and Langford, 1996; Rich et. al., 1986). For example, the elderly are more likely to experience terminal illness, and the loss of lifetime partners. Suicides among younger populations are, for example, more likely to be associated with drug-use problems.

It should also be noted that a large proportion of suicides are unreported (Hopper and Guttmacher, 1979). There are both practical and social reasons for underreporting of suicides. For example, the act of suicide will invalidate many insurance benefits for familial survivors, and therefore provides incentive to attain a different cause of death diagnosis. According to Hopper and Guttmacher (1979) "suicide is often purposively misdiagnosed and erroneously recorded by physicians and public officials who may attempt to protect members of their constituency from public shame" p. 421. For this analysis, it is assumed that the number of accurately determined cases is large enough to withstand underreporting and cases of misdiagnoses.

\subsubsection{Measuring Temporal Trends in Suicide}

Temporal trends in suicide are examined for both the 1980-1990 and 1990-2000 time periods. Due to relatively small numbers of deaths on an annual basis for individual LMAs, a three-year running average was used to generate rates of suicide mortality. To quantify suicide trends, a linear regression model was fitted to log-transformed ageadjusted suicide rates for each LMA using the following equation:

$$
\mathrm{s}=\alpha+\beta(\mathrm{t})+\mathrm{e}
$$


where $\mathrm{s}=\ln ($ age-adjusted suicide rate $), \mathrm{t}=\mathrm{year}, \mathrm{e}=$ error term, and $100\left(\mathrm{e}^{\beta}-1\right)=$ the average percent change in mortality. Linear regression of log-transformed rates assumes constant proportional change over time rather than constant absolute change over time. This approach has been shown to be a more appropriate model for examining temporal trends in mortality (Kleinman, 1986; Barnett and Halverson, 2000). Confidence intervals were calculated for each trend and where the confidence interval contained zero, LMAs were discarded from the analysis.

\subsection{Models of Suicide}

Regression models are used to determine the association between aggregate rates of suicide and socioeconomic conditions (research objective two) and the association between trends in suicide rates and socioeconomic conditions (research objective three) in the labor market areas of Appalachia. Separate models were estimated for each of the two age groups (25-44 and 45-64) and for each time period (1980-1990 and 1990-2000). All models were estimated using OLS.

The model for aggregate rates of suicide is as follows:

$$
\text { AGGSUICIDERATE }_{\mathrm{i}, \mathrm{j}, \mathrm{k}}=\alpha_{\mathrm{j}, \mathrm{k}}+\Sigma_{\mathrm{m}}\left(\beta_{\mathrm{j}, \mathrm{k}, \mathrm{m}} \text { CONTEXTVARIABLE }_{\mathrm{i}, \mathrm{k}, \mathrm{m}}\right)+\mathrm{e}_{\mathrm{i}, \mathrm{j}, \mathrm{k}}
$$

where AGGSUICIDERATE $\mathrm{i}_{\mathrm{i}, \mathrm{k}, \mathrm{k}}$ represents the aggregate suicide rate for age group $\mathrm{j}$ (2544 and 45-64) in time period $\mathrm{k}$ (1980-1990 and 1990-2000) for labor market area i (79 LMAs), CONTEXTVARIABLE $\mathrm{i}_{\mathrm{i}, \mathrm{k}, \mathrm{m}}$ refers to $\mathrm{m}$ different socioeconomic context variables for each labor market area (i) and each time period (k), $\alpha_{\mathrm{j}, \mathrm{k}}$ and $\beta_{\mathrm{j}, \mathrm{k}, \mathrm{m}}$ are parameters to be estimated and $\mathrm{e}_{\mathrm{i}, \mathrm{j}, \mathrm{k}}$ is an error term.

The model for trends in suicide rates is as follows:

$$
\text { SUICIDETREND }_{\mathrm{i}, \mathrm{j}, \mathrm{k}}=\alpha_{\mathrm{j}, \mathrm{k}}+\Sigma_{\mathrm{m}}\left(\beta_{\mathrm{j}, \mathrm{k}, \mathrm{m}} \text { CONTEXTVARIABLE }_{\mathrm{i}, \mathrm{k}, \mathrm{m}}\right)+\mathrm{e}_{\mathrm{i}, \mathrm{j}, \mathrm{k}}
$$


where SUICIDETREND ${ }_{\mathrm{i}, \mathrm{j}, \mathrm{k}}$ represents the trend in the suicide rate estimated from equation (1) in the previous section for age group $\mathrm{j}$ in time period $\mathrm{k}$ for labor market area $\mathrm{i}$, CONTEXTVARIABLE $\mathrm{i}_{\mathrm{i}, \mathrm{k}, \mathrm{m}}$ refers to $\mathrm{m}$ different socioeconomic context variables for each labor market area (i) and each time period (k), $\alpha_{\mathrm{j}, \mathrm{k}}$ and $\beta_{\mathrm{j}, \mathrm{k}, \mathrm{m}}$ are parameters to be estimated and $\mathrm{e}_{\mathrm{i}, \mathrm{j}, \mathrm{k}}$ is an error term.

The socioeconomic context variables (CONTEXTVARIABLE $E_{i, k, m}$ ) used in these models are discussed in detail in the next section.

\subsection{Measures of Socioeconomic Context}

Measures of socioeconomic context were constructed for five categories of variables: population, industrial structure, economic change, unemployment, and income. Data were extracted and derived from three primary resources; the 1990 and 2000 census, the Area Resource File (February 2001 release), and the Regional Economic Information System (REIS). The Area Resource File (ARF) was compiled by the National Center for Health Workforce Information \& Analysis, Bureau of Health Professions, Health Resources and Services Administration, Department of Health and Human Services. The REIS was complied by the Regional Economic Measurement Division of the Bureau of Economic Analysis (BEA). Annual economic estimates are available for each county, metropolitan area, BEA economic area, State, and BEA region, and for the United States.

Economic change is represented by examining variations in employment for selected industrial sectors; mining, manufacturing, service, and retail trade. Annual employment data for these industrial sectors was abstracted from the REIS for the years 1980-2000. These sectors were chosen to reflect the overall trend in the U. S. of manufacturing decline and coincident increases in service sector employment. Mining was chosen due to its historical and continued importance in the Appalachian region. 
Several measures have been constructed which represent both socioeconomic context and economic change. Unemployment volatility is used to reflect variable general stability/instability in the economic fortunes of LMAs in the region. The percent change in employment for each industrial sector is calculated to reflect shifts in the nature of local economies of the region. Industrial volatility is calculated by examining changes in annual employment for each industrial sector. A complete list of measures of socioeconomic context used in this research is shown in Table 3.2.

Table 3-2 Measures of Socioeconomic Context

\section{POPULATION}

- Percent change (over decade) in population

- Percent urban population

- Population density

\section{INDUSTRIAL STRUCTURE}

- Percent mining employment share

- Percent manufacturing employment share

- Percent service employment share

- Percent retail employment share

- Percent change (over decade) in mining employment share

- Percent change (over decade) in manufacturing employment share

- Percent change (over decade) in service employment share

- Percent change (over decade) in retail employment share

- Mining dependent

- Manufacturing dependent

\section{ECONOMIC CHANGE}

- Percent change (over decade) in all employment

- Percent change (over decade) in mining employment

- Percent change (over decade) in manufacturing employment

- Percent change (over decade) in service employment

- Percent change (over decade) in retail employment

- Volatility (annual standard deviation) in all employment

- Volatility (annual standard deviation) in mining employment

- Volatility (annual standard deviation) in manufacturing employment

- Volatility (annual standard deviation) in service employment

- Volatility (annual standard deviation) in retail employment 


\section{Table 3-2 (continued)}

\section{UNEMPLOYMENT}

- Unemployment rate

- Change (over decade) in unemployment rate

- Volatility (annual standard deviation) in unemployment rate

\section{INCOME}

- Median family income

- Change in median family income

- Percent in poverty

- Income inequality (mean income divided by median income)

\subsubsection{Population}

\subsubsection{Population Distribution}

Two general variables are utilized here to reflect the distribution of the population LMAs within the region: Percent Urban Population and Population per Square Mile. The Census Bureau defines urbanized areas as those, which have a population concentration of at least 50,000 inhabitants, generally consisting of a central city and the surrounding, closely settled, contiguous territory. Included in the urban population are persons living in places of 2,500 or more inhabitants outside urbanized areas. Levin and Leyland (2005) found that men in Scotland experienced significantly higher rates of suicide in rural towns and remote rural areas. Morrell et al (1999) found a higher risk of suicide among migrant males in non-metropolitan areas in New South Wales, Australia, but also found lower risk of suicide among women in non-metropolitan areas.

Population per square mile is an indicator of overall population density within each LMA. Zimmerman (1988) found inverse associations between population density and state suicide rates. Together these variables reflect a combination of the degree of rurality and social and economic infrastructure. Both the percent urban population and population per square mile were examined for the years 1980, 1990, and 2000. 


\subsubsection{Population Change}

The percentage change in population was derived from census data for the two key time periods 1980-1990 and 1990-2000. Population change provides a general measure of population stability, growth, and decline to compare with both aggregate rates of suicide as well as suicide trends. Population change rates were found to be positively associated with state suicide rates, in addition to the percentage of state population that were inmigrants (Zimmerman, 1988). Inverse associations were found between state suicide rates and the percentage of the state populations that live in the state in which they were born. In addition, the components of population change, primarily migration, may represent potential confounders to interpretations of associations between suicide and socioeconomic context. If, for example, large portions of the population migrate to other locations to follow jobs, the remaining population may consist of a higher proportion of individuals who are susceptible to depression and suicide.

\subsubsection{Industrial Structure}

\subsubsection{Sector Share of Total Employment}

Industrial structure is measured in this analysis using employment data for four industrial sectors; Mining, Manufacturing, Service, and Retail Trade. The sector share of total employment for each industrial sector has been examined for two time periods 1980-1990 and 1990-2000. The sector share of total employment reflects the overall importance of each industry in the local economy.

\subsubsection{Change in Sector Share of Total Employment}

The percentage change in the sector chare of total employment was calculated for each industrial sector over two time periods 1980-1990 and 1990-2000. The change in sector share of employment reflects major industrial changes that have occurred in the region between 1980 and 2000 . 


\subsubsection{Industrial Dominance}

Industrial dominance was determined for two key industry sectors, mining and manufacturing, by identifying LMAs in the top quintile of each employment sector share distribution. LMAs in the top quintile for each sector were assigned values of ' 1 ' and used as 'dummy' variables in subsequent regression analyses. Industrial dominance was used here in order to examine associations between rates and trends in suicide and measures of socioeconomic context among areas that relied on these industry sectors for significant proportions of their total employment.

\subsubsection{Economic Change}

One of the key theoretical arguments of this dissertation is that changes in industrial structure result in changes in the social and economic structure of local areas. Adverse changes in industrial structure may lead to increasing levels of stress and anxiety that may exacerbate feelings of depression and increased rates of suicide.

\subsubsection{Change in Employment}

Employment change was calculated between each decade (1980-1990 and 1990-2000), for each industrial sector as well as total employment. Employment change reflects overall employment changes that have occurred in each industrial sector.

\subsubsection{Volatility in Employment}

Employment volatility is examined by calculating differences in annual employment and deriving the standard deviations of the resultant distributions. Employment volatility reflects both the nature of the industry, e.g. systematically volatile industries, as well as changing economic fortunes of local areas. 


\subsubsection{Unemployment}

\subsubsection{Unemployment Rate}

Rates of unemployment are calculated as the number of people actively seeking work divided by the total number of people in the civilian labor force. High rates of unemployment have been shown to be highly correlated with adverse public health outcomes in general (Brenner, 1987) and specifically suicide ( Preti and Miotto, 1999; Weyerer and Wiedenmann, 1995; Leenaars et. al., 1993). For individuals, unemployment may result in economic hardships that limit lifestyle choices, options for health insurance, as well as access to medical care resources. When communities suffer persistently high rates of unemployment, social infrastructures that serve these communities may be difficult to establish and those that exist may break down. In addition, unemployment is a key indicator of local and regional development. However, the true burden of unemployment is hard to estimate due to the fact that standard unemployment definitions do not include the long-term unemployed, often referred to as discouraged workers, or those individuals who are not seeking work due to disability.

\subsubsection{Change in Unemployment Rate}

The change in unemployment rate was calculated over each decade (1980-1990 and 1990-2000. The change in unemployment rate reflects either overall improvement or deterioration of employment opportunities in each LMA over the period 1980-2000.

\subsubsection{Volatility in Rate of Unemployment}

Although rates of unemployment have generally decreased since 1980, the nature and rate of decrease fluctuates, in many cases, in local areas. A measure of volatility in rates of unemployment has been constructed by calculating annual differences in unemployment rates and deriving the standard deviation of the resulting distributions. Unemployment volatility was calculated for two time periods 1980-1990 and 1990-2000. 
Volatility in rates of unemployment reflects a number of potential phenomenon including, nature of the industry, e.g. systematically volatile industries, as well as changing economic fortunes of local areas.

\subsubsection{Income}

This analysis examines three generalized variables that reflect income and income related factors. Regional variations in median family income, poverty, and a measure of income inequality are examined. Variations in income and related factors may aid in explaining variations in aggregate rates of suicide. In addition, changes in median family income may help to clarify both changes in aggregate suicide rates and suicide trends.

\subsubsection{Median Family Income}

Family income is the sum of income received by all family members in a household. Median family income indicates that point at which incomes of half of the families are higher and half are lower. Median family income has been used independently as a measure of economic development (Nielsen and Alderson, 1997) and represents a key component of aggregate socioeconomic status. Income is critical for achieving 'quality of life' expectation and aspirations. In a society where quality of life expectations and aspirations are fueled by an increasingly ubiquitous media (magazines, television, radio), income becomes a primary factor in achieving those expectations.

\subsubsection{Changes in Median Family Income}

Changes in median family income were calculated over each decade (1980-1990 and 1990-2000). The change in median family income reflects either overall improvement or deterioration of aggregate economic conditions in each LMA over the period 1980-2000. 


\subsubsection{Percent of Persons Living in Poverty}

Poverty statistics provide a basic indicator of the socioeconomic status of a population within a given area. In general, poverty is one of the most important social determinants of health and well-being. While poverty does not influence all diseases in the same way, strong positive relationships have been consistently shown between poverty and cardiovascular diseases, gastrointestinal disease, chronic respiratory disease, as well as other adverse health outcomes, including accidental and violent deaths, and suicide (Adler and Ostrove, 1999; Hopper and Guttmacher, 1979). Typically, individuals who live in poverty have limited lifestyle choices and may therefore be more susceptible to anxiety and stress associated with economic hardship.

Individuals are classified below poverty if their total individual income was less than the poverty threshold specified for the applicable family size, age of householder, and number of related children under 18 present as defined by the federal government's official poverty definition (DeNavas-Walt et al, 2004). For this analysis the percent of persons living below the poverty threshold is utilize for three years; 1980, 1990, and 2000.

\subsubsection{Income Inequality}

In addition to median family income a local measure of income inequality was derived for each LMA by dividing the mean household income by the median household income. (Baqir, 2002). Income inequality is a measure of the distribution of wealth, reflecting the degree of income separation between highest and lowest income earning groups in a population. According to Waitzman and Smith (1998), high levels of income inequality may lead to "a deterioration of community attachment and involvement, resulting in deleterious psychosocial and material consequences". 


\section{Chapter 4 DESCRIPTIVE ANALYSIS}

In this chapter geographic variability in measures of suicide, and measures of socioeconomic context among LMAs in the Appalachian region are examined. The chapter consists of two general sections. The first section presents aggregate rates of suicide for persons ages 25 to 44 and 45 to 64 for two time-periods: 1980-1990 and 19902000. Estimated suicide trends are then presented for the same age-groups and timeperiods. The second section examines geographic variability in the measures of socioeconomic context used in subsequent analysis.

\subsection{Measures of Suicide}

In this section, geographic variability in measures of suicide (outlined in Chapter Three), are discussed. A total of eight suicide measures were calculated for this research (Table $3-1$ ), which correspond to two population subgroups (ages 25 to 44 and 45 to 64) and two time periods (1980-1990 and 1990-2000). Both aggregate rates and trends are discussed in the following sections.

Figure 4-1 provides a reference for the discussion of suicide rates among LMAs in the region by identifying each by its LMA number. These numbers are used to facilitate the discussion of variable rates and trends of suicide in the region.

\subsubsection{Suicide Rates Among Appalachian Labor Market Areas}

Maps of age-adjusted suicide rates for persons ages 25 to 44 and 45 to 64 are presented in Figures 4-2 and 4-3 for the time periods 1980-1990 and 1990-2000 respectively. The distribution of suicide rates among Appalachian LMAs for the period 1980-1990, (Figure 4.2), are similar in both the range of values and the geographic distribution for both agegroups. Suicide rates ranged from 9 deaths per 100,000 to 38 deaths per 100,000 among persons ages 25 to 44 and from 9 deaths per 100,000 to 33 deaths per 100,000 among 
persons ages 45 to 64 . In each case, considerable geographic disparities are evident within the region ( a 4.2-fold difference and 3.7-fold difference respectively).

Figure 4-1 Numbered Appalachian Labor Market Areas 1990

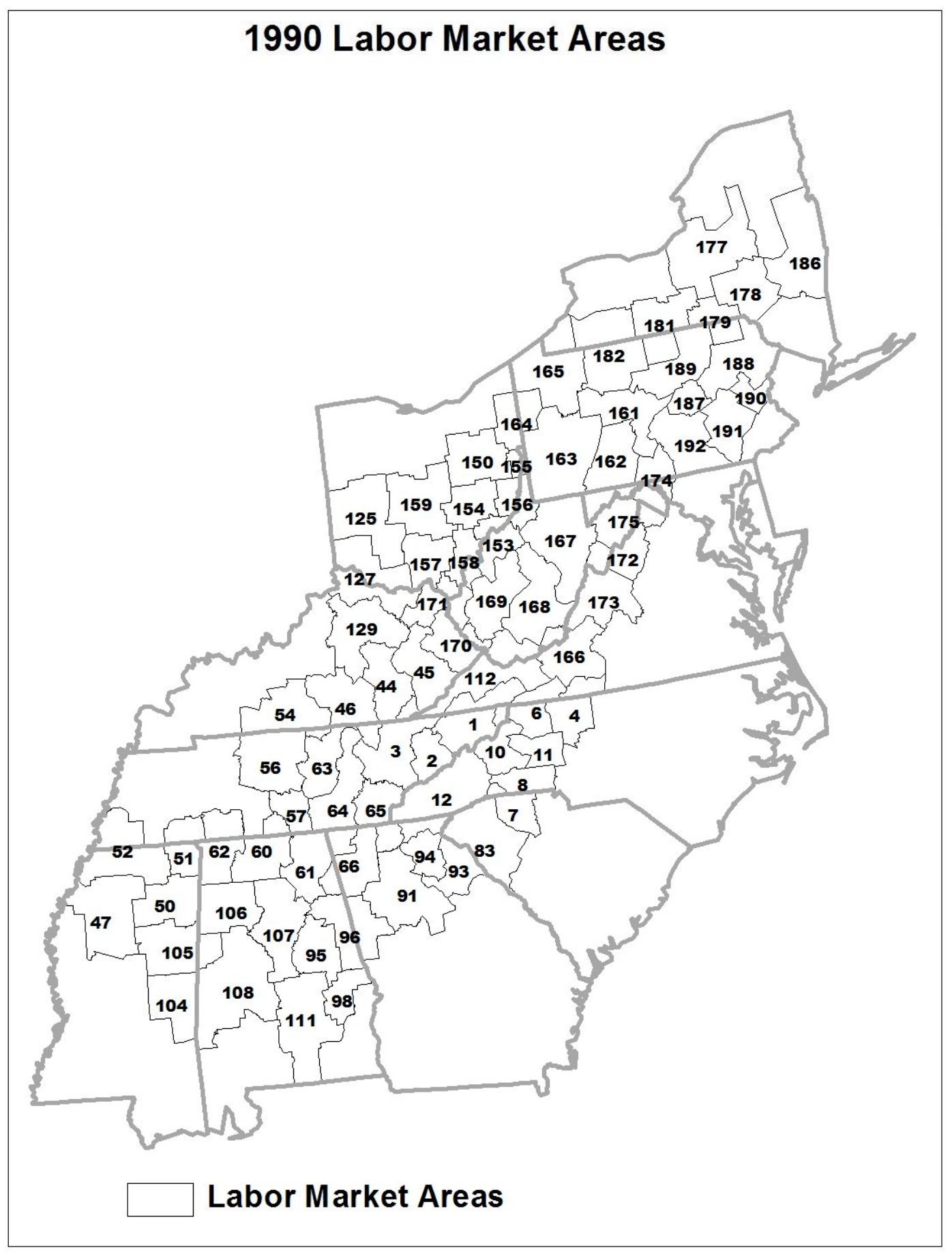


Roughly similar geographic patterns indicate generally higher rates of suicide in the Central and Southern portions of the regions. LMA 178 in Southeastern New York (see Figure 4-1 for reference LMA numbers) stands out in the northern portion of the region as the lone LMA in the top quintile. In general there appears to be a north-south gradient in rates of suicide, with higher rates occurring more frequently in LMAs in the Southern part of the region. This gradient appears to be more pronounced for persons 45 to 64 over the period 1980-1990.

The distribution of suicide rates among Appalachian LMAs for the period 1990-2000 (Figure 4-2) are similar in the range of values, however the geographic distribution suggest moderate geographic shifts in the relative predominance of high rate LMAs. Suicide rates ranged from 7 deaths per 100,000 to 47 deaths per 100,000 among persons ages 25 to 44 and from 7 deaths per 100,000 to 40 deaths per 100,000 among persons ages 45 to 64 ( a 6.7-fold difference and 5.7-fold difference respectively).

The distributions of suicide rates among Appalachian LMAs are shown separately for each age-group over both time periods in Figures 4-4 and 4-5, The distribution for age group 25 to 44 is very similar for both decades, however a few LMAs have experienced significant increases over the 1990-2000. The distribution for age-group 45 to 64 has changed considerably indicated by a downward shift towards reduced rates of suicide. Despite the overall downward shift a few LMAs have either maintained relatively high rates or experienced substantial increases.

When contrasted with the national suicide trend (Figure 2-1) which suggests precipitous declines over the period 1990-2000, the variations in the range of suicide rates between 1980-1990 and 1990-2000 for Appalachian LMAs suggest considerable increases in suicide among some LMAs and give cause for concern. 
Figure 4-2. Age-Adjusted Suicide Rates 1980-1990- Appalachian Labor Market Areas

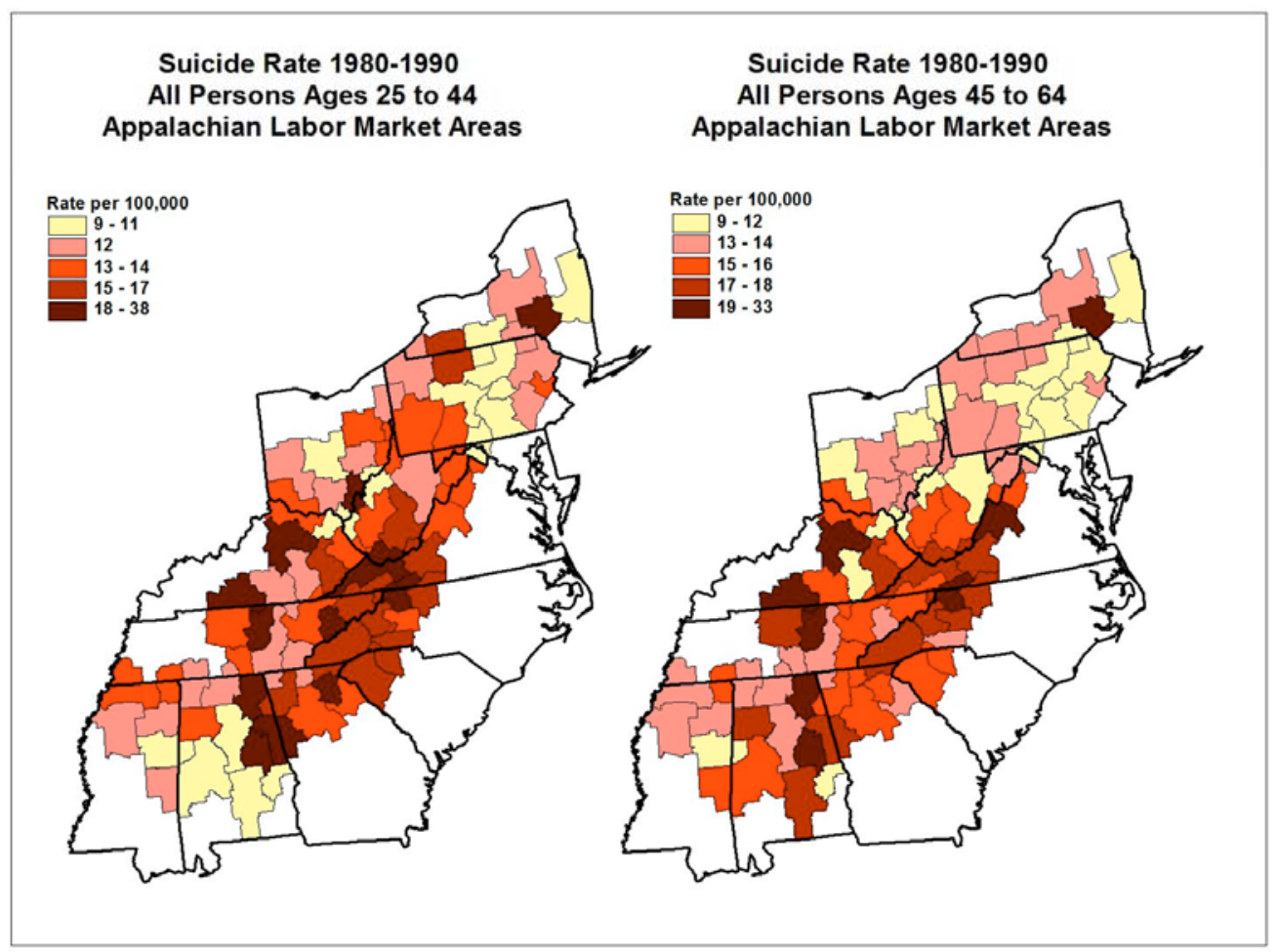

Figure 4-3. Age-Adjusted Suicide Rates 1990-2000, Appalachian Labor Market Areas




Figure 4-4. Distribution of Suicide Rates Among Appalachian LMAs, Persons 25 to 44, 1980 1990 and 1990-2000.

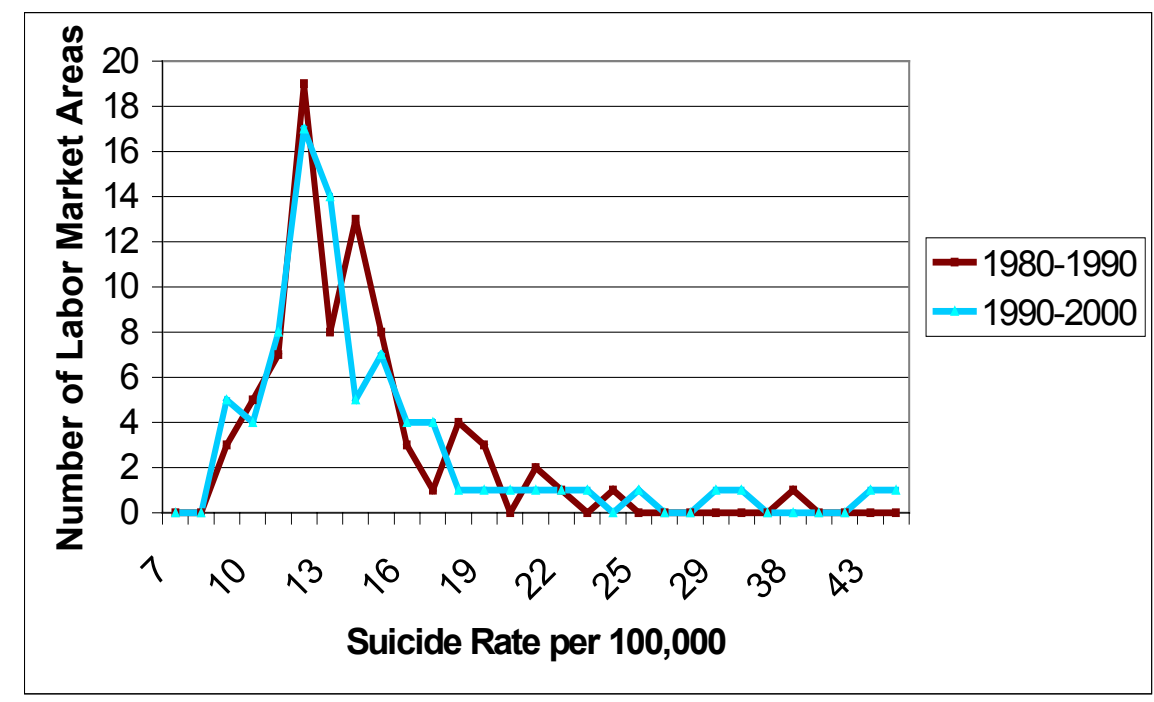

Figure 4-5-. Distribution of Suicide Rates Among Appalachian LMAs, Persons 45 to 64, 19801990 and 1990-2000.

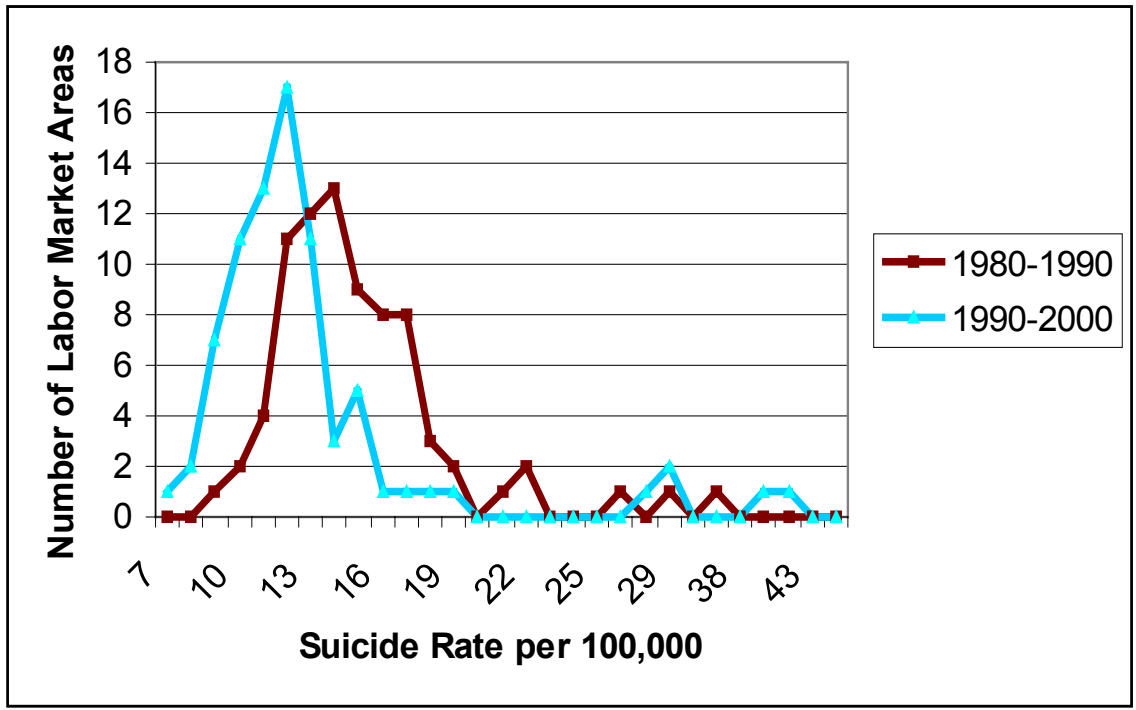

To highlight shifts in the relative predominance of suicide rates in the region, the difference in ranks over the two time periods was calculated for the 79 LMAs in the region. Maps showing changes in the relative predominance of suicide rates are shown in Figure 4-6. These maps do not depict the absolute change in suicide rates. Shifts in the 
predominance of suicide rates may occur due to decreases and/or increases in relatively few LMAs. However they these maps are useful in demonstrating a shifting relative landscape of suicide in the region. More adverse shifts are indicated by negative shifts in rank. Fairly extreme shifts (both positive and negative) in the relative predominance of suicide rates are evident, and in many cases are quite different between the two age groups. For example, LMAs 104, 108, and 111 in the extreme Southern part of the region experienced negative relative shifts in predominance among people ages 25 to 44 and positive shifts among people 45 to 64. LMA 44 in South-Central Kentucky and LMA 150 in Eastern Ohio, experienced negative relative shifts among people ages 45 to 64 and positive shifts among people ages 25 to 44 .

Figure 4-6 Rank Differences in Suicide Rates

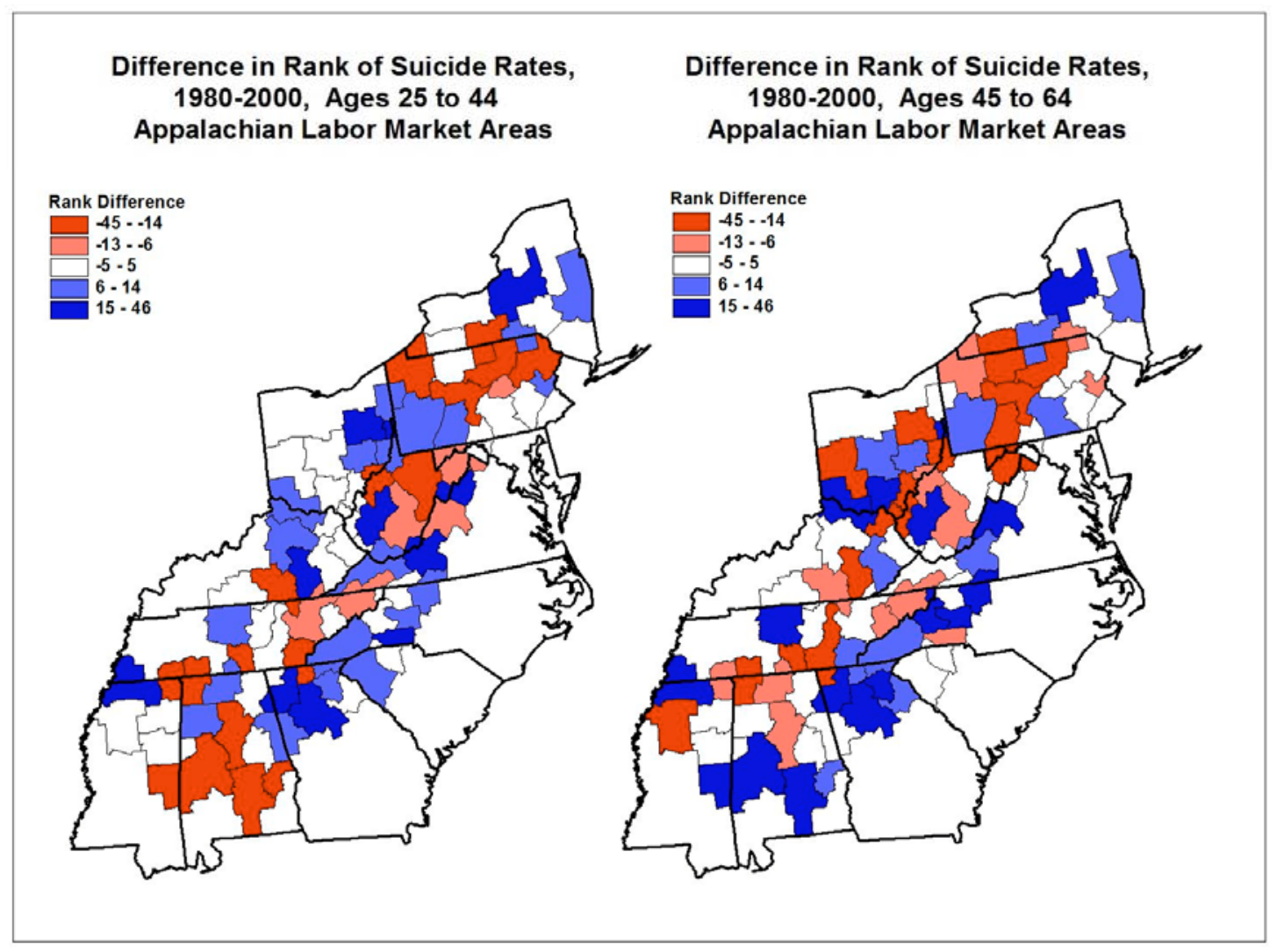




\subsubsection{Trends in Rates of Suicide 1980-1990 and 1990-2000}

Trends in rates of suicide were generated for persons in two-age groups, ages 25 to 44 and ages 45 to 64, for two time periods, 1980-1990 and 1990-2000 using equation 1 (Chapter 3, section 3.3.2). Geographic variability in suicide trends among Appalachian LMAs is shown in figures 4-7 and 4-8. Corresponding distribution graphs are shown in figures 4-9 and 4-10 respectively.

In general, suicide trends in Appalachian LMAs appear to reflect national suicide trends (Figure 2-1). Striking differences occur between the two time periods with the majority of LMAs experiencing increases over the period 1980-1990 and declines over the period 1990-2000. In fact, at first glance the maps for each age-group appear to be mirror images of each other with frequent occurrences of increasing trends over the period 19801990 changing to declining trends over the period 1990-2000. However, in age-group 25 to 44 there are cases where moderate increases over the period 1980-1990 became strong increases over the period 1990-2000 as well as moderate declines over the period 19801990 changing to strong declines over the period 1990-2000. For example, trends in LMA 108 in South-Central Alabama shifted from a moderate increase to a strong increase between the two time-periods. LMA 181 in South-Central New York and NorthCentral Pennsylvania shifted from a moderate decline to a strong decline over the two time-periods. Similar shifts have occurred among age-group 45 to 64. For example, LMA 3 in North-Eastern Tennessee and LMA 177 in Central New York experienced moderate declines over the period 1980-1990 and strong declines over the period 1990-2000. LMA 174 and 175 in Eastern West Virginia and Western Maryland experience moderate increases over both time-periods. 
Figure 4-7 Average Percent Change in Suicide Rates 1980-2000, Persons Ages 25 to 44

\section{Average Percent Change in Suicides 1980-2000}

All Persons Ages 25 to $\mathbf{4 4}$ - Labor Market Areas
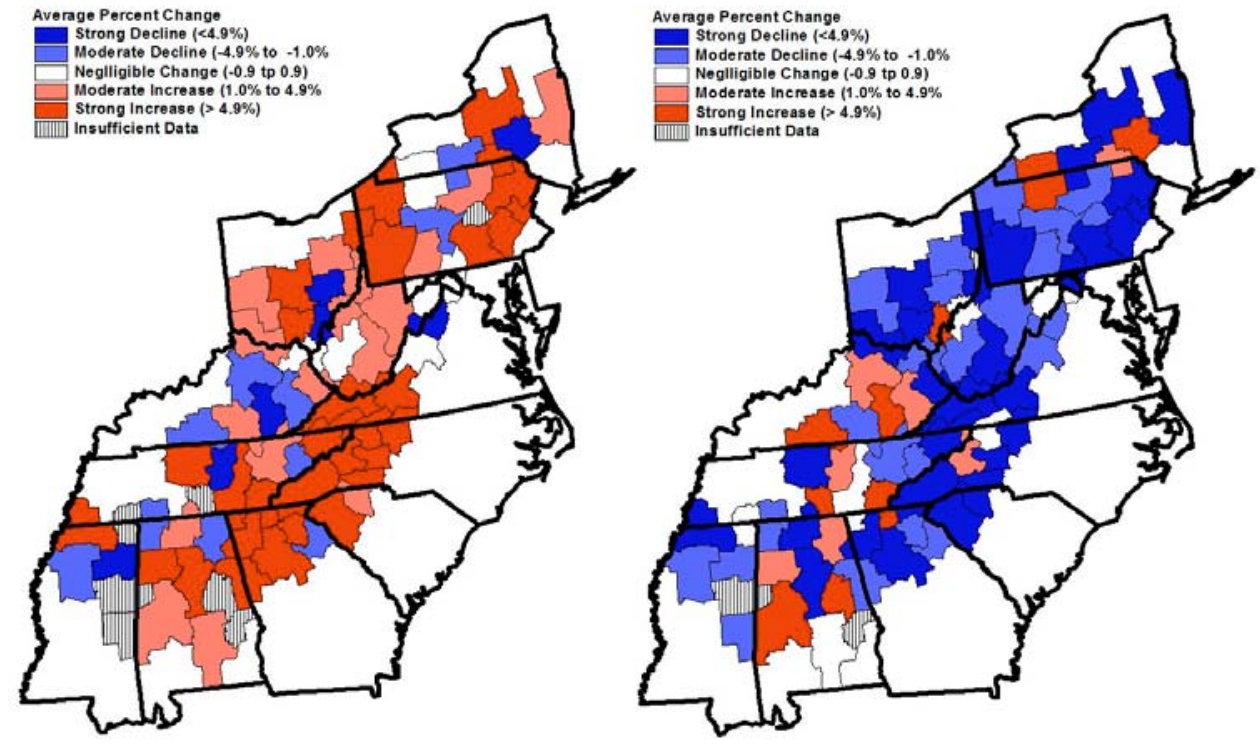

\section{Average Percent Change in Suicides 1980-2000}

All Persons Ages 45 to 64 - Labor Market Areas
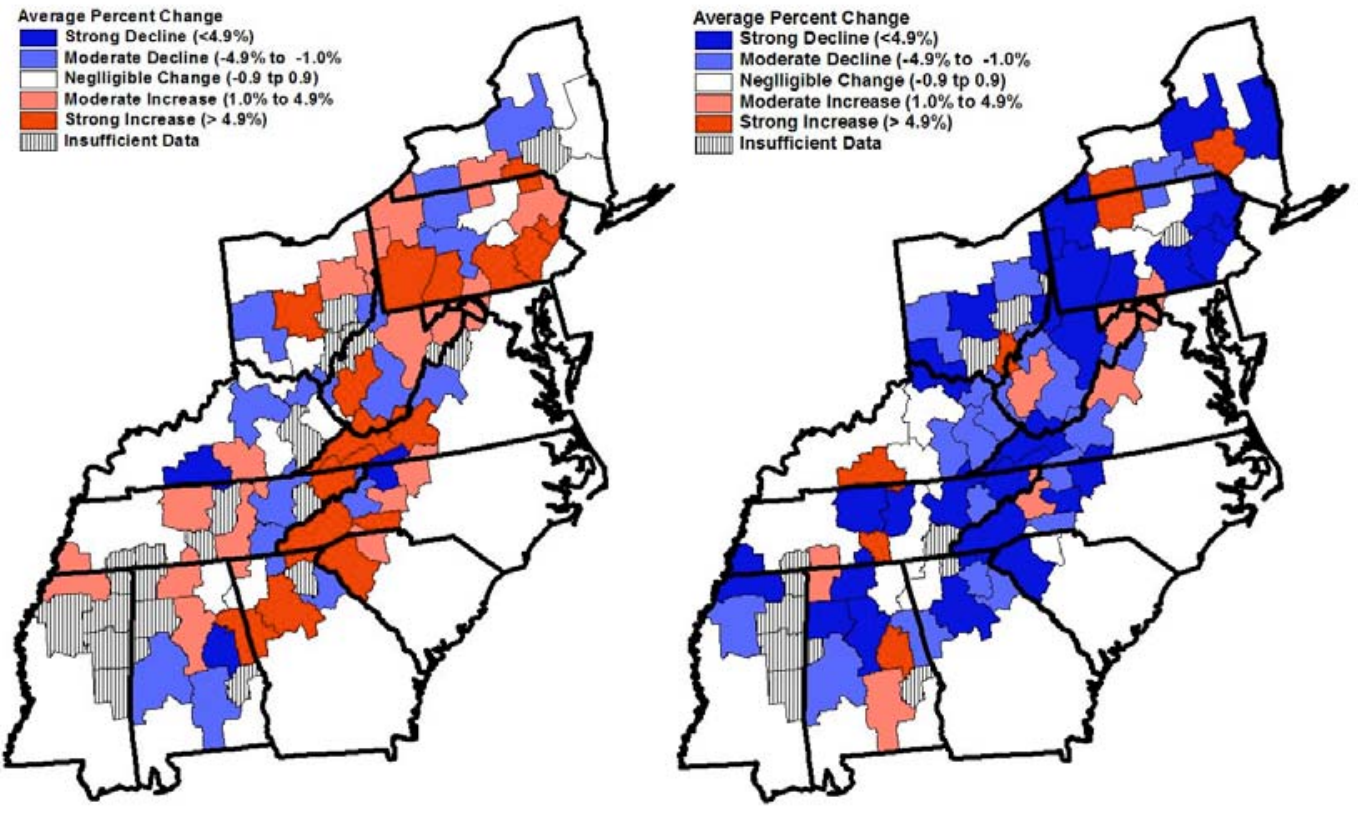
Figure 4-9. Distribution of Suicide Trend Values Among Appalachian LMAs, Ages 25 to 44, 1980-1990 and 1990-2000.

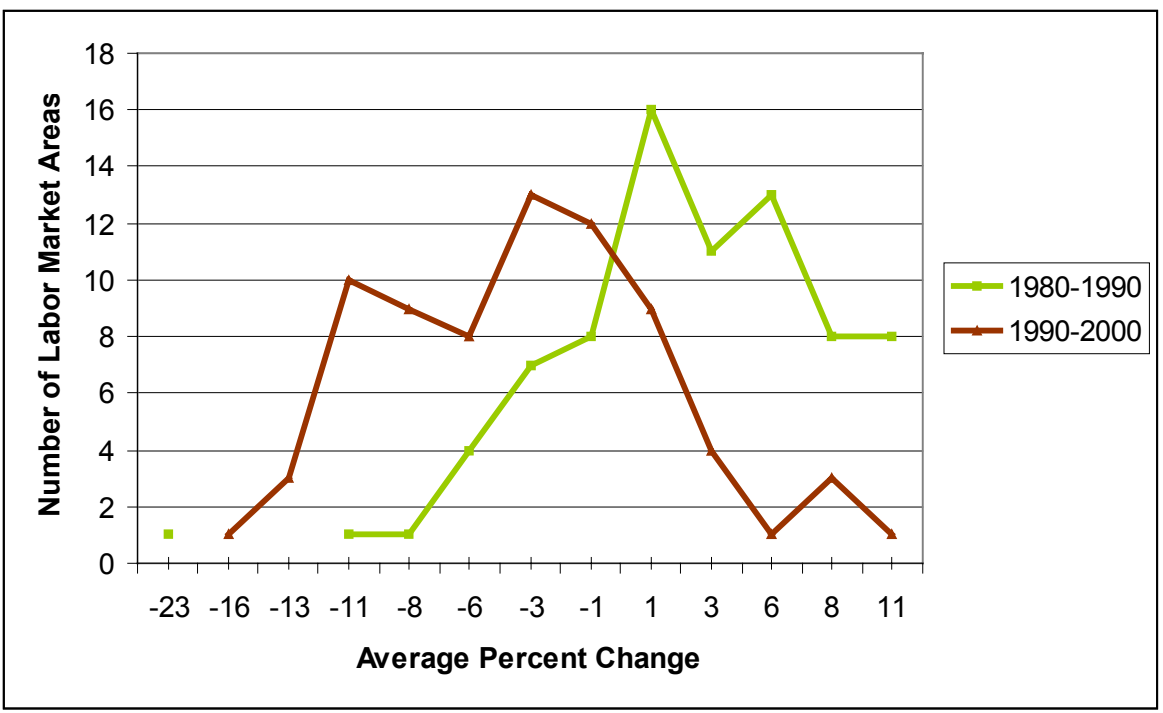

Figure 4-10. Distribution of Suicide Trend Values Among Appalachian LMAs, Ages 45 to 64, 1980-1990 and 1990-2000.

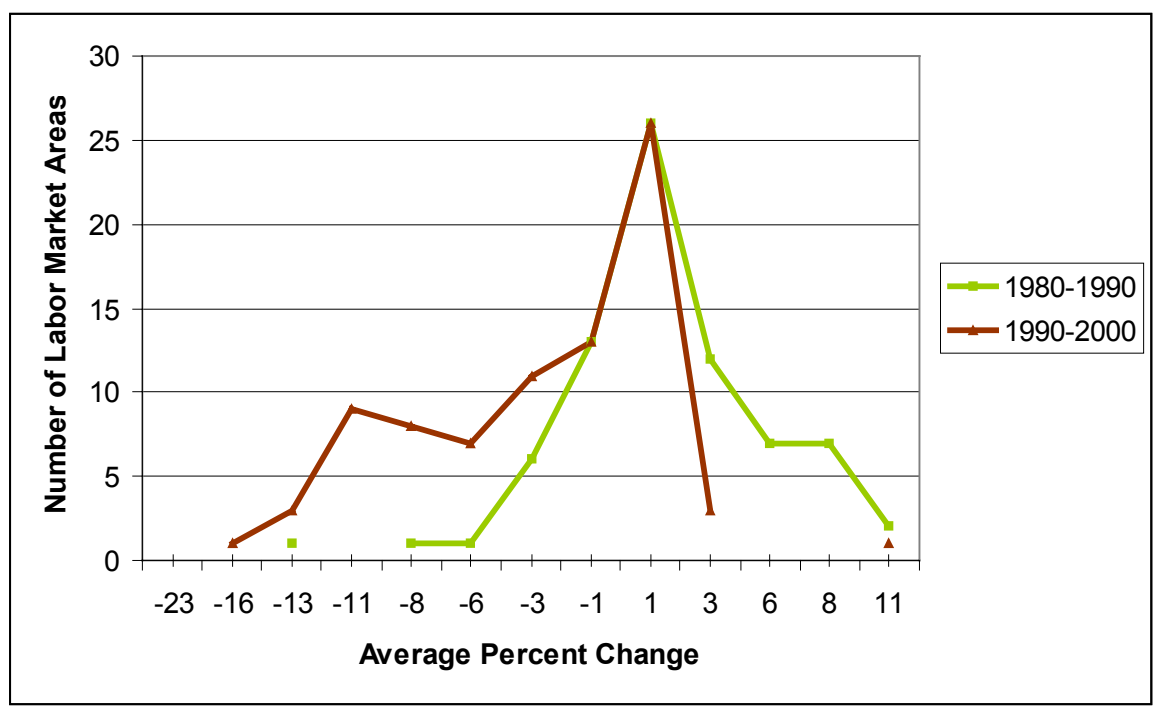




\subsection{Measures of Socioeconomic Context}

In this study a number of specific indices are examined which describe the socioeconomic conditions of Labor Market Areas (LMAs) in the Appalachian region including rurality, unemployment, income, poverty, and industrial structure. Collectively these indices help to define the general socioeconomic condition of local populations. These socioeconomic conditions provide the context within which individuals live their daily lives and within which institutions and regulatory systems are developed that are related to health care, education, public safety, working conditions, and local and regional economic development. Although region-wide these variables are highly correlated, local differences in the interaction of these variables may help to explain differential rates and trends of suicide in areas which are similar on a single (or several) indicators.

\subsection{Population Distribution}

Two general variables are utilized to reflect the distribution of the population among LMAs within the region: percent urban population and population per square mile. The Census Bureau defines urbanized areas as those which have a population concentration of at least 50,000 inhabitants, generally consisting of a central city and the surrounding, closely settled, contiguous territory. Included in the urban population are persons living in places of 2,500 or more inhabitants outside urbanized areas. Population per square mile is an indicator of overall population density within each county. Maps showing the distribution for percent urban population and population per square mile are shown in Figure 4-11 and 4-12 respectively. Data are shown for three cross-sections that correspond to census years; 1980,1990, and 2000.

Together these variables reveal the location of major population centers within the region as well as a general lack of many major metropolitan areas. Major metropolitan areas are typically those areas with the most well developed socioeconomic and public health infrastructures. In addition, these variables provide some important clues about the general distribution of the population within each LMA. In places where the percent 
urban population is low, many people are more likely to be distributed in relatively isolated rural areas and may suffer more from social isolation.

Although the relative differences in percent urban population among Appalachian LMAs remain generally constant over the three cross-sections (Figure 4-11), several notable differences are evident in West Virginian LMAs 168,169, and 178 which suggest increases in the proportion of the population living in urban areas. Conversely, LMA 178 in Southeastern New York has experienced a decline in the proportion of the population living in urban areas. Although the distributions for population density (population per square mile, Figure 4-12) suggest change in the absolute values, there appears to have been little relative change in population density among Appalachian LMAs.

Figure 4-11. Percent Urban Population - 1980,1990,2000

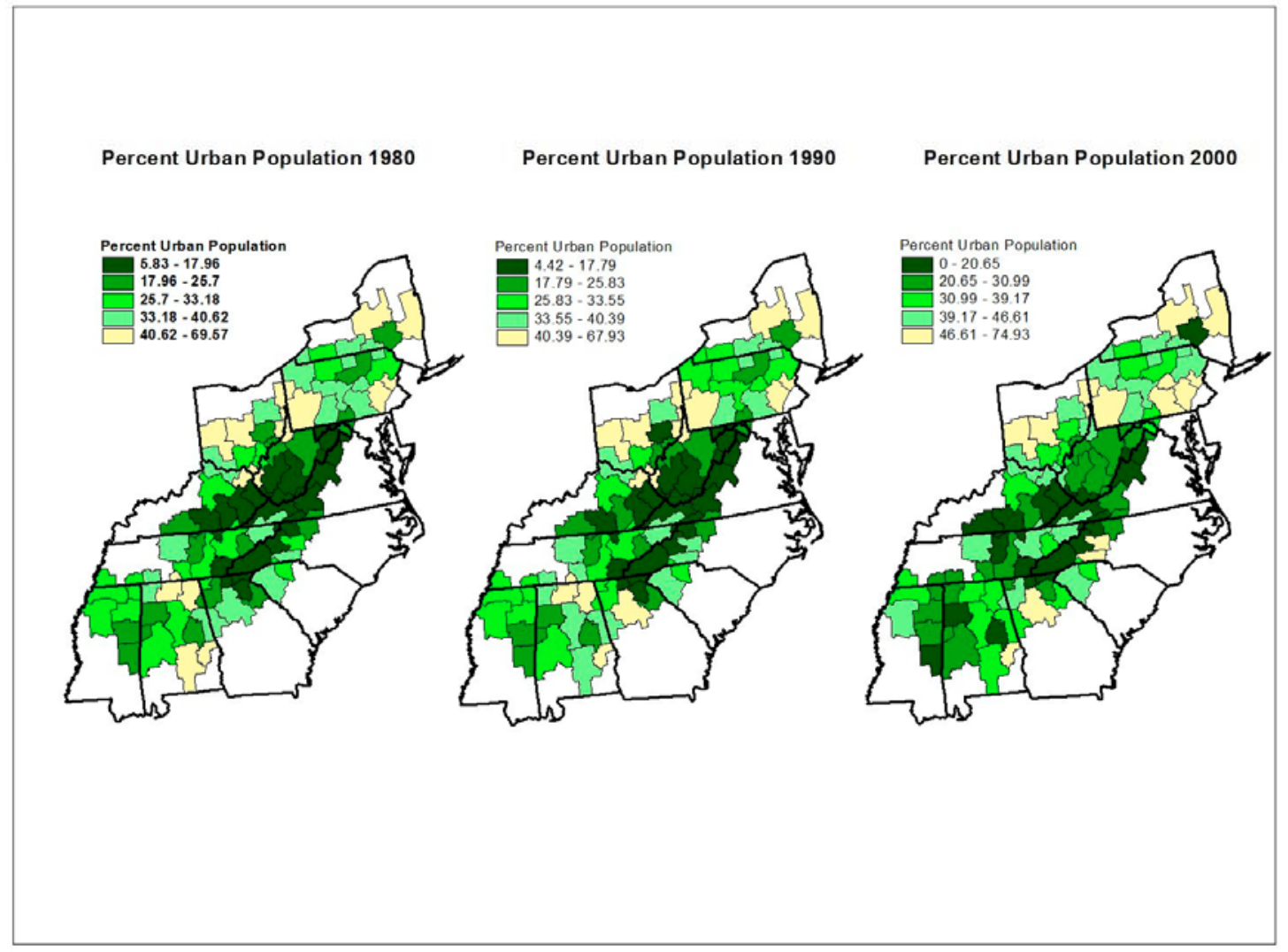


Figure 4-12. Population per Square Mile - 1980,1990, 2000

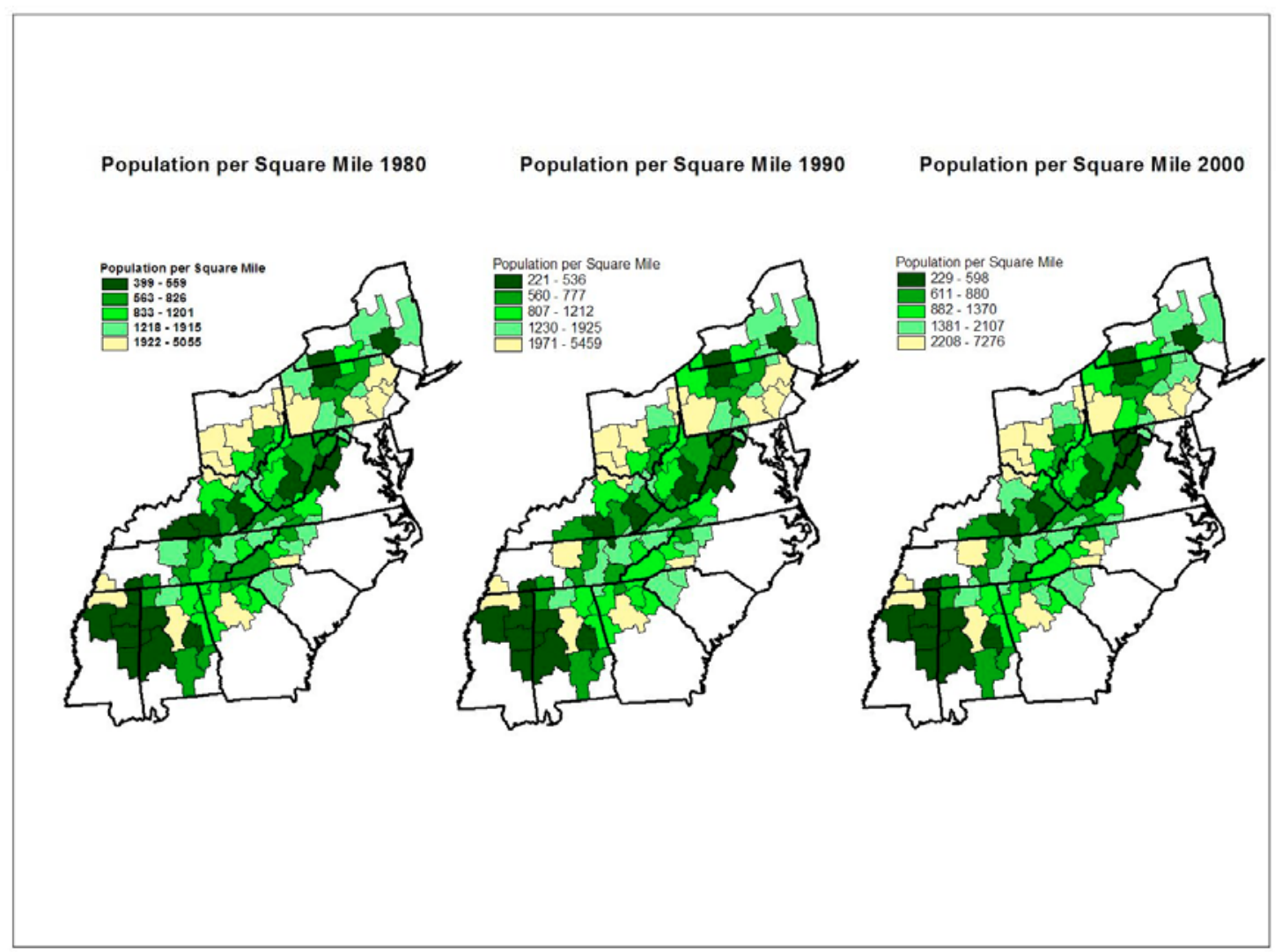

\subsubsection{Population Change}

The percent change in total population for each eleven-year period is shown in figure 4-13. Between 1980 and 1990, central Appalachian (including most of West Virginia) experienced significant population decline while the southern portion of the region experienced population growth, particularly around the Atlanta metropolitan area. Although the population appeared to have somewhat stabilized in the central Appalachian region between 1990 and 2000, the southern portion of the region experienced accelerated population growth, particularly in northern Georgia. 
Figure 4-13. Percent change in population 1980-1990, 1990-2000

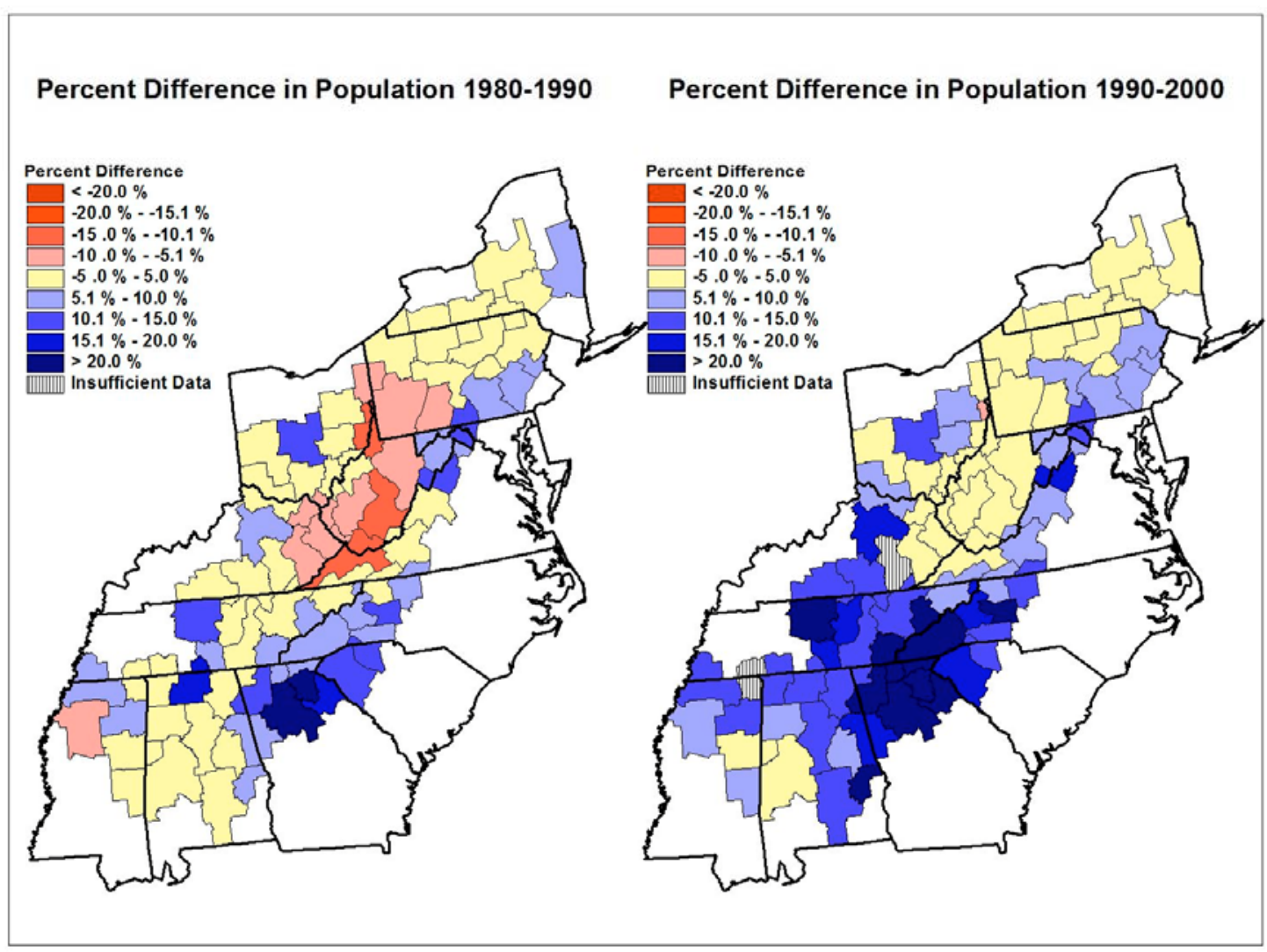

\subsubsection{Sector Share of Total Employment}

The sector share of total employment was calculated for four industrial sectors: mining, manufacturing, service, and retail trade for each eleven-year period. Industrial sector share of employment for Appalachian LMAs are shown in figures 4-14 through 4-17. Several key features of these distributions are 1) dominant mining regions in the central Appalachian region including almost all of West Virginia, 2) relatively high levels of manufacturing employment in the southern portion of the region (and in the northern region as well) and very low levels of manufacturing employment in central Appalachia, 3) high levels of service sector and retail trade employment in the northern part of the region, and 4) downward shifts in the distributions of sector share of employment in both mining and manufacturing and coincident upward shifts in the distributions of sector share of employment for service and retail trade. 
Figure 4-14. Mining sector share of total employment, 1980-1990 and 1990-2000.

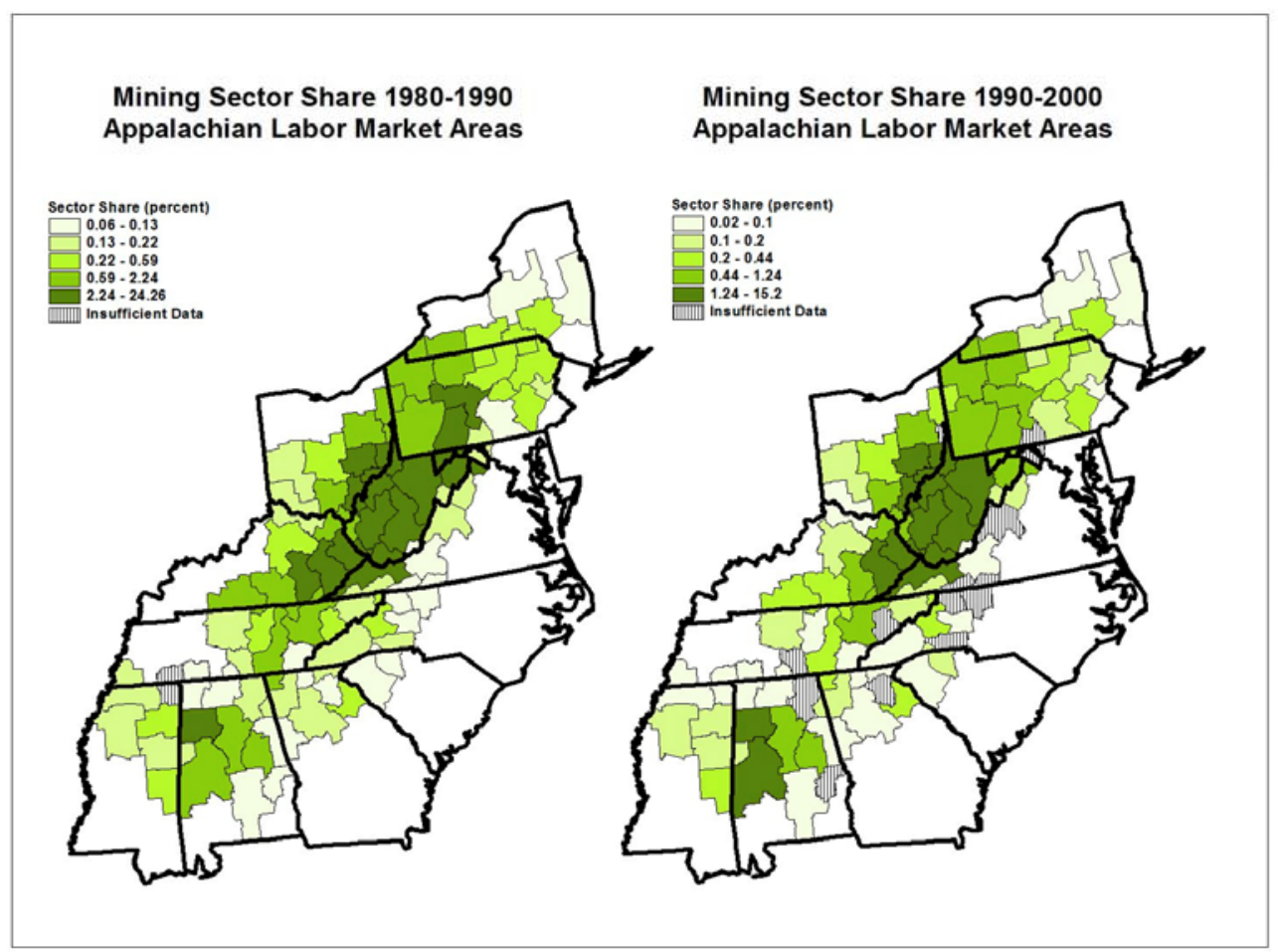

Figure 4-15. Manufacturing sector share of total employment 1980-1990 and 1990-2000

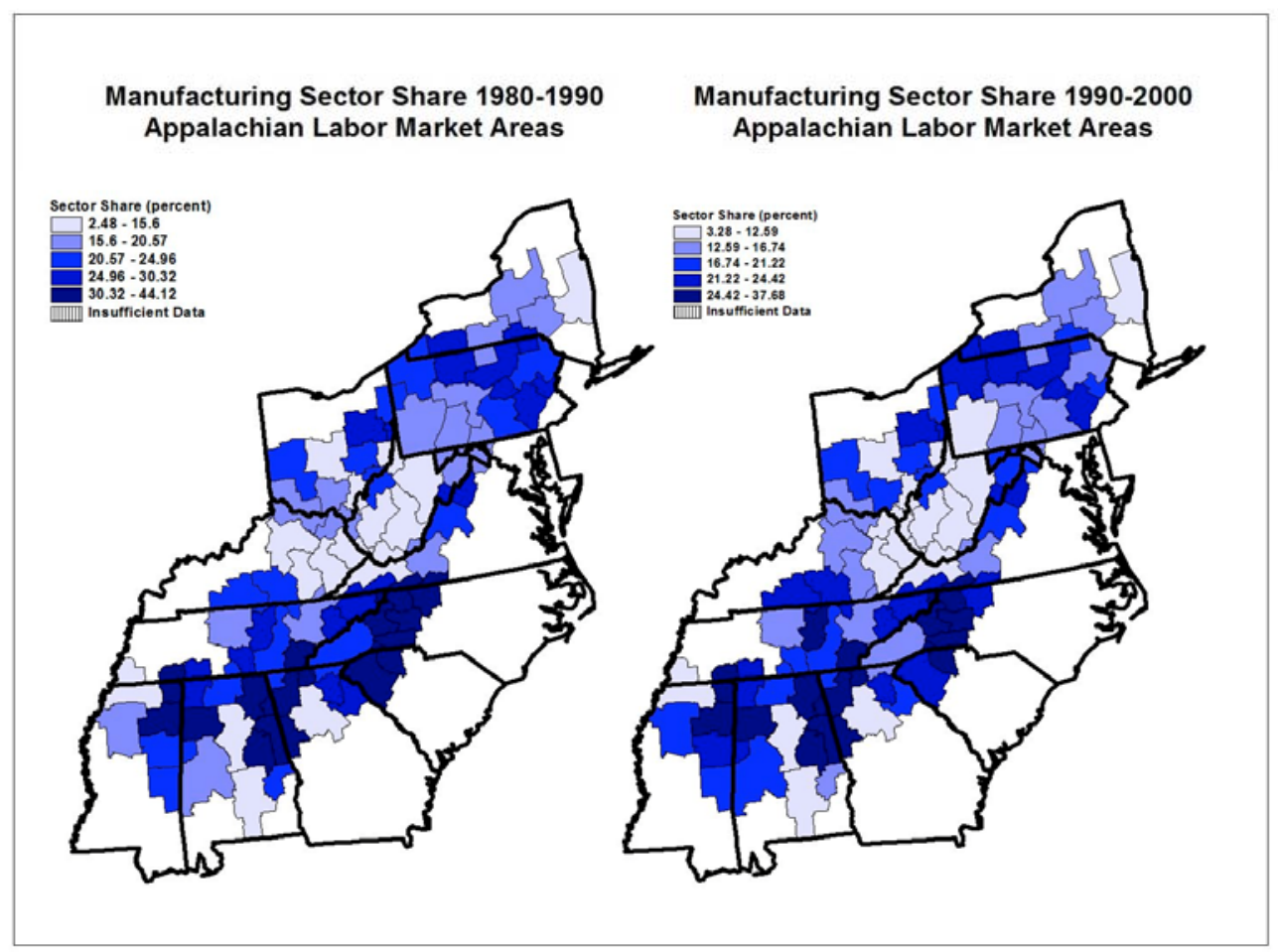


Figure 4-16. Service sector share of total employment, 1980-1990 and 1990-2000.

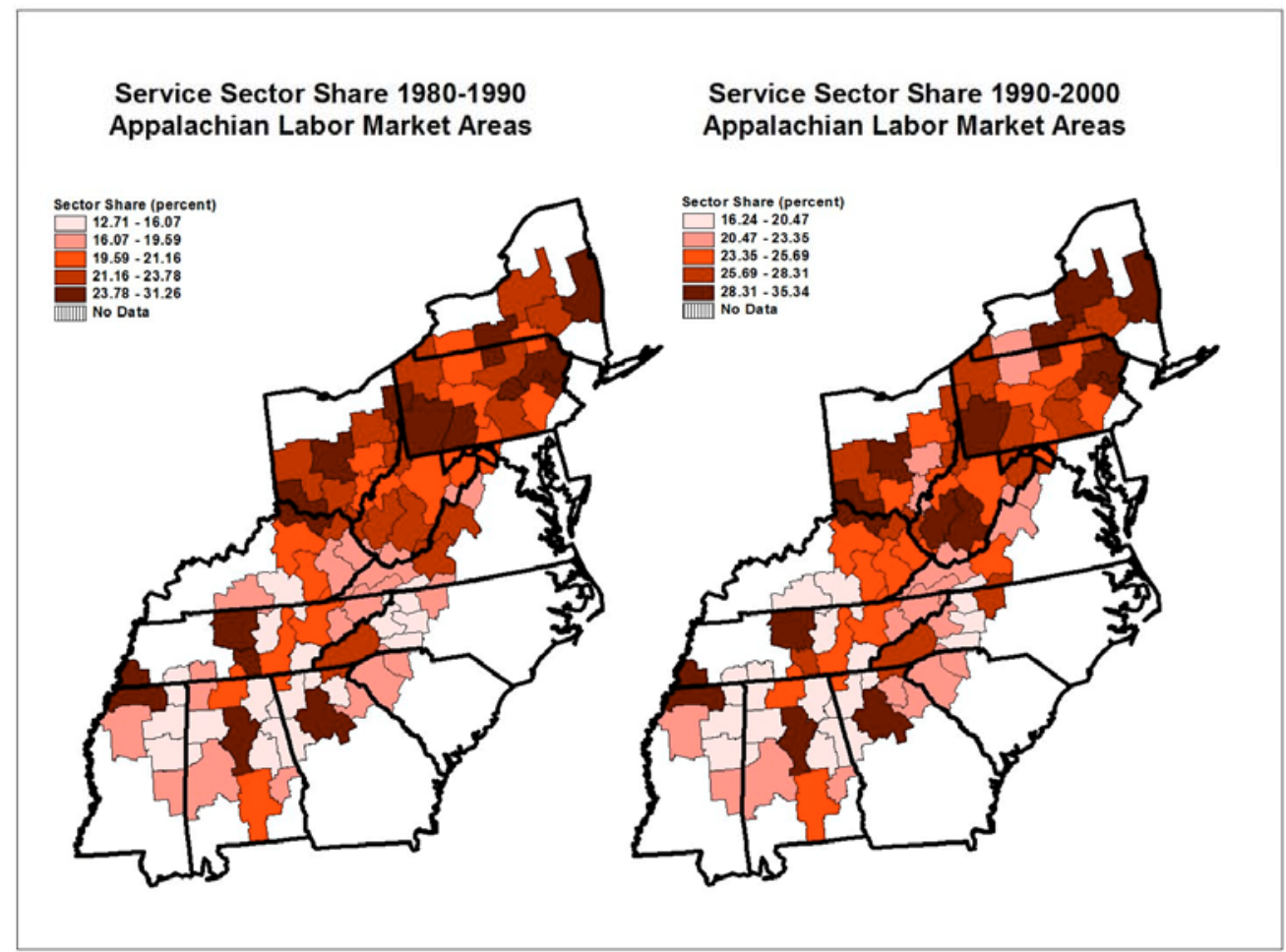

Figure 4-17. Retail trade sector share of total employment, 1980-1990 and 1990-2000

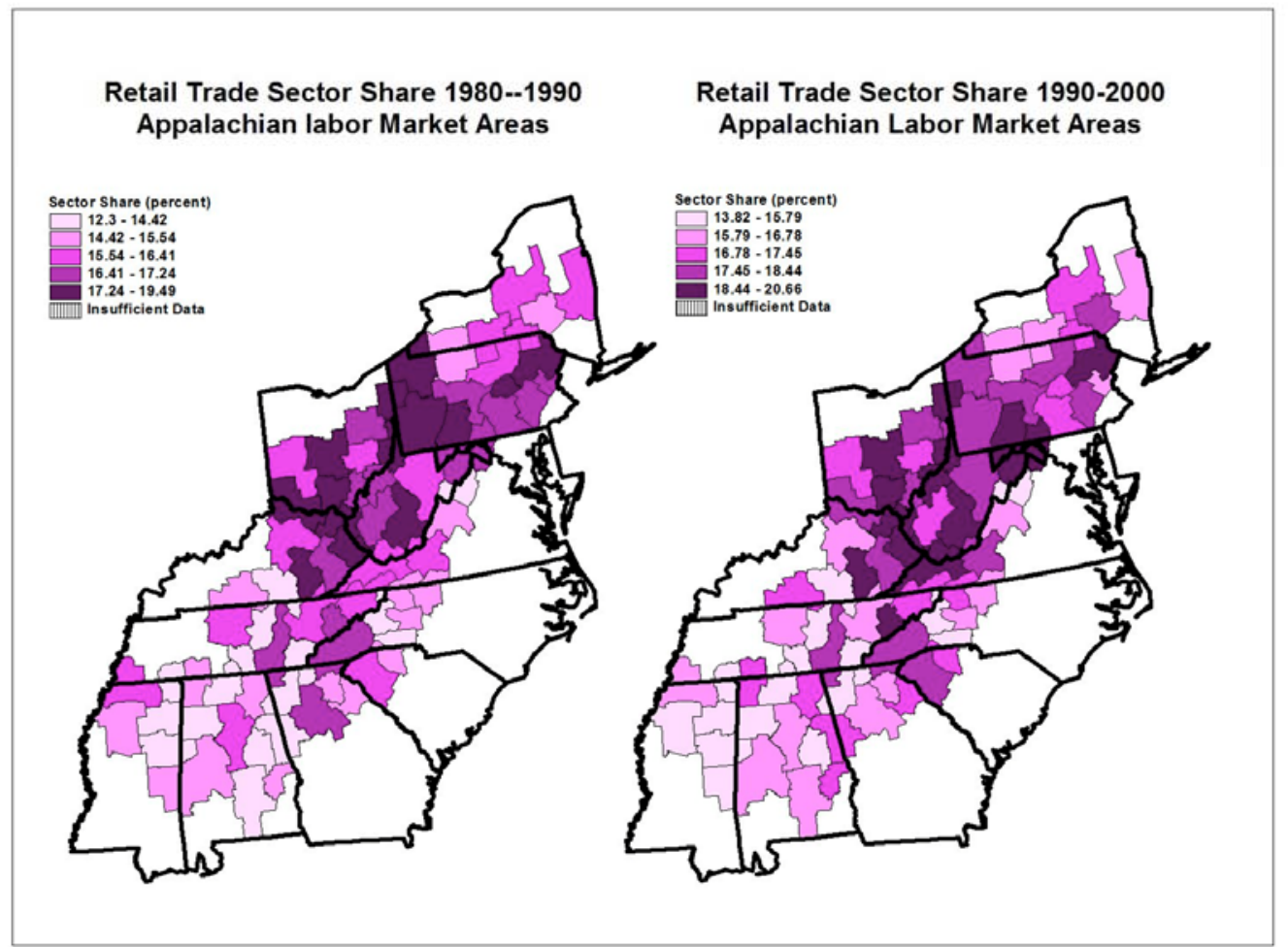




\subsubsection{Change in Sector Share of Total Employment by Industry}

To highlight variations in employment over the two time-periods used, the percent difference in employment in mining, manufacturing, service, and retail trade between census years 1980-1990 and 1990-2000 were calculated. Differences in levels of employment for each sector are intended to represent changes in the industrial structures of LMAs in the region. Maps showing employment changes in mining, manufacturing, service, and retail trade industries are shown in figures 4-18 through 4-21.

Widespread declines in employment in the mining industry are evident in both elevenyear periods (Figure 4-18). However, more dramatic declines occur in mining employment between 1990 and 2000. A few LMAs in the Southern portion of the region experienced large mining employment increases between 1980 and 1990. Between 1980 and 1990 there was a north-south gradient in manufacturing employment change with LMAs in the Northern half of the region generally experiencing declines and many LMAs in the Southern half of the region experiencing increases (Figure 4-19). Declines in manufacturing employment are more widespread over the period 1990-2000 although a number of LMAs throughout the region experienced increases in manufacturing employment, perhaps most notably in Eastern Kentucky. All LMAs in the region experienced increases in service sector employment over both decades however the largest increases occurred among LMAs in the Southern half of the region, particularly between 1990 and 2000 (Figure 4-20). Employment patterns similar to those of the service sector are evident in the retail trade industry however single LMAs experienced declines in retail trade employment for both 1980-1990 and 1990-2000 (Figure 4-21). LMA 155 in Northern West Virginia and Eastern Ohio experienced declines in employment in retail trade and over the period 1980-1990 and increases over the period 1990-2000. LMA 179 in Southcentral New York and Northeastern Pennsylvania experienced increases in retail trade employment over the period 1980-1990 and declines over the period 1990-2000. 
Figure 4-18. Percent Difference in Mining Employment 1980-1990 and 1990-2000.

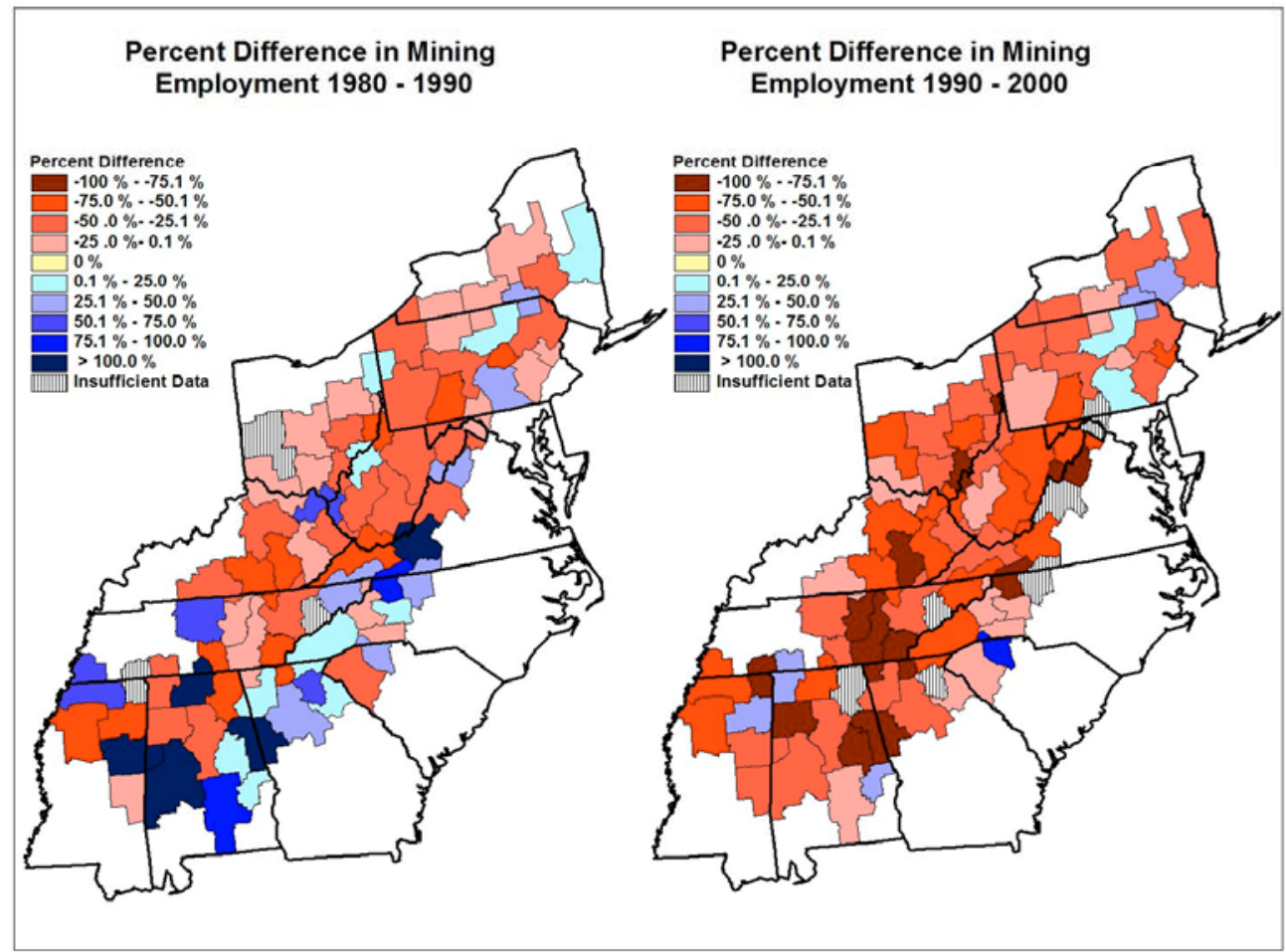

Figure 4-19. Percent Difference in Manufacturing Emnlovment 1980-1990 and 1990-2000.

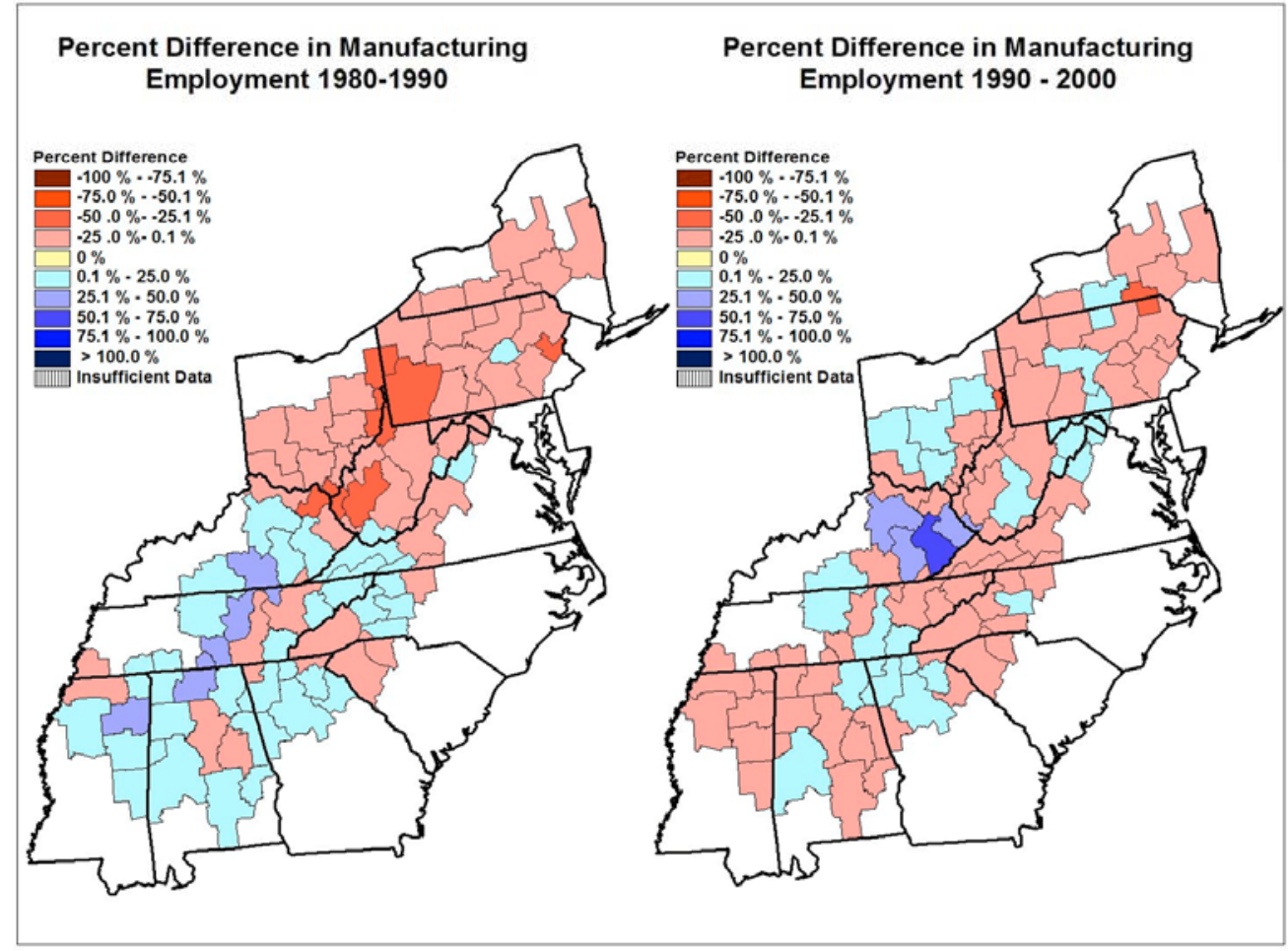


Figure 4-20. Percent Difference in Service Sector Employment 1980-1990 and 1990-2000.

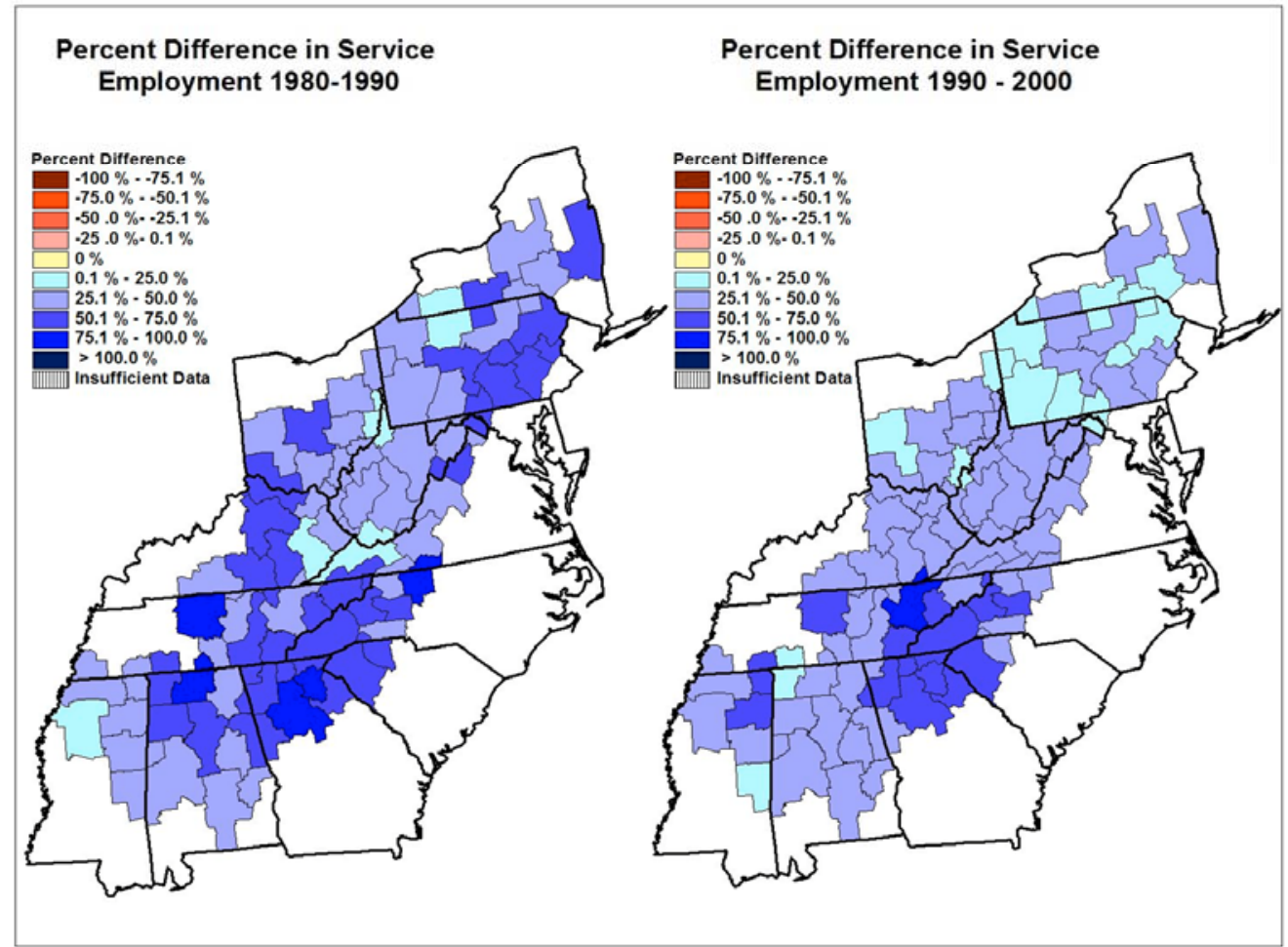

Figure 4-21. Percent Difference in Retail Trade Employment 1980-1990 and 1990-2000.

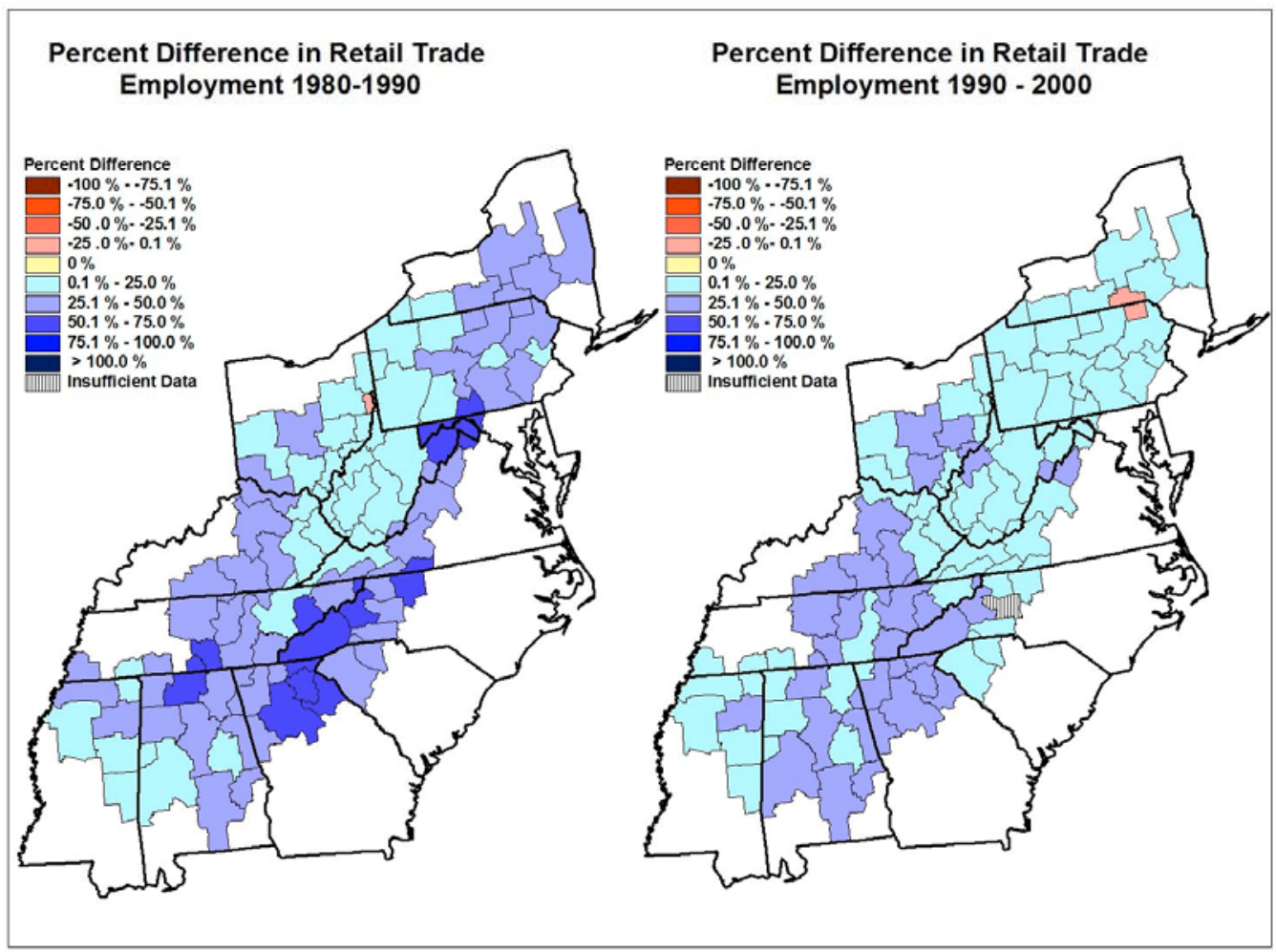




\subsubsection{Volatility in Employment}

In addition to absolute changes in employment between distinct periods of time (1980, 1990, and 2000), a measure of employment volatility was calculated for each industrial sector for each of the two time-periods used in this analysis. Employment volatility was derived by first calculating annual changes in employment for each industrial sector, then calculating the standard deviation of the resulting distributions of employment change. Volatility in employment reflects industry sector stability/instability in local labor markets and levels of employment security/insecurity among participants in local labor markets. Employment volatility within each LMA may mediate the impacts that overall levels of growth and decline have on local populations. For example, the positive affects of overall employment growth may be less positive if volatility is high and conversely, the negative affects of employment decline may be less negative is the decline is slow and gradual.

Geographic distributions of employment volatility for each industry are shown in Figures 4-22 through 4-25. Volatility in mining employment (Figure 4-22) suggests a highly variable landscape of employment change over each time period. Although overall mining employment decline is evident over the period 1980-2000 (Figure 4-18), the ways in which the declines (and increases) occurred are highly variable and in some cases extreme as indicated by the range of volatility values in mining employment (5.122131.36 between 1980-1990 and 3.827-322.033 between 1990-2000). The mining industry is by nature systematically volatile, often responding to seasonal demands. In addition the mining industry is often subject to demands of national and global economic conditions. For example, the employment in the coal mining industry may fluctuate based on national and global demands for steel.

Volatility in manufacturing employment appears to be less dramatic than mining employment (Figure 4-23). 
Figure 4-22. Mining Employment Volatility 1980-1990 and 1990-2000.

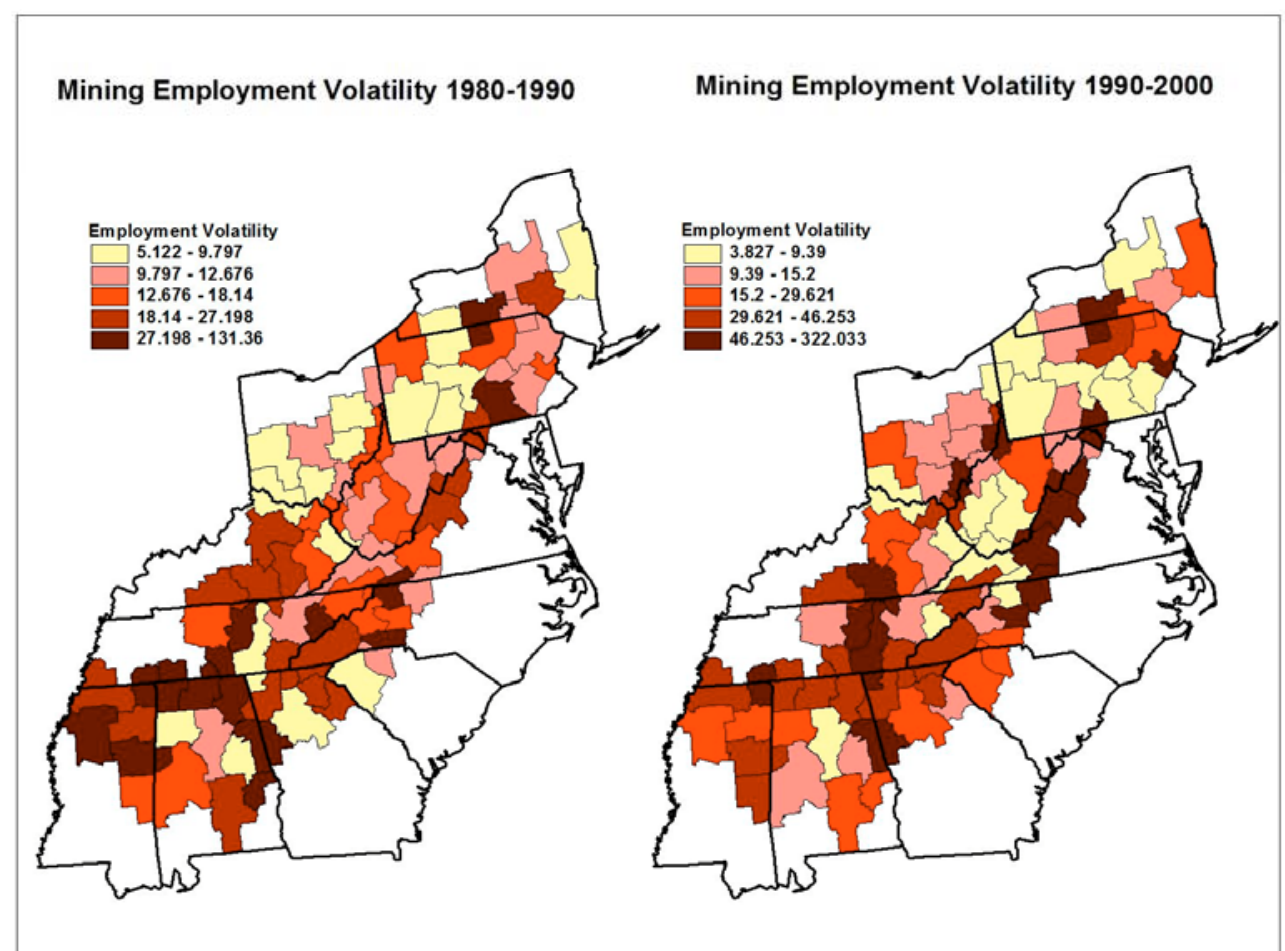

Figure 4-23. Manufacturing Employment Volatility 1980-1990 and 1990-2000.

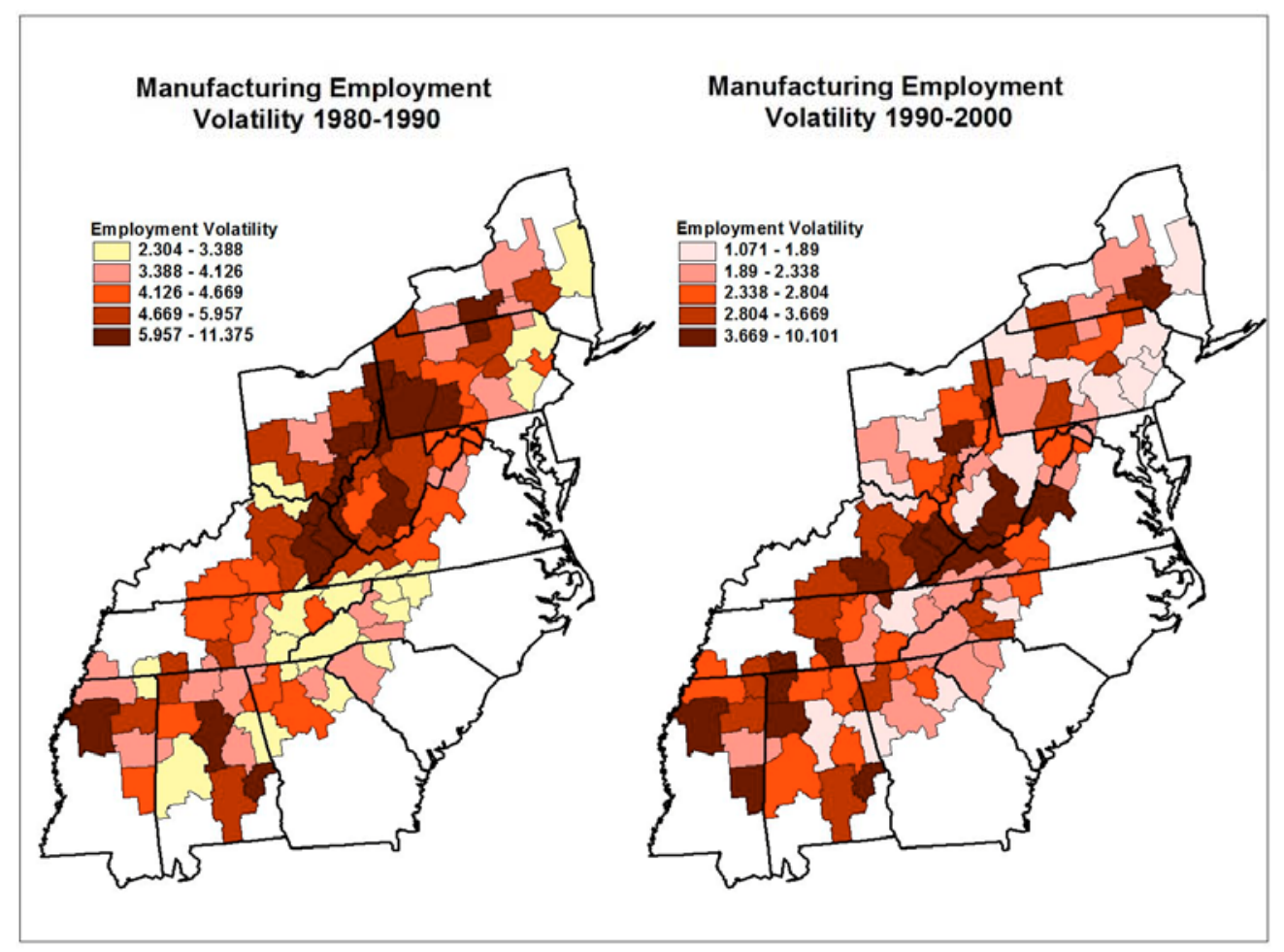


Figure 4-24. Service Employment Volatility 1980-1990 and 1990-2000.

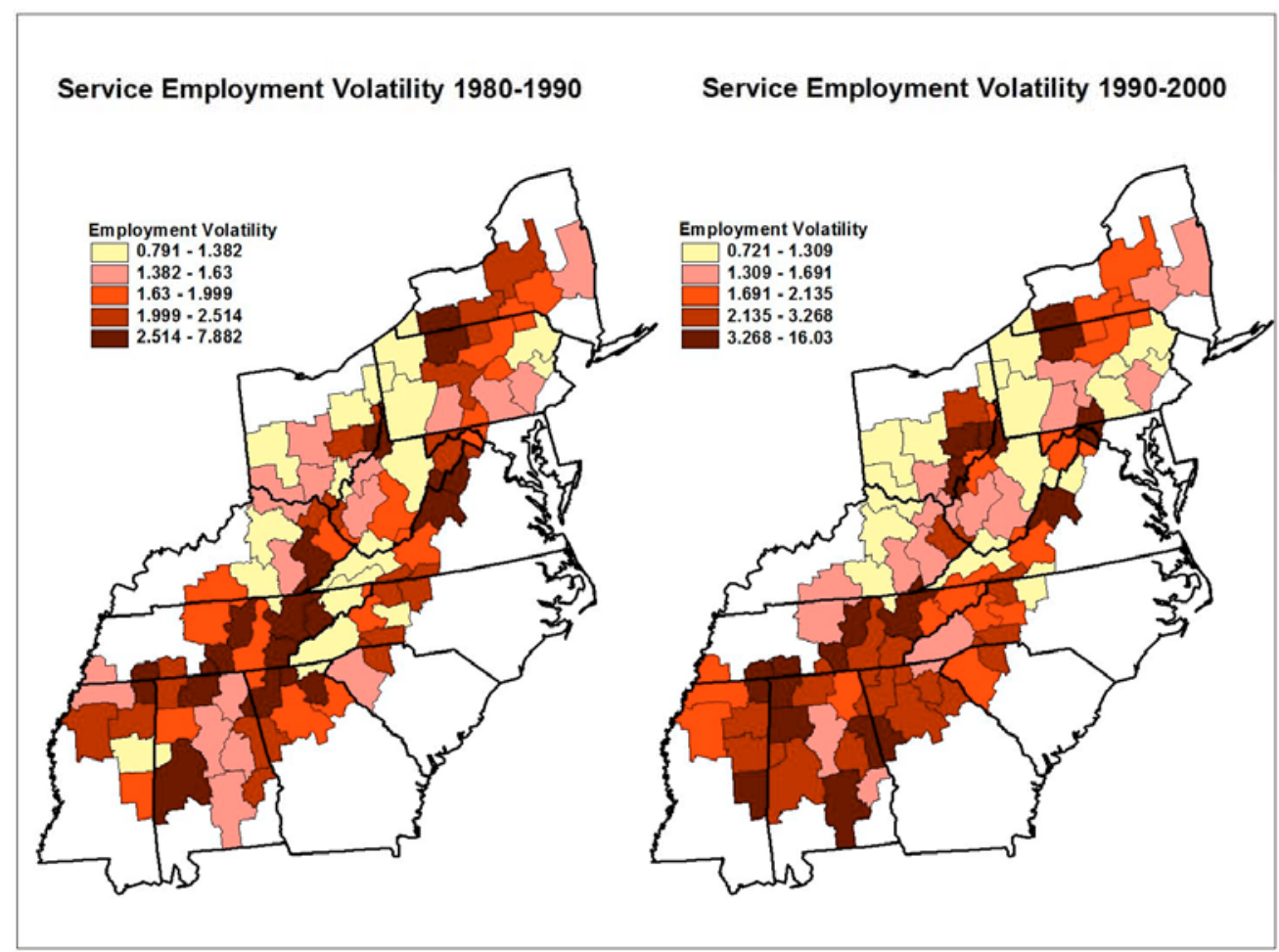

Figure 4-25. Retail Trade Employment Volatility 1980-1990 and 1990-2000

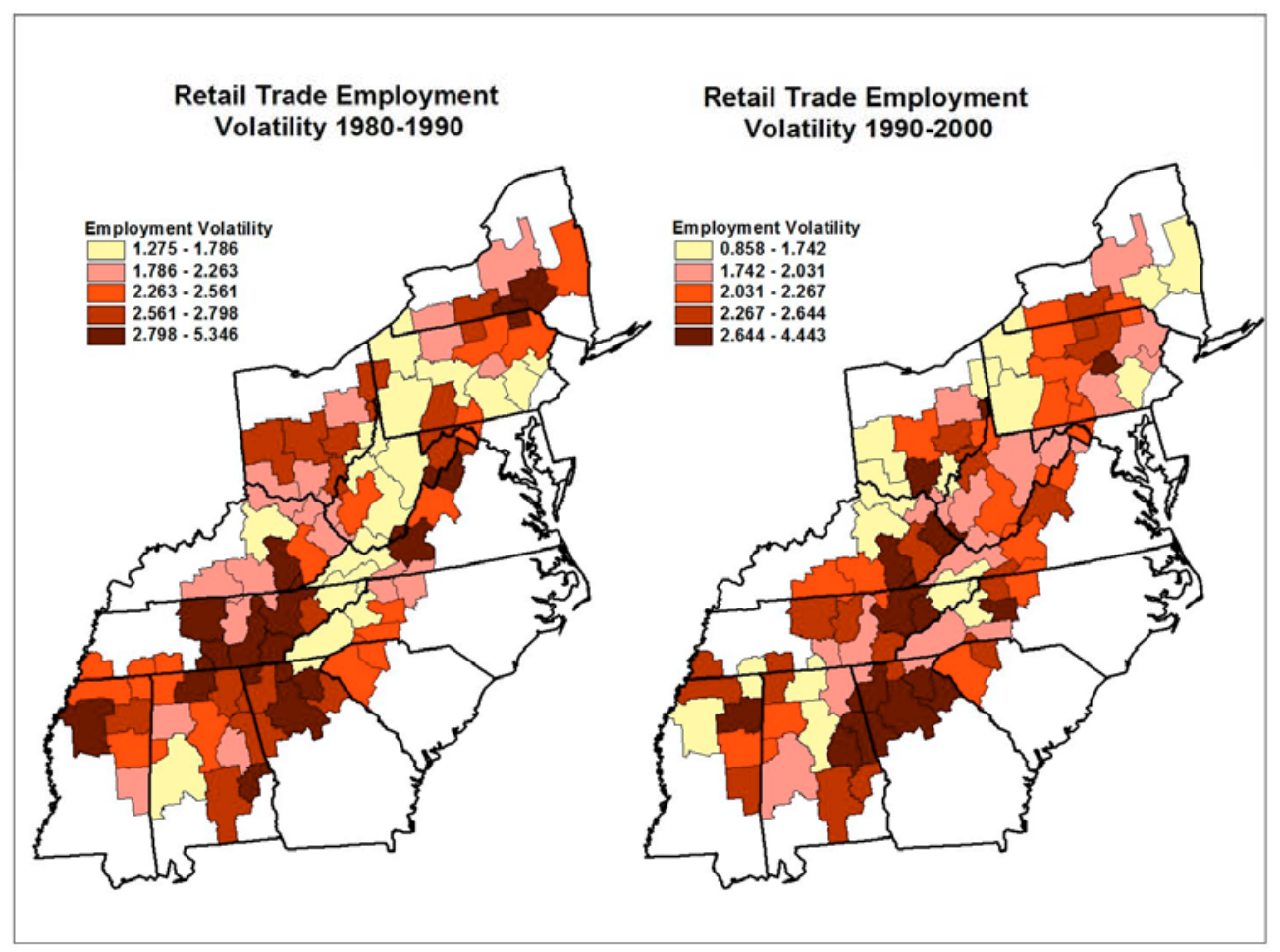




\subsubsection{Unemployment Rate}

Rates of unemployment are calculated as the number of people actively seeking work divided by the total number of people in the civilian labor force. High rates of unemployment have been shown to be highly correlated with adverse public health outcomes (Brenner, 1987) and specifically suicide ( Preti and Miotto, 1999; Weyerer and Wiedenmann, 1995; Leenaars et. al., 1993). For individuals, unemployment may result in economic hardships that limit lifestyle choices. When communities suffer persistently high rates of unemployment, social infrastructures that serve these communities may be difficult to establish and those that exist may break down. In addition, unemployment is a key indicator of local and regional development.

The true burden of unemployment is hard to estimate due to the fact that standard unemployment definitions do not include the long-term unemployed, often referred to as discouraged workers, or those individuals who are not seeking work due to disability. Maps of the geographic distribution of unemployment rates in the Appalachian region are shown in Figure 4-26 for three cross-sections of time; 1980,1990, and 2000. The maps were constructed on the same scale to demonstrate overall declines in rates of unemployment over the study period. Despite considerable declines in unemployment between 1980 and 2000, a number of LMAs have experienced persistently high unemployment rates relative to other LMAs in the region. High relative unemployment rates occur in LMAs in the central region of Appalachia (Southeastern Ohio, Eastern Kentucky, and Southern West Virginia) in the Southern part of the region in LMAs in Northeastern Mississippi and Western Alabama.

Although region-wide unemployment decreased between 1980 and 2000, the nature of unemployment change among Appalachian LMAs is highly variable. To demonstrate variability in changes in unemployment, a measure of volatility in rates of unemployment was examined by calculating annual differences in the unemployment rates and then calculating the standard deviation of the resulting distributions. Maps showing the distribution of unemployment volatility are presented in Figure 4-27. For each 11-year period, the most volatile and least volatile LMAs have been highlighted and the annual 
unemployment distributions used to calculate the volatility measure are shown in Figures 4-28 and 4-29 respectively.

Volatility in rates of unemployment reflect a number of potential phenomenon including, nature of the industry, e.g. systematically volatile industries, as well as changing economic fortunes of local areas. For example, mining represents a systematically volatile industry in which employment fluctuates with seasonal demands. In general, unemployment volatility provides a measure of employment instability/stability in each LMA.

Figure 4-26. Unemployment rates among Appalachian Labor Market Areas- 1980,1990, and 2000 .



The contrasting trends in unemployment rates for in Figures 4-28 and 4-29 highlight two important situations. First the gradual decline of unemployment rates versus erratic 
fluctuations in unemployment. Second, in these cases the LMAs with the least unemployment volatility also have considerably lower rates of unemployment than their highly volatile counterparts in all years. Low levels of volatility in unemployment rates may generally reflect more diversified economies that are able to rebound (in terms of employment) during periods of industrial decline. For many LMAs, unemployment volatility has also changed substantially between the periods 1980-1990 and 1990-2000.

Figure 4-27 Volatility in Rates of Unemployment Between 1980-1990 and 1990-2000.

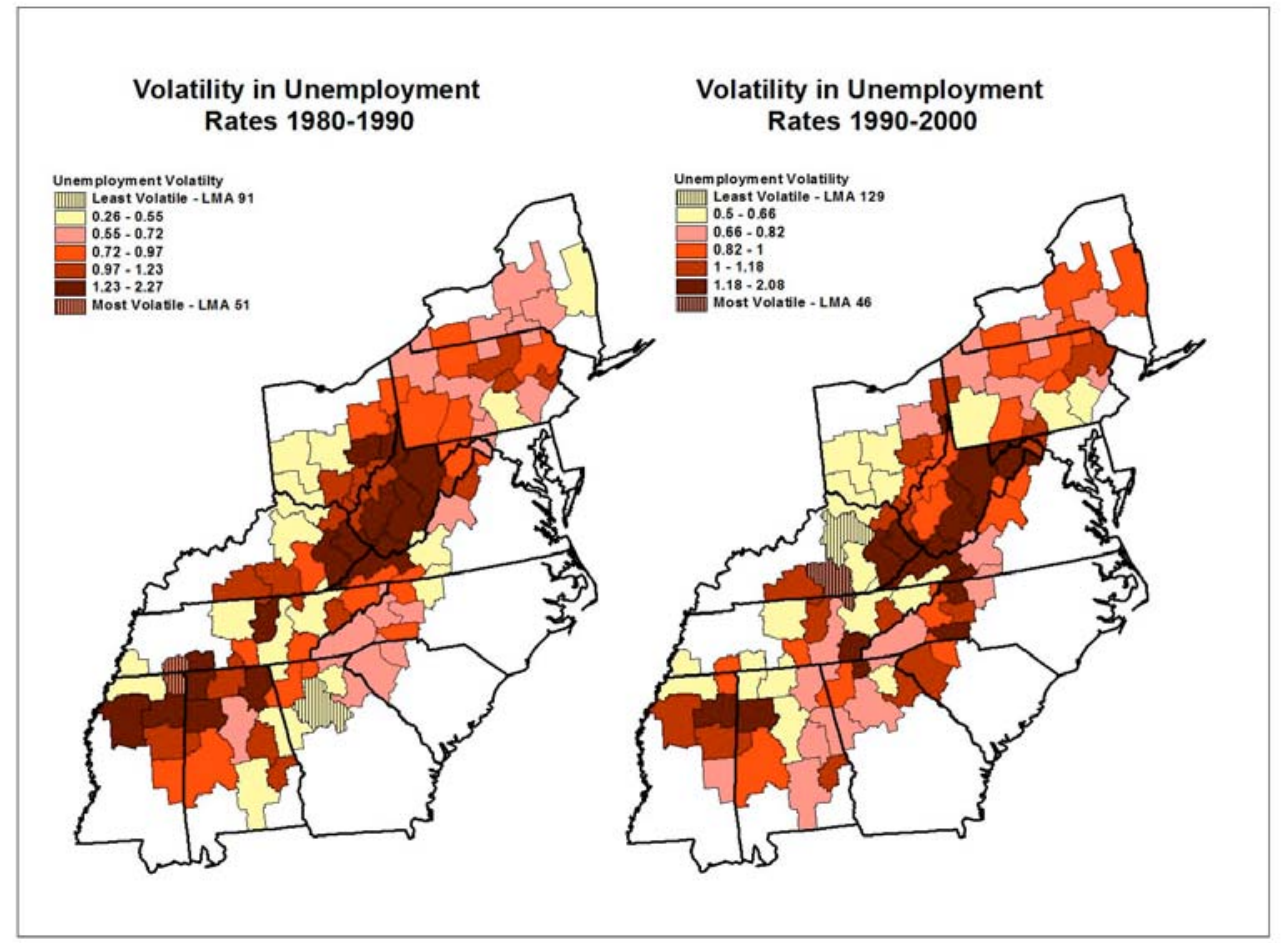

Figure 4-28 Annual Rates of Unemployment Between 1980 and 1990 for LMAs 51 and 91.

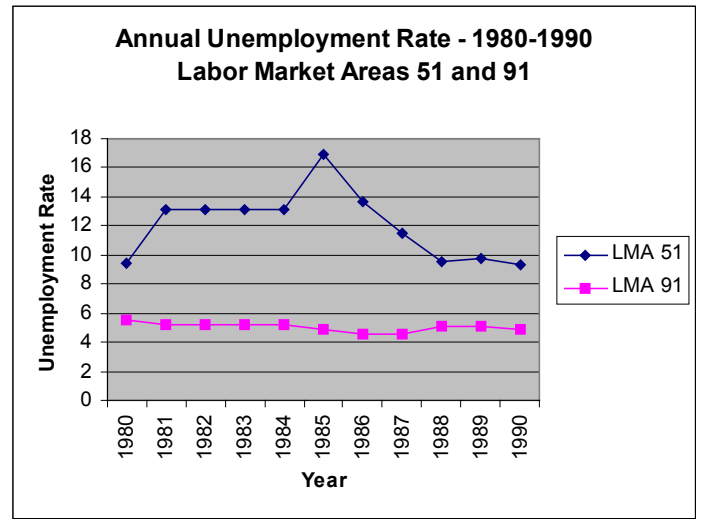

Figure 4-29 Annual Rates of Unemployment Between 1990 and 2000 for LMAs 46 and 129.

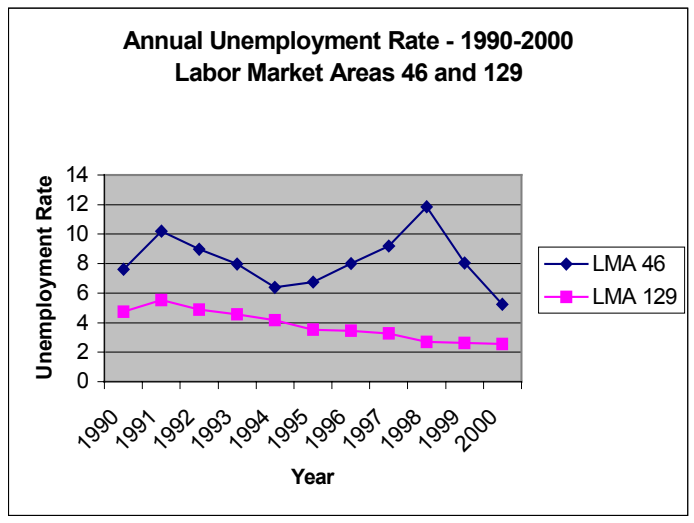




\subsubsection{Income}

Income and poverty are key measures of socioeconomic status (SES) among individuals. Strong relationships have long been recognized between individuals of lower economic status and more adverse health outcomes. However, there is not a clear understanding of how SES influences the health outcomes of more disadvantaged individuals. Theoretically, individuals of lower economic status are at greater risk of poor health because they suffer from some level of deprivation that results in lack of basic needs (food, clothing, housing), access to medical care and resources, access to recreational/physical activities, employment opportunities, etc. In the context of suicide, the socioeconomically disadvantaged may not have the opportunities to achieve goals and aspirations necessary to live fulfilling lives. Individuals who suffer from various forms of deprivation may also be more likely to adopt higher risk health behaviors (Winkleby et al, 1999). Collective deprivation measured by aggregate measures among populations may also reflect deleterious conditions in local areas. Low incomes are indicative of places with less well-developed economies, and therefore have fewer resources for public infrastructure. High levels of poverty may also indicate poorly developed economies, with fewer opportunities for gainful employment.

\subsubsection{Median Family Income}

Family income is the sum of income received by all family members in a household. Median family income indicates that point at which incomes of half of the families are higher and half are lower. Median family income has been used independently as a measure of economic development and income inequality (Nielsen and Alderson, 1997), however the relationship between median family income and economic development appears to have changed since the 1970 s.

Maps showing the geographic distribution of median family income in the Appalachian region are shown in Figure 4-30 for three cross-sections of time, 1979, 1989, and 2000.

Relative differences (disparities) in the distribution of median family income have remained 
fairly constant over this twenty- two year period, despite overall increase in median family income, with several notable exceptions. The relative position of several groups of LMAs in Western Pennsylvania and West Virginia have shifted downward.

4-30. Median Family Income Among Appalachian Labor Market Areas- 1979,1989, and 2000.

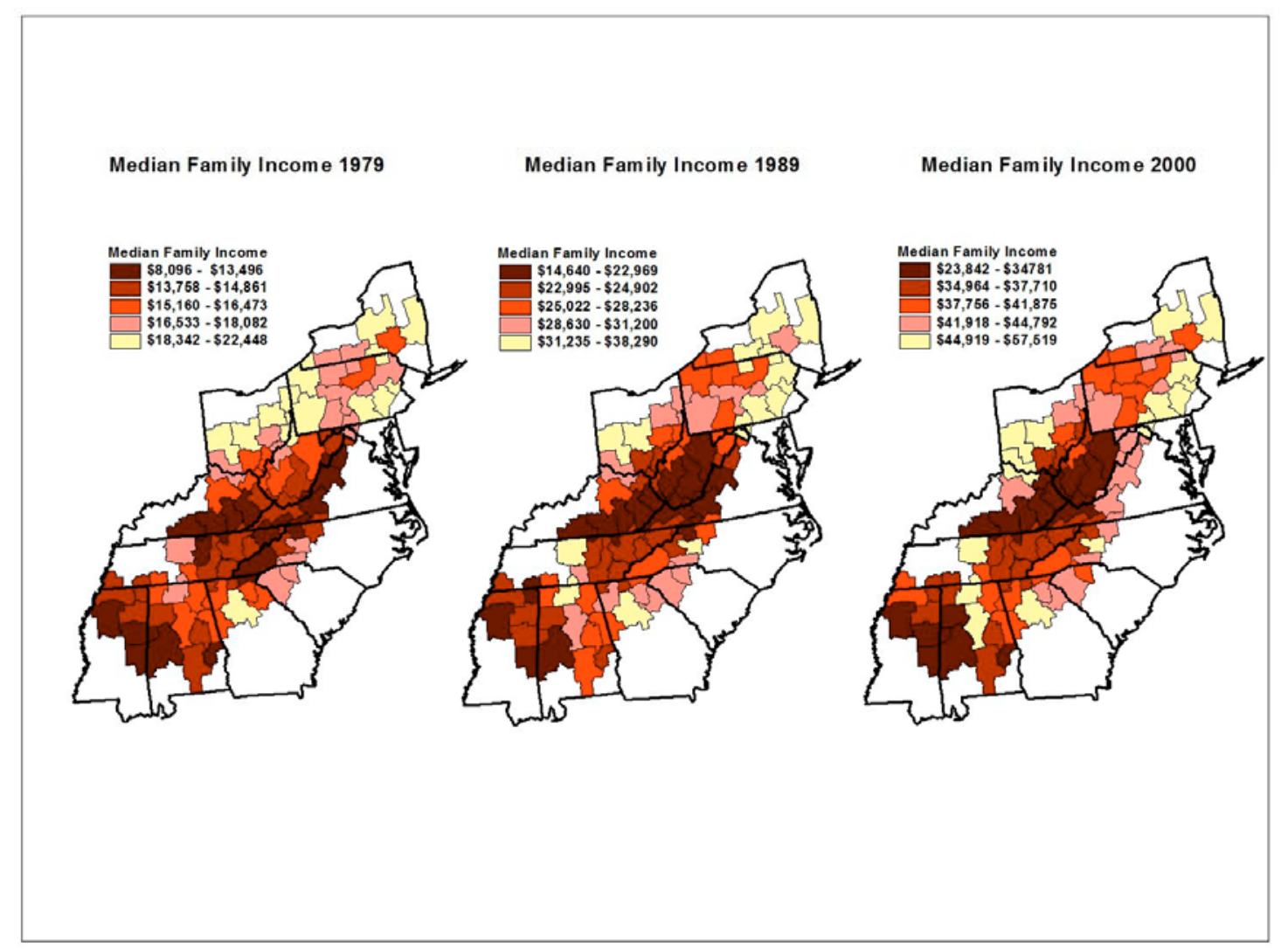

\subsubsection{Percent of Persons Living in Poverty}

Poverty statistics provide a basic indicator of the socioeconomic status of populations within given areas and one of the most important social determinants of health and wellbeing (Adler and Ostrove, 1999; Hopper and Guttmacher, 1979). A map showing the distributions of the percent of people living below the poverty level for the years 
1980,1990, and 2000 is shown in Figure 4-31. The highest relative levels of poverty occur primarily in the central and extreme southern portions of the region. Relatively minor geographic shifts in the percent of people living in poverty have occurred over the three decades although the overall distribution of values increases over each decade suggesting increasing disparity in poverty status among Appalachian LMAs.

Figure 4-31. Percent of Persons Living Below the Poverty Level - 1979, 1990, 2000.

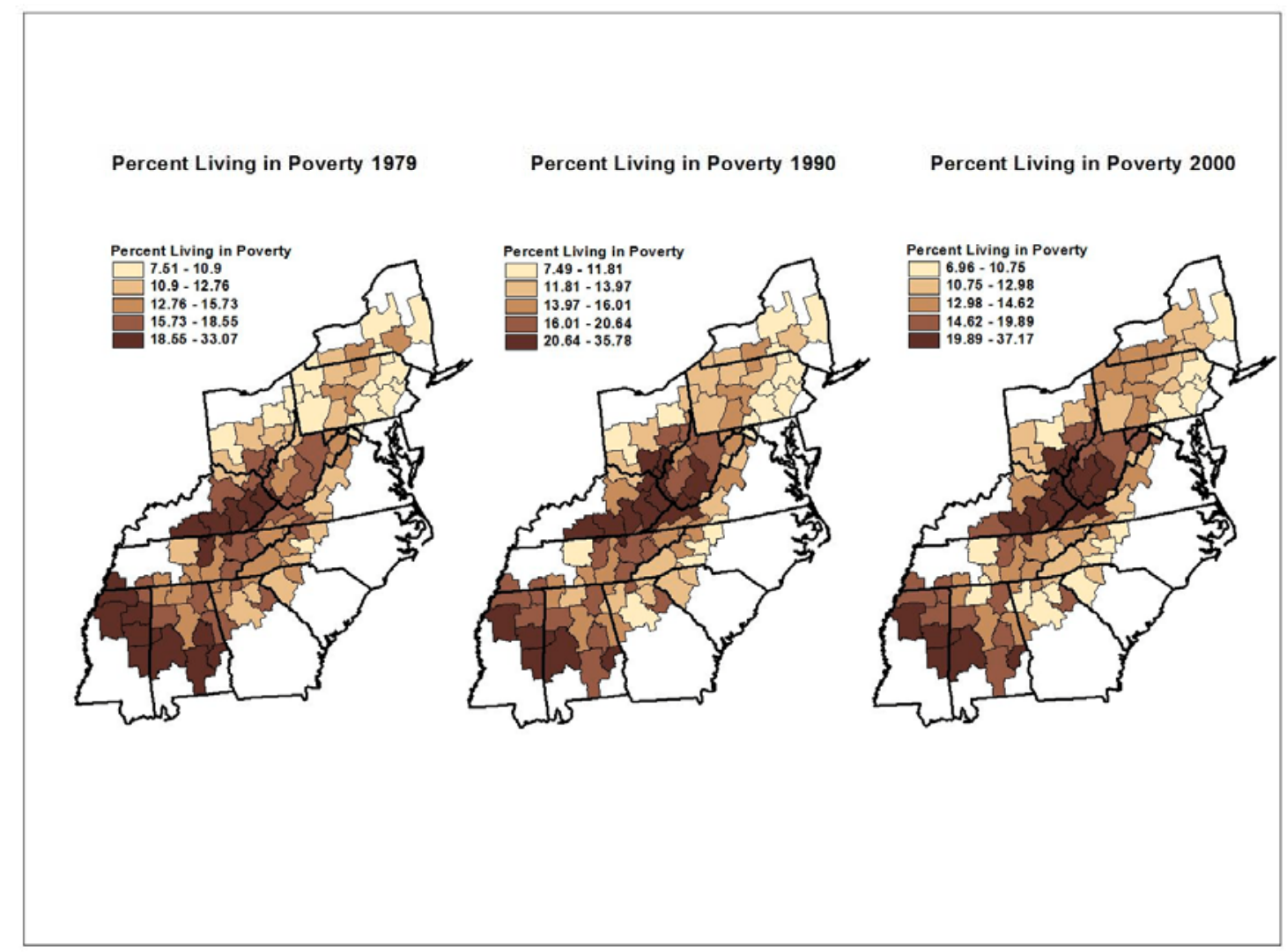

\subsubsection{Income Inequality}

Income Inequality reflects distribution of wealth in local populations, reflecting the degree of separation between the highest and lowest income earning groups. Waitzman and Smith (1998) have suggested that high levels of income inequality may lead to "a deterioration of community attachment and involvement, resulting in deleterious 
psychosocial and material consequences". Kawachi (1999) highlights that between 1977 and 1992, the average incomes of the top fifth of American families rose by $28 \%$, the average incomes of the middle fifth of American families stagnated, and the incomes of poor families fell by $17 \%$. Increasing trends in income inequality have "forced Americans to spend longer hours at work and to send more family members into the work force, just to keep from slipping back down the economic ladder" (Kawachi, 1999, p. 126). Although it is assumed that relative deprivation that results from income inequality is responsible for associations between inequality and health outcomes, Kawachi suggests that links between income inequality and poor health outcomes is likely to be "mediated by the erosion of sociability, trust, and reciprocity" p. 127.

For this analysis a measure of income inequality was derived by dividing the mean household income for each LMA by the median household income (Baqir, 2002). A map showing the distribution of income inequality among Appalachian LMAs is shown in Figure 4-32.

Figure 4-32. Income Inequality Among Appalachian Labor Market Areas 1990 and 2000.

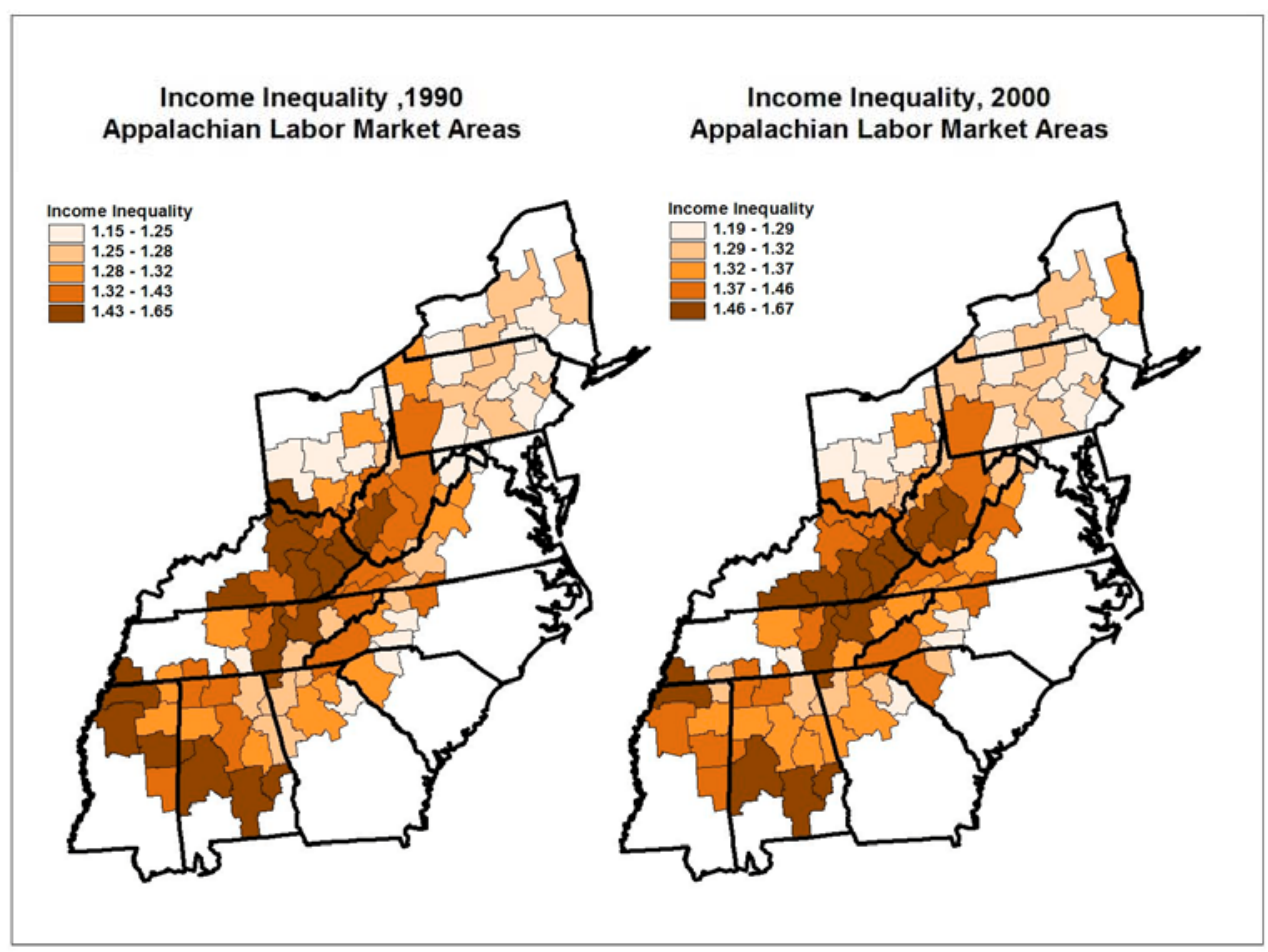


The geographic patterns of income inequality suggest relatively high levels in the central and southern portions of the region in both 1990 and 2000. Although there does not appear to be a direct correspondence between rates of suicide (Figures 4-2 and 4-3), this pattern is consistent with general north-south suicide gradients, i.e. generally higher suicide rates in the central and southern portions of Appalachia.

\section{3 Conclusion}

Rates of suicide are highly variable within the Appalachian region. Roughly similar geographic patterns in the rates of suicide are between ages groups 25-44 and 45 to 64, however in both cases there are considerable disparities in suicide rates. Although suicide trends suggest overall declines in rates of suicide, there are considerable differences in rates of decline among Appalachian LMAs and a few have experienced increases in rates of suicide.

There is also considerable variability and diversity within the Appalachian region, as evidenced by measures of socioeconomic context and industrial change. Examination of rates and trends of suicide in conjunction with these measures may help to identify factors and conditions that either contribute to, or mediate, increased incidence of suicide. 


\section{Chapter Five REGRESSION ANALYSIS}

The goal of this chapter is to present the results of the regression models of suicide discussed in Chapter Three. In the first section of this chapter, the two models are outlined again, together with a detailed listing of the socioeconomic context measures used as explanatory variables in the models. The models are expanded in the second section to determine whether there are significant interaction effects on suicide between a labor market area's industrial structure and other socioeconomic context variables. The results of the aggregate suicide rate models are presented in sections 5.3.1 - 5.3.4. The results of the suicide trend models are presented in sections 5.4.1-5.4.4. The chapter ends with concluding statements regarding the analytical findings of the study.

\subsection{Models of Suicide}

As presented in chapter three, the model for aggregate rates of suicide is as follows:

$$
\text { AGGSUICIDERATE }_{\mathrm{i}, \mathrm{j}, \mathrm{k}}=\alpha_{\mathrm{j}, \mathrm{k}}+\Sigma_{\mathrm{m}}\left(\beta_{\mathrm{j}, \mathrm{k}, \mathrm{m}} \text { CONTEXTVARIABLE }_{\mathrm{i}, \mathrm{k}, \mathrm{m}}\right)+\mathrm{e}_{\mathrm{i}, \mathrm{j}, \mathrm{k}}
$$

where AGGSUICIDERATE $\mathrm{i}_{\mathrm{i}, \mathrm{j}, \mathrm{k}}$ represents the aggregate suicide rate for age group $\mathrm{j}$ (2544 and 45-64), in time period k (1980-1990 and 1990-2000) and for labor market area i (79 LMAs), CONTEXTVARIABLE $\mathrm{i}_{\mathrm{i}, \mathrm{k}, \mathrm{m}}$ refers to $\mathrm{m}$ different socioeconomic context variables for each labor market area (i) and each time period $(\mathrm{k}), \alpha_{\mathrm{j}, \mathrm{k}}$ and $\beta_{\mathrm{j}, \mathrm{k}, \mathrm{m}}$ are parameters to be estimated and $\mathrm{e}_{\mathrm{i}, \mathrm{j}, \mathrm{k}}$ is an error term.

The model for trends in suicide rates is as follows:

$$
\operatorname{SUICIDETREND~}_{\mathrm{i}, \mathrm{j}, \mathrm{k}}=\alpha_{\mathrm{j}, \mathrm{k}}+\Sigma_{\mathrm{m}}\left(\beta_{\mathrm{j}, \mathrm{k}, \mathrm{m}} \operatorname{CONTEXTVARIABLE}_{\mathrm{i}, \mathrm{k}, \mathrm{m}}\right)+\mathrm{e}_{\mathrm{i}, \mathrm{j}, \mathrm{k}}
$$

where SUICIDETREND $\mathrm{i}_{\mathrm{i}, \mathrm{k}, \mathrm{k}}$ represents the trend in the suicide rate estimated from equation (1) in Chapter Three for age group j, in time period $\mathrm{k}$ and for labor market area $\mathrm{i}$, CONTEXTVARIABLE $\mathrm{i}_{\mathrm{i}, \mathrm{k}, \mathrm{m}}$ refers to $\mathrm{m}$ different socioeconomic context variables for 
each labor market area (i) and each time period $(\mathrm{k}), \alpha_{\mathrm{j}, \mathrm{k}}$ and $\beta_{\mathrm{j}, \mathrm{k}, \mathrm{m}}$ are parameters to be estimated and $\mathrm{e}_{\mathrm{i}, \mathrm{j}, \mathrm{k}}$ is an error term.

The socioeconomic context variables (CONTEXTVARIABLE $\mathrm{i}_{\mathrm{i}, \mathrm{k}, \mathrm{m}}$ ) used in these models are listed below, together with their abbreviations:

\section{POPULATION}

- Percent change in population (POPCHANGE)

- Average percent urban population (URBAN)

- Average population density (DENSITY)

\section{INDUSTRIAL STRUCTURE}

- Average percent mining employment share (MINSHARE)

- Average percent manufacturing employment share (MANSHARE)

- Average percent service employment share (SERVSHARE)

- Average percent retail employment share (RETSHARE)

- Percent change in mining employment share (MINSHARECHANGE)

- Percent change in manufacturing employment share (MANSHARECHANGE)

- Percent change in service employment share (SERVSHARECHANGE)

- Percent change in retail employment share (RETSHARECHANGE)

- Mining dominant (MINDOMINANT)

- Manufacturing dominant (MANDOMINANT)

\section{ECONOMIC CHANGE}

- Percent change in all employment (ALLEMPCHANGE)

- Percent change in mining employment (MINEMPCHANGE)

- Percent change in manufacturing employment (MANEMPCHANGE)

- Percent change in service employment (SERVEMPCHANGE)

- Percent change in retail employment (RETEMPCHANGE)

- Volatility in all employment (ALLEMPVOLATILE)

- Volatility in mining employment (MINEMPVOLATILE)

- Volatility in manufacturing employment (MANEMPVOLATILE)

- Volatility in service employment (SERVEMPVOLATILE)

- Volatility in retail employment (RETEMPVOLATILE)

\section{UNEMPLOYMENT}

- Unemployment rate (UNEM)

- Change in unemployment rate (UNEMCHANGE)

- Volatility in unemployment rate (UNEMVOLATILE)

\section{INCOME}

- Median family income (INCOME) 
- Change in median family income (INCOMECHANGE)

- Percent in poverty (POVERTY)

- Income inequality (INEQUALITY)

\subsection{Expanded Models of Suicide}

Prior to their estimation, ten interaction terms were added to both models. The purpose of an interaction term is to determine whether the effect of one contextual variable on suicide depends on changes in the value of another contextual variable. Statistically, the interaction terms are incorporated into the suicide model by means of Casetti's expansion method, a model building procedure used in geographic research since the 1970s (Casetti, 1972). The first step of this procedure involves expressing the $\beta_{\mathrm{j}, \mathrm{k}, \mathrm{m}}$ parameter of a given contextual variable in the original equation as a linear function of another contextual variable. In the second step, this linear function is substituted for $\beta_{\mathrm{j}, \mathrm{k}, \mathrm{m}}$ back into the original equation. The net result is a new variable in the original equation equal to the product of the two contextual variables.

Five interaction terms in this study combined the variable MINDOMINANT, a binary dummy variable which represents LMAs with a dominant mining sector, with five other socioeconomic variables (MINEMPCHANGE, UNEM, UNEMCHANGE, UNEMVOLATILE AND INCOMECHANGE). The rational for including these interaction terms in the models is that the effect of the five chosen socioeconomic variables on suicide (both aggregate rates and trends) is expected to differ depending on whether an LMA is dominated by the mining sector or not. The resulting new interaction variables are as follows:

- MIN*MINEMPCHANGE

- MIN*UNEM

- MIN*UNEMCHANGE

- MIN*UNEMVOLATILE

- MIN*INCOMECHANGE 
The remaining five interaction terms combined the variable MANDOMINANT, a binary dummy variable which represents LMAs with dominant manufacturing sectors, with the same or manufacturing-equivalent socioeconomic variables (MANEMPCHANGE, UNEM, UNEMCHANGE, UNEMVOLATILE AND INCOMECHANGE). In this case, it is hypothesized that the effect of the five chosen socioeconomic variables on suicide (both aggregate rates and trends) is expected to differ depending on whether an LMA is dominated by manufacturing or not. These interaction variables are as follows:

- MAN*MANEMPCHANGE

- MAN*UNEM

- MAN*UNEMCHANGE

- MAN*UNEMVOLATILE

- $M A N * I N C O M E C H A N G E$

\subsection{Aggregate Suicide Rate Model}

This section presents the results of the estimated regression model for aggregate suicide rates in equation (2), including interaction variables, for both age groups (25-44 and 4564) and each time period (1980-1990 and 1990-2000). The model included all of the contextual variables listed in section 5.1, as well as all interaction variables listed in section 5.2. This and all further regression models discussed in this chapter were estimated by a forward stepwise version of OLS because of the inevitable multicollinearity bias introduced into the estimation procedure by virtue of the large number of explanatory variables involved. Only coefficients significant at the 5\% level are included in the estimated models.

\subsubsection{Suicide Rates Among Persons Aged 25 to 44 for the Period 1980-1990}

Only one contextual variable, the percent of the population that lives in urban areas (URBAN), was significantly associated with the aggregate suicide rates of persons aged

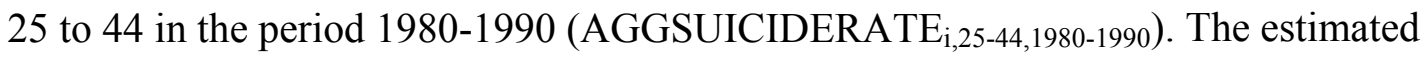
model is as follows: 


\section{AGGSUICIDERATE $\mathrm{i}_{\mathrm{i}, 25-44,1980-1990}=16.49-0.086 \mathrm{URBAN}$.}

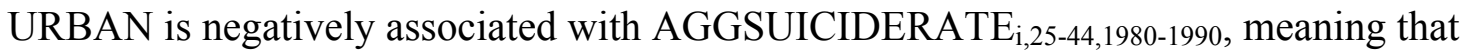
the suicide rate among persons aged 25 to 44 was generally higher in less urbanized (more rural) labor market areas of Appalachia over the period 1980-1990 and lower in the more urbanized areas of the region. This finding is consistent with both theoretical and empirical evidence regarding the role of rurality/urbanicity in health outcomes. More rural areas are typically less economically diverse, have less well developed infrastructures for public welfare, lower incomes, and may be more sensitive to economic change. However, the model only explains six percent of the variation in suicide rates, which indicates that the socioeconomic variables overall perform poorly. This could be due to the fact that socioeconomic context, with the exception of a population's urbanization, plays little role in explaining suicide rates among persons 25 to 44 throughout Appalachia, or that its effect is more localized than the regional scale analyzed in this study.

A scatterplot of AGGSUICIDERATE $\mathrm{i}_{\mathrm{i}, 25-44,1980-1990}$ against URBAN is shown (with regression line) in Figure 5.1.

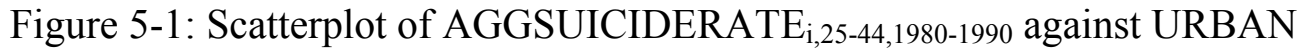
for Appalachian Labor Market Areas.

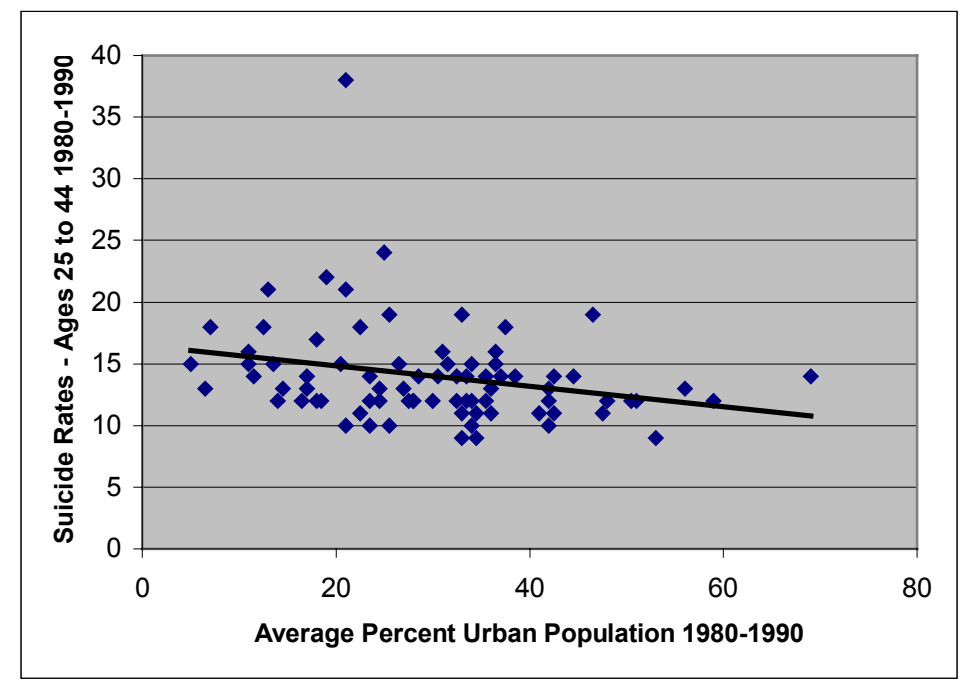




\subsubsection{Suicide Rates Among Persons Aged 25 to 44 for the Period 1990-2000}

Two contextual variables, the percent of the population that lives in urban areas (URBAN) and the interaction between the change in the unemployment rate and mining dominance (MIN*UNEMCHANGE), were significantly associated with the aggregate suicide rates of persons aged 25 to 44 in the period 1990-2000 (AGGSUICIDERATE $_{\mathrm{i}, 25-}$ 44,1990-2000). The estimated model is as follows:

AGGSUICIDERATE $\mathrm{i}_{\mathrm{i}, 25-44,1990-2000}=22.34-0.21 \mathrm{URBAN}+1.39 \mathrm{MIN} *$ UNEMCHANGE .

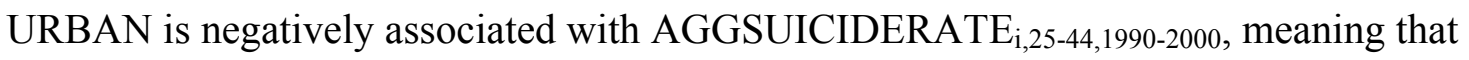
the suicide rate among persons aged 25 to 44 was also higher in less urbanized (more rural) labor market areas of Appalachia over the period 1990-2000 and lower in the more urbanized areas of the region. Furthermore, the positive coefficient for MIN*UNEMCHANGE indicates that suicide rates for this age group rose as unemployment rates increased, but only in labor market areas dominated by the mining sector. There was no association between suicide and changes in unemployment in areas not dominated by mining. This finding is also fairly consistent with both theoretical and empirical evidence regarding the role of rurality/urbanicity and unemployment in influencing rates of suicide. The finding that unemployment was only important in mining areas conflicts somewhat with the overall theoretical expectation. Much of the area dominated by the mining industry (Figure 4-21), is also generally rural and likely to be less economically diverse, making these areas potentially more sensitive to adverse conditions of unemployment. It may also be that populations in these areas which have a long mining history and likely expectations of mining careers, and are unable to adequately resolve conflicts generated by the overall declines in mining employment which were more widespread over the period 1990-2000 (Figure 4-25). It may also reflect areas of continued socioeconomic decline, particularly since there were declines in mining employment for most of these LMAs in the preceding decade (Figure 2-24). 
This model explains seventeen percent of the variation in suicide rates in the 1990s, which indicates that the socioeconomic variables overall still perform relatively poorly, although the model is more effective than for the 1980s.

A scatterplot of AGGSUICIDERATE $\mathrm{i}_{\mathrm{i} 25-44,1990-2000}$ against URBAN is shown in Figure 5.2 and a scatterplot of AGGSUICIDERATE $\mathrm{i}_{\mathrm{i}, 25-44,1990-2000}$ against UNEMCHANGE is shown in Figure 5.3, which also differentiates between mining dominated LMAs and those that are not.

Figure 5-2: Scatterplot of AGGSUICIDERATE $\mathrm{i}_{\mathrm{i}, 25-44,1990-2000}$ against URBAN for Appalachian Labor Market Areas.

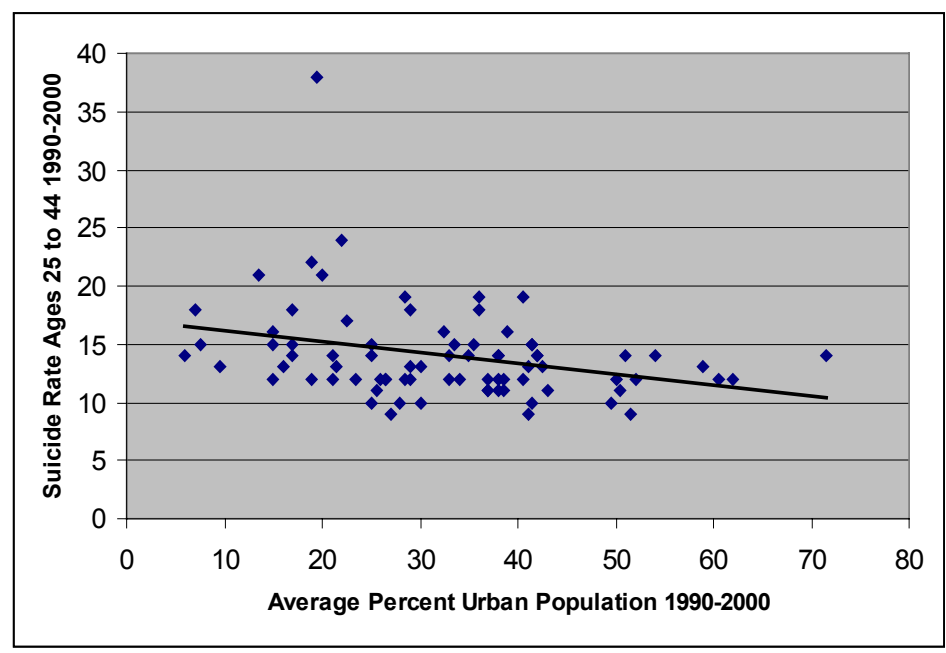

Figure 5-3. Scatterplot of AGGSUICIDERATE $\mathrm{i}_{\mathrm{i}, 25-44,1990-2000}$ against UNEMCHANGE for Appalachian Labor Market Areas.

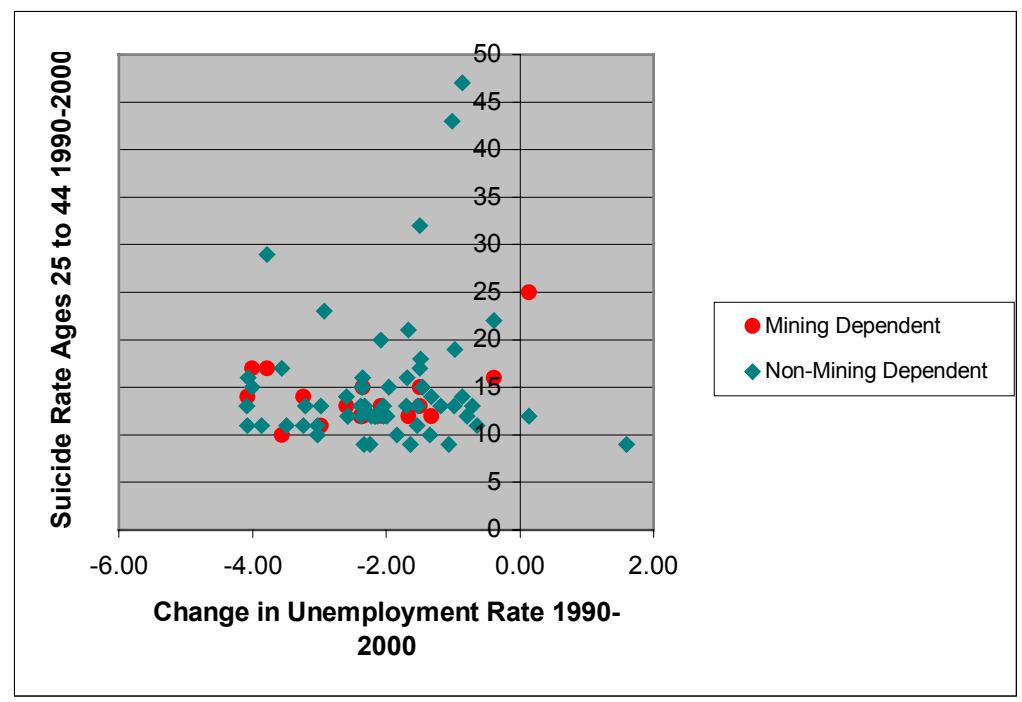




\subsubsection{Suicide Rates Among Persons Aged 45 to 64 for the Period 1980-1990}

Three contextual variables, the percent of the population that live in urban areas (URBAN), the annual volatility in all employment (ALLEMPVOLATILE) and the interaction between the unemployment rate and manufacturing dominance (MAN*UNEM), were significantly associated with the aggregate suicide rates of persons

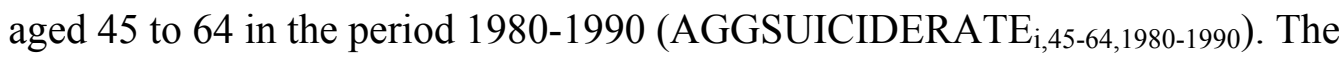
estimated model is as follows:

\section{AGGSUICIDERATE $_{\mathrm{i}, 45-64,1980-1990}=21.25-0.08 \mathrm{URBAN}-2.21$ ALLEMPVOLATILE +0.43 MAN*UNEM.}


the suicide rate among persons aged 45 to 64, like the younger age group, was also higher in less urbanized (more rural) labor market areas of Appalachia over the period 19801990 and lower in the more urbanized areas of the region. The negative coefficient for ALLEMPVOLATILE indicates that the suicide rate in the older age group was higher in LMAs exhibiting less volatile annual employment change and lower where employment was more volatile. The positive coefficient for MAN*UNEM indicates that suicide rates for the older age group were higher where unemployment rates were high, but only in labor market areas dominated by the manufacturing sector. There was no association between suicide and unemployment in areas not dominated by manufacturing. The association of more rural areas to higher rates of suicide among persons ages 45 to 64 is consistent with those in the younger age-group (25 to 44). The association of low suicide rates with areas of highly volatile levels of employment change, however, seems counterintuitive. One possible explanation is that some areas that have experienced low levels of employment volatility are also areas that have experienced progressive (although gradual) employment decline and associated declines in overall socioeconomic condition. This finding highlights the need for further analysis regarding the impact of employment volatility on mental health outcomes. The association of higher rates of unemployment among manufacturing dependent LMAs with higher rates of suicide is 
theoretically consistent with literature which suggests the importance of manufacturing employment to socially beneficial outcomes (Lobao and Rulli, 1997). Many LMAs in Appalachia, particularly in the northern part of the region, experienced declines in manufacturing employment over the period 1980-1990. This represented a continuation of manufacturing employment loss in the Northeastern U.S. that began in the previous decade (1970-1980). In addition to general socioeconomic decline in many LMAs that experienced continuing losses in manufacturing employment, many people in this age group (45 to 64) may have had a significant number of years invested in manufacturing careers. Understandably, this may have resulted in considerable hardships among people of this age group.

A scatterplot of AGGSUICIDERATE $\mathrm{i}_{\mathrm{i}, 45-64,1980-1990}$ against URBAN is shown in Figure 5.4, a scatterplot of AGGSUICIDERATE $\mathrm{i}_{1,45-64,1980-1990}$ against ALLEMPVOLATILE is

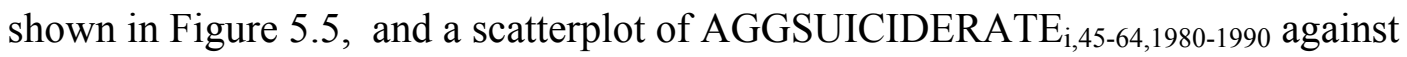
UNEM is shown in Figure 5.6, which also differentiates between manufacturing dominated LMAs and those that are not.

Figure 5-4. Scatterplot of AGGSUICIDERATE $\mathrm{i}_{\mathrm{i}, 45-64,1980-1990}$ against URBAN for Appalachian Labor Market Areas.




Figure 5-5. Scatterplot of AGGSUICIDERATE $\mathrm{i}_{\mathrm{i}, 45-64,1980-1990}$ against ALLEMPVOLATILE for Appalachian Labor Market Areas

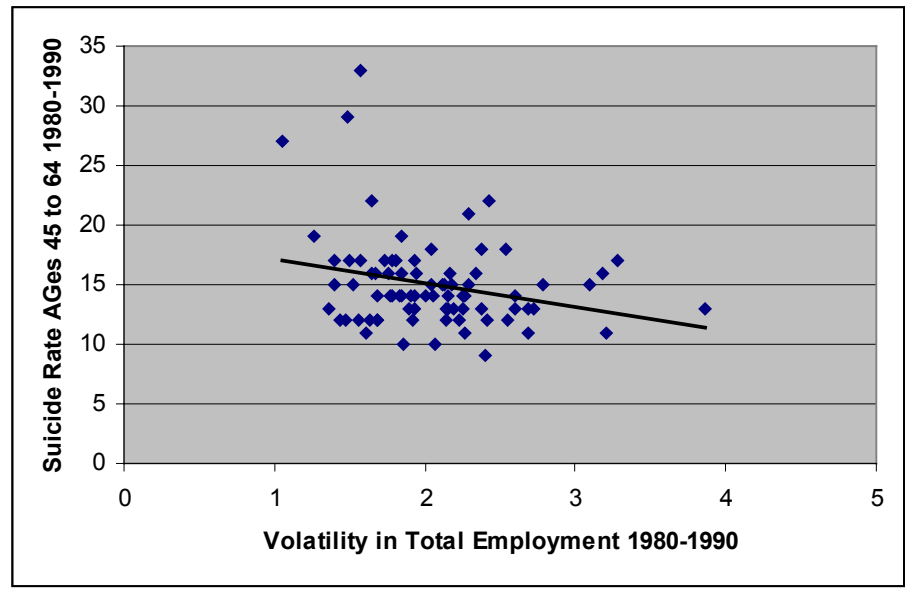

Figure 5-6. Scatterplot of AGGSUICIDERATE $\mathrm{i}_{\mathrm{i}, 45-64,1980-1990}$ against MAN*UNEM for Appalachian Labor Market Areas.



This model explains twenty-six percent of the variation in suicide rates in the older age group in the 1980s. The model performs markedly better than the previous two, although overall the socioeconomic variables still perform relatively poorly. 


\subsubsection{Suicide Rates Among Persons Aged 45 to 64 for the Period 1990-2000}

Only one contextual variable, the percent of the population that lives in urban areas (URBAN), was significantly associated with the aggregate suicide rates of persons aged

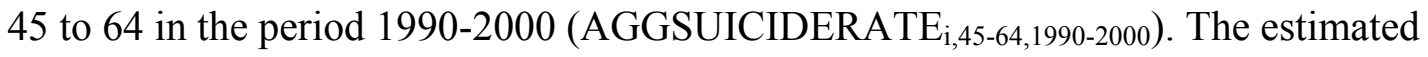
model is as follows:

$$
\text { AGGSUICIDERATE } E_{\mathrm{i}, 45-64,1990-2000}=17.52-0.14 \mathrm{URBAN} \text {. }
$$

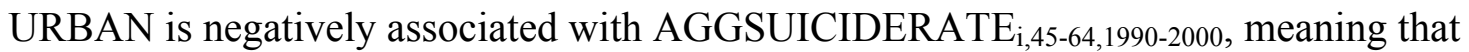
the suicide rate among persons aged 45 to 64 was generally higher in less urbanized (more rural) labor market areas of Appalachia during the 1990s and lower in the more urbanized areas of the region. This finding is consistent with the three previous models and suggests that higher rates of suicide are consistently associated with more rural areas in the Appalachian region.

A scatterplot of AGGSUICIDERATE $\mathrm{i}_{1,45-64,1990-2000}$ against URBAN is shown (with regression line) in Figure 5.7.

Figure 5-7. Scatterplot of AGGSUICIDERATE $\mathrm{i}_{\mathrm{i}, 45-64,1990-2000}$ against URBAN for Appalachian Labor Market Areas.

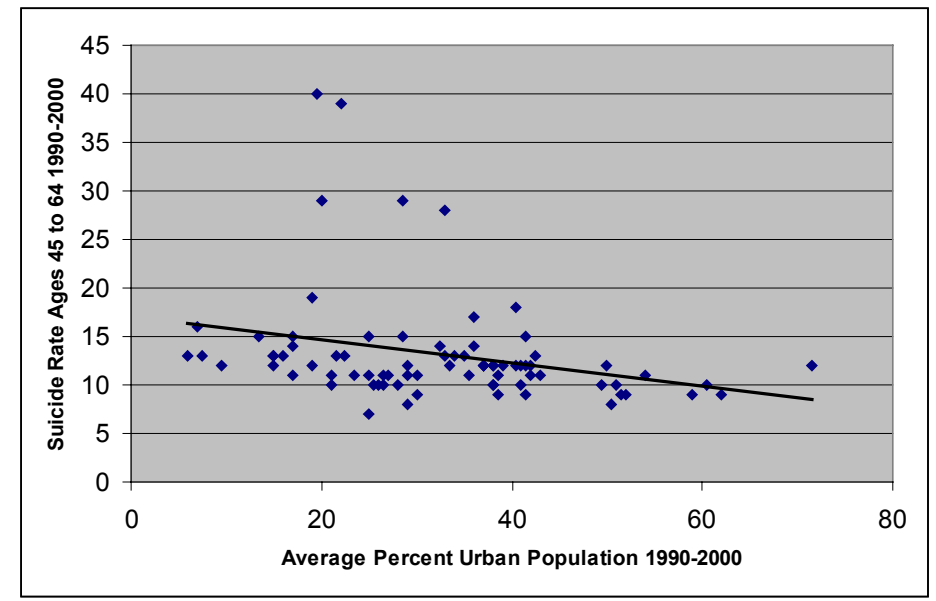


This model explains only nine percent of the variation in suicide rates in the older age group in the 1990s, again an overall poor indication of the region-wide influence of the contextual variables.

\subsection{Suicide Trend Model}

This section presents the results of the estimated regression model for trends in suicide rates in equation (3), including interaction variables, for both age groups (25-44 and 4564) and each time period (1980-1990 and 1990-2000). The model included all of the contextual variables listed in section 5.1, as well as all interaction variables listed in section 5.2. Only coefficients significant at the 5\% level are included in the estimated models.

\subsubsection{Suicide Trends Among Persons Aged 25 to 44 for the Period 1980-1990}

Only one contextual variable, population density (DENSITY), was significantly associated with the trend in suicide rates of persons aged 25 to 44 in the period 19801990 (SUICIDETREND ${ }_{i, 25-44,1980-1990)}$ ). The estimated model is as follows:

$$
\text { SUICIDETREND }{ }_{\mathrm{i}, 25-44,1980-1990}=0.87+0.0025 \text { DENSITY } .
$$

DENSITY is positively associated with SUICIDETREND ${ }_{i, 25-44,1980-1990,}$, meaning that there was a rising suicide trend among persons aged 25 to 44 in more densely populated labor market areas of Appalachia over the period 1980-1990. The trend in less densely populated areas of the region was either falling or rising more slowly. This finding highlights the importance of constructing alternative measures that describe the condition of health outcomes (rates and trends). Associations identified in sections 5.3.1-5.3.4, suggested consistent associations between high rates of suicide and low percentages of urban populations (rural areas). So, although more densely populated areas and urban 
populations experienced lower aggregate rates of suicide in the region over the period 1980-1990, rates of suicide were also more likely to be increasing in these areas.

The majority of LMAs in the region experienced increasing rates of suicide over the period 1980-1990 (figure 4-7), however many of the relatively few LMAs that experienced declining rates also had low population density (Figure 4-12). The lack of other significant socioeconomic context variables in this model, makes it more difficult to explain associations between population density and suicide trends.

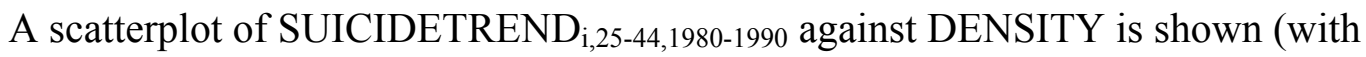
regression line) in Figure 5.8.

Figure 5-8 Scatterplot of SUICIDETREND ${ }_{\mathrm{i}, 25-44,1980-1990}$ against DENSITY for Appalachian Labor Market Areas

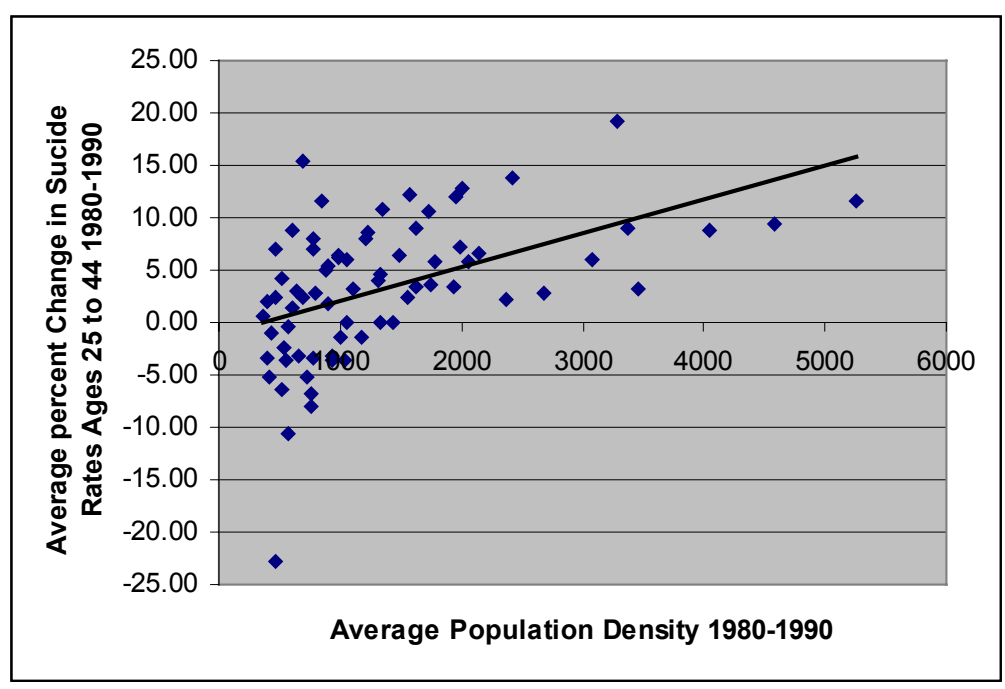

This model explained thirty percent of the variation in suicide trends over the period, which is a good result considering that only one contextual variable was significant. However, it is important to recognize the fact that the contextual variables in general failed to account for the trend in suicides at the region-wide scale of Appalachia. 


\subsubsection{Suicide Trends Among Persons Aged 25 to 44 for the Period 1990-2000}

As in the previous decade, only population density (DENSITY) was significantly associated with the trend in suicide rates of persons aged 25 to 44 in the period 1990-

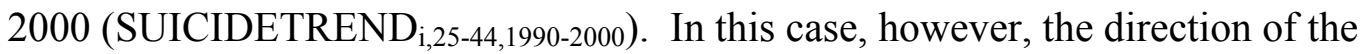
relationship is reversed. The estimated model is as follows:

\section{SUICIDETREND ${ }_{\mathrm{i}, 25-44,1990-2000}=-0.92-0.0025$ DENSITY.}

The negative coefficient for DENSITY means that there was a rising suicide trend among persons aged 25 to 44 in less densely populated labor market areas of Appalachia during the 1990s. The trend in more densely populated areas of the region was either falling or rising more slowly. This finding is not suprising considering the almost wholesale shift in suicide trends among Appalachian LMAs between 1980-1990 and 1990-2000 (Figure 47). One plausible explanation for declines in more densely populated areas is the increased prescription and use of anti-depressant medications in the 1990s. National declines in rates of suicide (Figure 2-1) have been attributed to increases in the use of anti-depressant medications (Mitchell, 2004). Populations in rural (less densely populated) areas may have limited access to medical care resources. Therefore individuals in these areas may be less likely to attain either clinical recognition of depression or medications to treat depressive symptoms.

A scatterplot of SUICIDETREND ${ }_{i, 25-44,1990-2000}$ against DENSITY is shown in Figure 5.9. 
Figure 5-9 Scatterplot of SUICIDETREND ${ }_{\mathrm{i}, 25-44,1990-2000}$ against DENSITY for Appalachian Labor Market Areas



This model explained twenty-one percent of the variation in suicide trends over the period, which again is a good result considering that only one contextual variable was significant.

\subsubsection{Suicide Trends Among Persons Aged 45 to 64 for the Period 1980-1990}

The estimated model for the 45-64 age group in the 1980s was very similar to that of the younger age group. Only population density (DENSITY) was significantly associated with the trend in suicide rates of people in the age group (SUICIDETREND ${ }_{i, 45-64,1980-1990)}$ ), and its coefficient was positive. The estimated model is as follows:

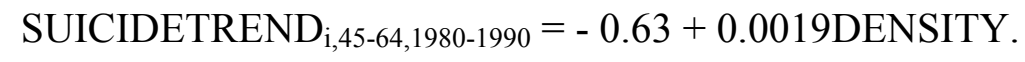


The positive coefficient for DENSITY means that there was a rising suicide trend among persons aged 45 to 64 in more densely populated labor market areas of Appalachia during the 1980s, but that the trend in less densely populated areas of the region was either falling or rising more slowly. Again, the majority of LMAs in the region experienced increasing rates of suicide over the period 1980-1990 (figure 4-8), however many of the relatively few LMAs that experienced declining rates also had low population density (figure 4-12). The lack of other significant socioeconomic context variables in this model, makes it more difficult to explain associations between population density and suicide trends.

A scatterplot of SUICIDETREND $\mathrm{i}_{\mathrm{i}, 45-64,1980-1990}$ against DENSITY is shown (with regression line) in Figure 5.10.

Figure 5-10. Scatterplot of SUICIDETREND $\mathrm{i}_{\mathrm{i}, 45-64,1980-1990}$ against DENSITY for Appalachian Labor Market Areas.

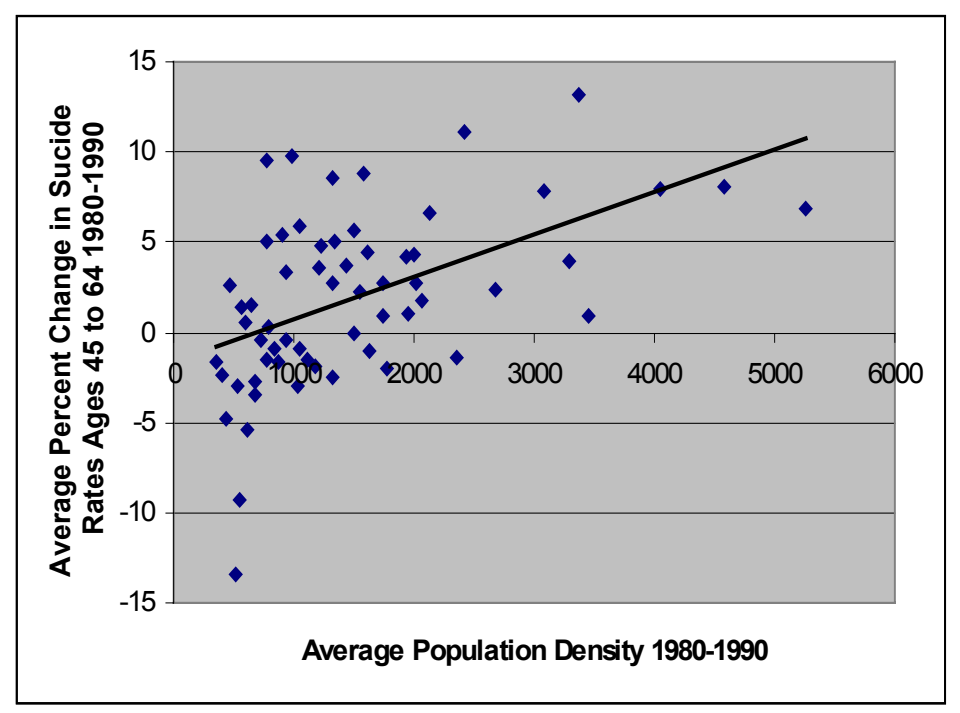

This model explained twenty-three percent of the variation in suicide trends over the period, which again is a good result for only one significant contextual variable. 


\subsubsection{Suicide Trends Among Persons Aged 45 to 64 for the Period 1990-2000}

The estimated model for the 45-64 age group in the 1990s comprised more significant variables than that of the younger age group. Population density (DENSITY) was again significant and negatively associated with the trend in suicide rates of people in the older age group (SUICIDETREND ${ }_{i, 45-64,1990-2000)}$ ), but the model also contained significant estimates for the share of an LMA's employment that is in manufacturing (MANSHARE) and the change in that share (MANSHARECHANGE). The estimated model is as follows:

\section{SUICIDETREND $_{\mathrm{i}, 45-64,1990-2000}=-3.53-0.0030 \mathrm{DENSITY}+0.41 \mathrm{MANSHARE}+$ 0.97MANSHARECHANGE.}

The negative coefficient for DENSITY means that there was a rising suicide trend among persons aged 45 to 64 in less densely populated labor market areas of Appalachia during the 1980s, compared to either a falling or more slowly rising trend in more densely populated areas of the region. The positive coefficients for both MANSHARE and MANSHARECHANGE indicate that that there was more likelihood of a rising trend in suicide in LMAs which had a large share of their employment in manufacturing and in those areas where this share was growing. As in section 5.4.2, declining trends in rates of suicide over the period 1990-2000 for a large proportion of LMAs may be partially attributable to increases in the use of antidepressant medications (Mitchell, 2004) and rural areas may have more limited access to medical care resources. Theoretically increases in manufacturing employment should have positive social affects by tending to homogenized incomes in local areas (Lobao and Rulli, 1997). It is not clear then why the model suggests increasing suicide trends are associated with increasing manufacturing employment. 
A scatterplot of SUICIDETREND ${ }_{i, 45-64,1990-2000}$ against DENSITY is shown in Figure 5.11, a scatterplot of SUICIDETREND $\mathrm{i}_{\mathrm{i}, 45-64,1990-2000}$ against MANSHARE is shown in Figure 5.12, and a scatterplot of SUICIDETREND ${ }_{i, 45-64,1990-2000}$ against MANSHARECHANGE is shown in Figure 5.13.

Figure 5-11 Scatterplot of SUICIDETREND ${ }_{\mathrm{i}, 45-64,1990-2000}$ against DENSITY for Appalachian Labor Market Areas

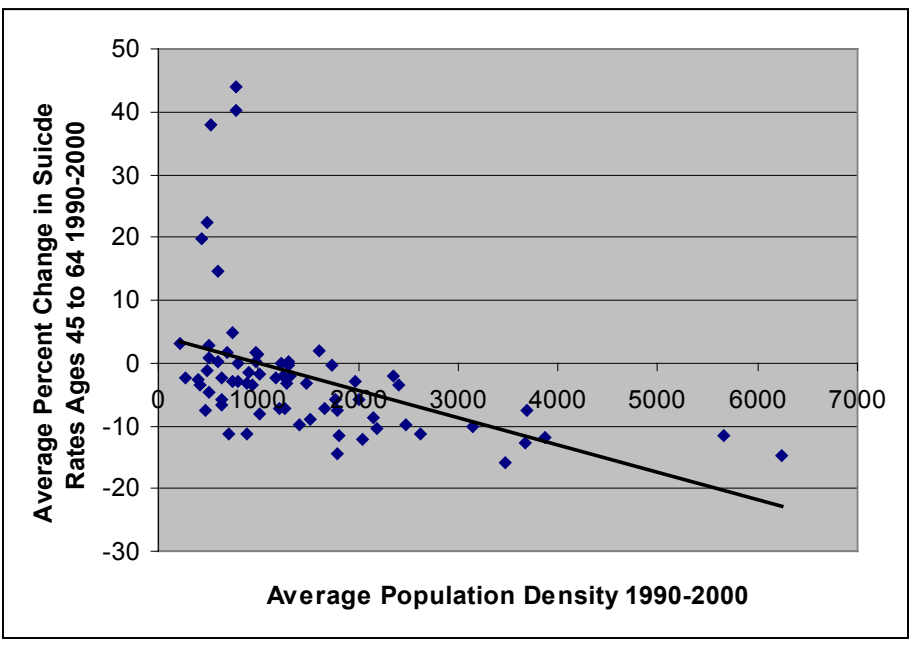

Figure 5-12 Scatterplot of SUICIDETREND ${ }_{\mathrm{i}, 45-64,1990-2000}$ against MANSHARE for Appalachian Labor Market Areas

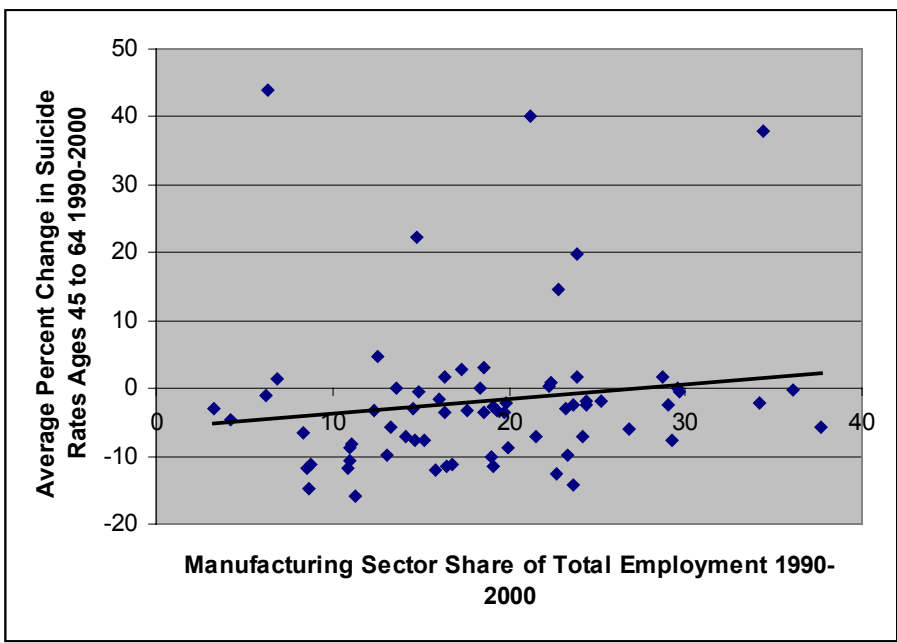


Figure 5-13 Scatterplot of SUICIDETREND ${ }_{i, 45-64,1990-2000}$ against MANSHARECHANGE for Appalachian Labor Market Areas.

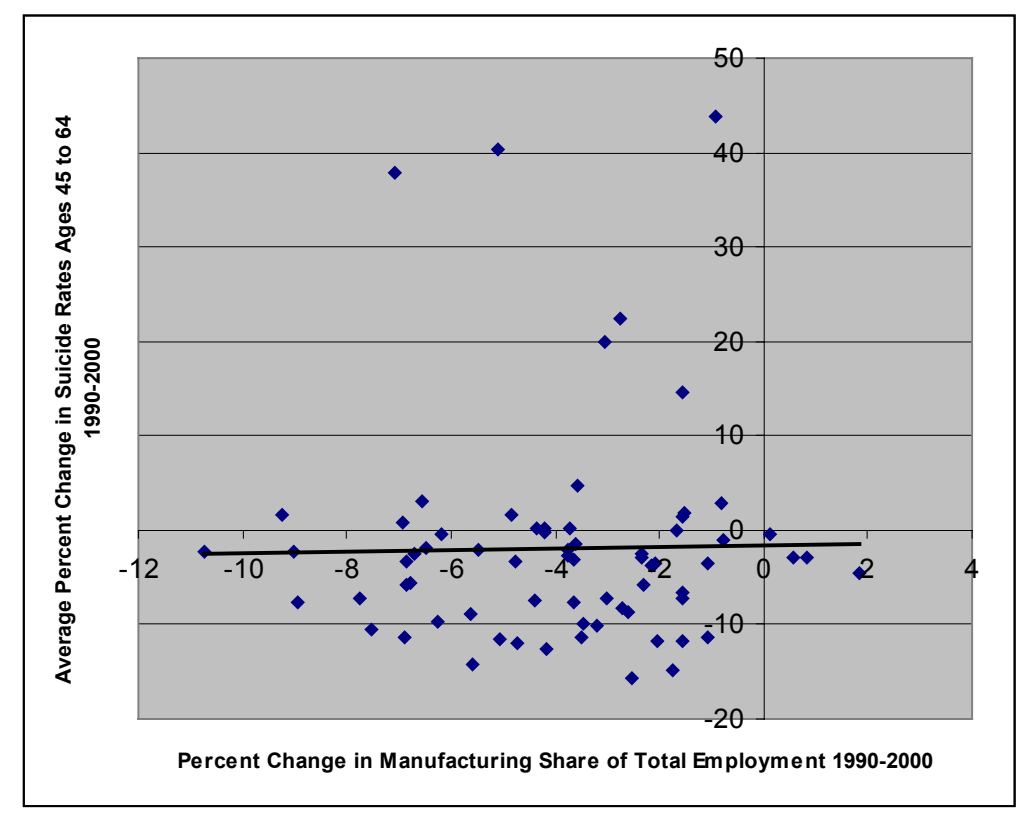

This model explained forty-six percent of the variation in trends in suicide rates among LMAs in the Appalachian region, which is higher than all the previous models.

\subsection{Conclusion}

There are persistent, positive associations between rurality (measured by percent urban population and population density) and aggregate rates of suicide for both age-groups and time-periods. The models for suicide trends also suggest a persistent association with measures of rurality, although the changing direction of the association is more difficult to assess and may be complicated by suggestions that decreases in rates of suicide in the 1990s were influenced by increased use of antidepressant medications.

Models associating measures of socioeconomic context with suicide rates and trends, in general, perform poorly. For the most part the models explained very low percentages of 
the total variation in suicide rates and trends. This may be due to the fact that socioeconomic context does not influence suicide rates or trends region-wide (or in the same ways region-wide), suggesting that the impacts of socioeconomic context maybe more localized. In many of the models the values seem widely dispersed and there are a considerable number of extreme residual values. These results suggest that an alternative statistical model that captures local variability in both measures of socioeconomic context and measures of suicide should be used. This may be particularly appropriate given the geographic sub-regions in Appalachia (the 'Rust Belt" in the north, coal mining in central portion, and high growth in the south) and differing socioeconomic trajectories experienced by each of these sub-regions.

There may also be insufficient variability in both measures of socioeconomic context and measures of suicide within the Appalachian region to detect associations. A broader geographic analysis, that includes the entire U.S., may aid in revealing associations between measures of socioeconomic context and suicide rates and trends, given the broader range of socioeconomic landscapes. 


\section{Chapter Six CONCLUSIONS}

Suicide continues to be a serious public health problem in the U.S. In 2002 suicides outnumbered homicides by five to three and deaths due to AIDS by two to one (Kochanek, et.al. 2002). However rates of suicides vary considerably across demographic sub-populations defined by age, race, gender, measures of socioeconomic status, and geographic location.

One of the objectives of this study was to identify the extent to which rates and trends of suicide varied among labor market areas in the Appalachian region over two periods of time (1980-1990 and 1990-2000), and for two population subgroups (ages 25 to 44 and 45 to 64$)$. This study has shown that local rates of suicide vary considerably among labor market areas in the Appalachian region. The highest suicide rates are roughly four times higher than the lowest suicide rates over the period 1980-1990. Over the period 19902000 the disparity in rates of suicide increased among both age-groups. The geographic distributions of suicide rates in the Appalachian region are roughly similar for both agegroups and both time periods, i. e. high and low rates of suicide are generally found in similar parts of the region. There appears to be a north-south gradient in rates of suicide, with higher suicide rates occurring more frequently in LMAs in the Southern half of the region. This gradient appears to be most pronounced for persons 45 to 64 over the period 1980-1990.

The overall distribution of suicide rate values for populations ages 25 to 44 , with the exception of an increase in the upper end of the distribution, remains very similar between the two time periods. In contrast, there is an overall downward shift in the suicide rates among populations ages 45 to 64 between 1980-1990 and 1990-2000. However a few LMAs have also experienced rate increases between the two time periods, as evidenced by an increase in the upper end of the rate distribution in 1990-2000. Dramatic shifts in trends of suicide rates occur between 1980-1990 and 1990-2000, with the majority of LMAs experiencing increase in rates of suicide over the period 1980-1990 
and declines over the period 1990-2000. These trends largely mirror national trends in suicide, which suggests increasing suicide rates in the early 1980s followed by a continuous and precipitous decline beginning late 1980s. There is considerable geographic variability, however, in the rate of decline and some labor market areas experience increasing rates of suicide despite the national and regional trend.

Why do places have such disparate rates of suicide? Why do some places experience declines and some places experience increases? A number of theoretical arguments have been made which suggest strong associations between rates of suicide and specific measures of socioeconomic context. Empirical studies indicate associations between individual measures of socioeconomic condition, socioeconomic context, and the risk suicide. Individual factors associated with suicide risk include marital status, educational attainment, unemployment, living alone, rural place of residence, social isolation, poverty, and income. Aggregate measures of socioeconomic context that are typically associated with rates of suicide and population health in general include rates of unemployment, industrial structure, rurality/urbanicity, income, income inequality, and rates of poverty. Although the Appalachian region has (as a whole) economically lagged the rest of the U.S., there is considerable diversity in the region with regard to measures of socioeconomic condition. This diversity provides a framework with which to examine associations between locally disparate rates of suicide and locally variable measures of socioeconomic context in the Appalachian region.

In addition, over the period 1980 to 2000 , a number of broad swings occur in the U.S. economy; an economic recession in the early 1980s, post-recession structural adjustment in the mid-to-late 1980s, another economic recession in the early 1990s, followed by several years of economic growth through the end of the 1990s. Economic changes in measures of socioeconomic context in Appalachia are likely to have occurred during these events. In conjunction with broader shifts in industrial geography, (e.g. manufacturing and mining employment declines and shifts, increases in service employment, declines in unemployment), variability in the type of economic changes that have occurred in the region may be reflected in trends in rates of suicide. 
Another objective of this dissertation was to assess the level of association between aggregate rates and trends of suicide and measures of socioeconomic context and industrial change in Appalachian labor market areas for both time periods, 1980-1990 and 1990-2000. Models associating measures of socioeconomic context with suicide rates and trends, were tested for each age-group (24 to 44 and 45 to 64) and over each time period (1980 to 1990 and 1990-2000). The models identified relatively few variables that are significant in explaining variability in rates of suicide in the region. However, several key associations indicate persistent, positive associations between high rates of suicide and rurality (measured by percent urban population and population density). Similarly, relatively few variables are significant in explaining variability in suicide trends in the region. However, models for suicide trends also suggest a persistent association with measures of rurality, although there is a changing direction of association between the two time periods (from positive to negative association) for both age groups.

The statistical models, in general, perform poorly and explain very low percentages of the total variation in suicide rates and trends. This may be due to the fact that socioeconomic context does not influence suicide rates or trends region-wide (or in the same ways region-wide), suggesting that the impacts of socioeconomic context maybe more localized than global. In many of the models the values seem widely dispersed and there are a considerable number of extreme residual values. These results suggest that an alternative statistical model that captures local variability in both measures of socioeconomic context and measures of suicide. This may be particularly appropriate given the geographic sub-regions in Appalachia (the 'Rust Belt" in the north, coal mining in central portion, and high growth in the south) and differing socioeconomic trajectories experienced by each of these sub-regions.

It may also be that there is insufficient geographic variation, in terms of both suicide measures and measures of socioeconomic context, within the Appalachian region to 
detect potential associations. A national level analysis may aid in revealing associations between measures of socioeconomic context and measures of suicide, given the broader range of socioeconomic landscapes. National analyses suggest much higher rates of suicide among states in the Western U.S. (USDHHS/CDC, 1997). Although many of these states are highly rural, settlement patterns are likely to be much different than those in the Eastern U.S. For example, populations in many Western U.S. states tend to concentrate in urban areas with vast tracts of land left unpopulated. In the Eastern U.S. rural populations are more likely to be widely dispersed in rural areas. It is likely, for example, that measures of rurality used in this study will continue to show strong positive associations with suicide at the national level. However, interpretations of this relationship are also likely to vary across geographic regions of the U.S. Other measures of socioeconomic context such as income, poverty, employment/unemployment are also likely to show more significant variability across the entire U.S. than within the Appalachian region and may lead to more conclusive results.

The act of suicide may be the extreme response to personal, social, and/or socioeconomic adversity. It is also seems to have a variety of complex and diverse etiologies, i.e. a diverse range of reasons behind the act which may vary from individual to individual.

In this sense, suicide may be less generalizable than other health outcomes, e.g. cardiovascular disease, obesity. Many people and places experience adversity, although most people do not commit suicide. However, individuals may adopt other forms of selfdestructive behavior in response to personal, social, and/or economic stress and adversity. Measurement of these types of behavior may be particularly difficult, especially over large geographic areas. As a measure of collective mental health, suicide may be the most amenable for the study of populations. Geographic variation in suicide rates suggests that understanding characteristics of places (contexts), will elucidate social factors that contribute to poor mental health outcomes. Suicide in more rural areas, for example, may be partially due to lack of (or access to) mental health resources and services. 
In addition to using statistical techniques to account for local variability in measures of suicide and socioeconomic context, a case-study approach may be instructive in understanding the influence of place on mental health outcomes. Such an approach could target, for example, areas with high suicide rates and/or increasing trends and contrast these with areas with low suicide rates and decreasing trends. Case-study approaches allow for a deeper understanding of place (context) than is achievable using secondary data analysis over broad geographic areas. 
APPENDIX A3

\begin{tabular}{|c|c|c|c|c|c|c|c|c|}
\hline $\begin{array}{c}\text { Labor } \\
\text { Market } \\
\text { Area }\end{array}$ & $\begin{array}{c}\text { Suicide } \\
\text { Death Rate } \\
-1980- \\
1990- \\
\text { Ages } 25 \text { to } \\
44\end{array}$ & $\begin{array}{c}\text { Suicide } \\
\text { Death Rate } \\
-1990- \\
2000- \\
\text { Ages } 25 \text { to } \\
44\end{array}$ & $\begin{array}{c}\text { Suicide } \\
\text { Death Rate } \\
-1980- \\
1990- \\
\text { Ages } 45 \text { to } \\
64\end{array}$ & \begin{tabular}{|c|} 
Suicide \\
Death Rate \\
$-1990-$ \\
$2000-$ \\
Ages 45 to \\
64
\end{tabular} & $\begin{array}{c}\text { Average } \\
\text { Percent } \\
\text { Change in } \\
\text { Suicide } \\
\text { Death Rate - } \\
\text { 1980-1990 - } \\
\text { Ages } 25 \text { to } 44\end{array}$ & $\begin{array}{c}\text { Average } \\
\text { Percent } \\
\text { Change in } \\
\text { Suicide } \\
\text { Death Rate - } \\
\text { 1990-2000 - } \\
\text { Ages } 25 \text { to } 44\end{array}$ & $\begin{array}{c}\text { Average } \\
\text { Percent } \\
\text { Change in } \\
\text { Suicide } \\
\text { Death Rate - } \\
\text { 1980-1990 - } \\
\text { Ages } 45 \text { to } 64\end{array}$ & $\begin{array}{c}\text { Average } \\
\text { Percent } \\
\text { Change in } \\
\text { Suicide } \\
\text { Death Rate - } \\
\text { 1990-2000 - } \\
\text { Ages } 45 \text { to } 64\end{array}$ \\
\hline 1 & 15 & 16 & 17 & 15 & 10.88 & -15.39 & 5.04 & -9.79 \\
\hline 2 & 18 & 14 & 17 & 12 & -1.31 & -1.16 & . & -2.43 \\
\hline 3 & 14 & 16 & 16 & 13 & 3.38 & -3.60 & -1.08 & -7.54 \\
\hline 4 & 15 & 17 & 14 & 11 & 9.07 & -8.42 & 4.40 & -7.21 \\
\hline 6 & 18 & 22 & 20 & 16 & 8.85 & -0.93 & -5.42 & -2.33 \\
\hline 7 & 15 & 15 & 15 & 12 & 2.46 & -12.96 & 2.20 & -0.48 \\
\hline 8 & 15 & 14 & 12 & 12 & 6.51 & -6.01 & 6.57 & -2.22 \\
\hline 10 & 15 & 17 & 15 & 12 & 5.02 & 3.18 & -1.58 & 1.55 \\
\hline 11 & 14 & 18 & 13 & 12 & 10.70 & -10.11 & 2.79 & -5.69 \\
\hline 12 & 16 & 17 & 14 & 13 & 6.95 & -10.06 & 5.02 & -11.32 \\
\hline 44 & 12 & 12 & 10 & 11 & -5.12 & 9.42 & -0.44 & -2.89 \\
\hline 45 & 15 & 17 & 15 & 13 & -2.49 & 2.77 & . & -4.65 \\
\hline 46 & 12 & 15 & 15 & 13 & 2.42 & -2.89 & 2.56 & 0.86 \\
\hline 47 & 12 & 13 & 12 & 13 & -3.39 & -3.22 & . & -2.67 \\
\hline 50 & 12 & 13 & 12 & 11 & -6.46 & -1.08 & . & . \\
\hline 51 & 14 & 16 & 21 & 15 & . & 0.79 & . & $\cdot$ \\
\hline 52 & 13 & 13 & 11 & 9 & 7.12 & -10.35 & 4.33 & -10.55 \\
\hline 54 & 21 & 27 & 29 & 29 & -3.64 & 16.61 & -9.35 & 14.54 \\
\hline 56 & 14 & 18 & 13 & 12 & 5.74 & -7.57 & 1.80 & -9.95 \\
\hline 57 & 14 & 14 & 32 & 28 & . & 14.26 & . & 40.24 \\
\hline 60 & 12 & 14 & 11 & 12 & 3.93 & -11.76 & 2.71 & -8.88 \\
\hline 61 & 19 & 21 & 22 & 18 & -3.68 & 3.10 & -0.44 & 0.16 \\
\hline 62 & 12 & 13 & 18 & 13 & -3.25 & -1.76 & . & 1.55 \\
\hline 63 & 22 & 22 & 23 & 19 & -10.58 & 1.38 & . & -5.87 \\
\hline 64 & 12 & 13 & 12 & 15 & 8.09 & 0.59 & 3.55 & 0.10 \\
\hline 65 & 12 & 16 & 19 & 12 & 15.44 & 7.13 & -3.47 & \\
\hline 66 & 15 & 15 & 13 & 11 & 5.99 & -9.47 & -0.96 & -0.16 \\
\hline 83 & 16 & 15 & 14 & 12 & 12.27 & -12.94 & 8.84 & -14.33 \\
\hline 91 & 14 & 16 & 9 & 11 & 9.33 & -12.73 & 8.07 & -14.81 \\
\hline 93 & 13 & 14 & 13 & 11 & -3.58 & -4.83 & -3.03 & -2.06 \\
\hline 94 & 18 & 15 & 15 & 11 & 6.25 & -4.41 & & -2.00 \\
\hline 95 & 24 & 33 & 43 & 39 & . & 22.22 & -13.43 & 37.85 \\
\hline 96 & 18 & 17 & 16 & 14 & 5.38 & -4.59 & 5.45 & -1.81 \\
\hline 98 & 9 & 12 & 12 & 9 & . & . & . & \\
\hline 104 & 12 & 16 & 13 & 10 & . & -1.51 & . & . \\
\hline 105 & 10 & 9 & 9 & 7 & . & . & . & . \\
\hline 106 & 14 & 17 & 13 & 15 & 7.04 & 1.72 & . & -7.67 \\
\hline 107 & 11 & 14 & 12 & 12 & 12.78 & -11.80 & 2.77 & -8.70 \\
\hline
\end{tabular}




\begin{tabular}{|c|c|c|c|c|c|c|c|c|}
\hline 108 & 9 & 15 & 13 & 11 & 2.04 & 8.74 & -2.42 & -3.61 \\
\hline 111 & 11 & 17 & 13 & 12 & 2.50 & 0.71 & -2.68 & 4.70 \\
\hline 112 & 21 & 18 & 17 & 15 & 8.00 & -11.93 & 9.48 & -11.27 \\
\hline 125 & 12 & 12 & 12 & 12 & 2.17 & -1.51 & -1.36 & -3.65 \\
\hline 127 & 14 & 15 & 13 & 11 & 3.16 & -9.58 & 0.88 & -7.67 \\
\hline 129 & 19 & 19 & 16 & 17 & -1.31 & 1.30 & -1.86 & -0.48 \\
\hline 150 & 14 & 11 & 12 & 12 & 3.38 & -4.51 & 4.24 & -2.94 \\
\hline 153 & 11 & 10 & 12 & 10 & 1.88 & 0.65 & . & -3.18 \\
\hline 154 & 12 & 13 & 11 & 10 & -6.73 & -4.14 & . & . \\
\hline 155 & 13 & 13 & 11 & 9 & 2.90 & . & 2.35 & . \\
\hline 156 & 13 & 14 & 12 & 13 & 3.19 & -9.77 & -1.53 & -8.23 \\
\hline 157 & 12 & 14 & 12 & 8 & 11.51 & -10.93 & -0.95 & . \\
\hline 158 & 19 & 14 & 25 & 29 & -7.93 & 45.03 & . & 43.92 \\
\hline 159 & 10 & 13 & 9 & 10 & 5.96 & -12.48 & 7.89 & -15.77 \\
\hline 161 & 11 & 12 & 12 & 11 & -3.46 & -1.02 & -1.55 & -0.04 \\
\hline 162 & 13 & 13 & 12 & 12 & 4.69 & -1.57 & 8.60 & -7.14 \\
\hline 163 & 14 & 13 & 13 & 10 & 8.74 & -9.10 & 7.96 & -11.79 \\
\hline 164 & 12 & 11 & 11 & 9 & 19.29 & -9.91 & 4.00 & -10.22 \\
\hline 165 & 12 & 14 & 15 & 12 & 8.55 & -1.84 & 4.81 & -7.23 \\
\hline 166 & 17 & 17 & 13 & 13 & 6.34 & -8.61 & 9.72 & -1.56 \\
\hline 167 & 12 & 12 & 14 & 10 & 3.04 & -3.82 & 1.55 & -6.67 \\
\hline 168 & 15 & 16 & 17 & 14 & 4.23 & -6.45 & -2.98 & -1.16 \\
\hline 169 & 14 & 15 & 12 & 11 & -0.06 & -4.26 & 5.87 & 1.31 \\
\hline 170 & 13 & 15 & 13 & 12 & 2.79 & -5.93 & 0.36 & -2.86 \\
\hline 171 & 11 & 11 & 11 & 11 & -0.04 & -2.14 & -2.53 & -3.27 \\
\hline 172 & 13 & 16 & 11 & 13 & -5.13 & -4.50 & . & -2.41 \\
\hline 173 & 14 & 19 & 15 & 13 & 0.62 & -3.44 & -1.64 & 3.08 \\
\hline 174 & 10 & 12 & 9 & 10 & -0.01 & -7.47 & 3.66 & 1.82 \\
\hline 175 & 13 & 14 & 14 & 13 & -0.41 & -0.99 & 1.34 & 2.81 \\
\hline 177 & 12 & 13 & 10 & 9 & 5.86 & -5.84 & -2.01 & -5.76 \\
\hline 178 & 38 & 29 & 47 & 40 & -22.73 & 84.05 & . & 22.35 \\
\hline 179 & 12 & 10 & 11 & 10 & 6.31 & 4.48 & 5.69 & -3.38 \\
\hline 181 & 11 & 13 & 12 & 10 & -3.18 & -5.29 & 3.35 & -3.63 \\
\hline 182 & 16 & 14 & 16 & 14 & -0.92 & 8.58 & -4.74 & 19.90 \\
\hline 186 & 11 & 12 & 9 & 8 & 3.66 & -10.05 & 0.92 & -11.70 \\
\hline 187 & 9 & 12 & 10 & 10 & . & -1.84 & 0.00 & . \\
\hline 188 & 12 & 11 & 13 & 9 & 11.93 & -7.37 & 1.04 & -12.03 \\
\hline 189 & 10 & 12 & 12 & 11 & 1.47 & -3.85 & 0.54 & 0.21 \\
\hline 190 & 14 & 14 & 13 & 12 & 11.51 & -9.31 & 6.85 & -11.48 \\
\hline 191 & 12 & 12 & 12 & 10 & 9.01 & -6.14 & 13.16 & -12.68 \\
\hline 192 & 10 & 12 & 10 & 9 & 13.73 & -11.90 & 11.09 & -11.43 \\
\hline
\end{tabular}




\section{REFERENCES}

Adler, N.E. \& Ostove, J.M. (1999). SES \& Health: What We Know and What We Don't. In Adler, N.E., Marmot, M., McEwen, B.S. \& Stewart, J. (Eds.) Socioeconomic Status and Health in Industrial Nations: Social, Psychological and Biological Pathways. 896:315. New York, NY: NY Academy of Sciences.

Anderson R.N., Kochanek K.D., Murphy S.L. (1995). Report of final Mortality statistics, http://www.suicidepreventtriangle.org/UsRates.htm.

Barnett E., Halverson J.A. (2001). Local Increases in Coronary Heart Disease Mortality Among Blacks and Whites in the United States, 1985-1995. American Journal of Public Health. 91:1499-1506.

Barnett E., Elmes G.A., Braham V.E., Halverson J.A., Lee J.Y., Loftus S. (1998). Heart Disease in Appalachia: An Atlas of County Economic Conditions, Mortality, and Medical Care Resources. Prevention Research Center, West Virginia University, Morgantown, WV.

Bartley M., Owen C. (1996) Relation Between Socioeconomic Status, Employment, and Health During Economic Change, 1973-93. British Medical Journal. 313:445-449.

Baqir, R. (2002). Districting and Government Overspending, Journal of Political Economy. 1318-1354.

Bell C. (2001). What Depression is and What Depression Feels Like. Accessed on September 27, 2002: http://www.emufarm.org/ cmbell/depress/depwhat.html

Berkman L.F., Glass T., Brissette I., Seeman T.E. (2000), From Social Integration to Health: Durkheim in the New Millenium, Social Science and Medicine. 51:843-857.

Brenner M.H. (1979). Mortality and the National Economy. The Lancet. 2(8142):568-73.

Brenner M.H. (1987). Economic Instability, Unemployment Rates, Behavioral Risks, and Mortality Rates in Scotland, 1952-1983. International Journal of Health Services. 17(3):475-87.

Casetti, E. (1972). Generating Models by the Expansion Method: Applications to Geographic Research, Geographical Analysis. 4:81-91.

Crawford M.J., Prince M. (1999). Increasing Rates of Suicide in Young Men in England During the 1980s: the Importance of Social Context. Social Science and Medicine. 49:1419-1423. 
Cox K. (1998). Spaces of Dependence, Spaces of Engagement and the Politics of Scale, or: Looking for Local Politics. Political Geography.17(1):1-23.

Cox K., Mair A. (1988). Locality and Community in the Politics of Local Economic Development. Annals of the Association of American Geographers. 78(20):307-325.

DeNavas-Walt C., Proctor B.D., Mills R.J., U.S. Census Bureau. (2004). Current Population Reports, P60-226, Income, Poverty, and Health Insurance Coverage in the United States: 2003. U.S. Government Printing Office. Washington, D.C.

Dooley D., Catalano R. (1984). The Epidemiology of Economic Stress. American Journal of Community Psychology.12:387-409.

Eitzen D.L., Zinn M.B. (1989). The Reshaping of America: Social Consequences of the Changing Economy. New Jersey: Prentice Hall.

Eyer J. (1976). Review of Mental Illness and The Economy. International Journal of Health Services. 6(1):139-168.

Farber M. (1968). Theory of Suicide. New York: Funk, \& Wagnalls.

Ferrie J.E., Shipley M.J., Marmot M.G., Standfeld S.A., and Smith G.D. (1998). An Uncertain Future: the Health Effects of Threats to Employment Security in White-Collar Men and Women. American Journal of Public Health. 88(7):1030-1036.

Gibbs G., Martin W. (1964). Status Integration \& Suicide. Eugene: University of Oregon Press.

Halverson J.A., Ma L., Harner E.J. (2004). An Analysis of Disparities in Health Status and Access to Medical Care in the Appalachian Region, Report to the Appalachian Regional Commission.

Hopper K., Guttmacher S. (1979). Rethinking Suicide: Notes Toward a Critical Epidemiology. International Journal of Health Services. 9:3: 417-438.

Isserman A.M. (1997) Appalachia Then and Now: An Update of "The Realities of Deprivation" reported to the President in 1964. Journal of Appalachian Studies. 3(1), 4369.

Johansson S.E., Sundquist J. (1997) Unemployment is an important risk factor for suicide in contemporary Sweden: an 11-year follow-up study of a cross-sectional sample of 37,789 people. Public Health. 111, 41-45. 
Kawachi I. (1999). Social Capital and Community Effects on Population and Individual Health. In Adler, N.E., Marmot, M., McEwen, B.S. \& Stewart, J. (Eds.) Socioeconomic Status and Health in Industrial Nations: Social, Psychological, and Biological Pathways. 896: 120-130. New York, NY Academy of Sciences.

Kearns RA, Joseph A.E. (1993). Space in its Place: Developing the Link in Medical Geography. Social Science and Medicine. 37(6):711-7.

Kennedy B.P., Kawachi I., Glass R.,Prothrow-Stith D. (1998). Income Distribution, Socioeconomic Status, and Self Rated Health: Multilevel Analysis. British Medical Journal. 317(7163):917-921.

Kleinman J.C. (1986). State trends in infant mortality, 1968-83, American Journal of Public Health. 76(6): 681-687.

Kochanek, K. D., Murphy, S. L., Anderson, R. N., \& Scott, C. (2004). Deaths: Final data for 2002. National Vital Statistics Reports, 53 (5). Available online at http://www.cdc.gov/nchs/data/nvsr/nvsr53/nvsr53 05acc.pdf. Hyattsville, Maryland: National Center for Health Statistics.

Kposowa A.J. (1999). Marital Status and Suicide in the National Longitudinal Mortality Study. Journal of Epidemiology and Community Health. 54: 254-261.

Leenaars A.A., Yang B., Lester D. (1993) The Effect of Domestic and Economic Stress on Suicide Rates in Canada and the United States. Journal of Clinical Psychology. 49(6):918-921.

Levin K.A., Leyland A.H. (2005). Urban/Rural Inequalities in Suicide in Scotland, 19811999. Social Science and Medicine. 60: 2877-2890.

Lobao L. and Rulli J. (1996). Economic Change and its Extraeconomic Consequences. Commentaries. Environment and Planning A. 28: 606-610.

Lobao L.M. (1990). Locality and Inequality: Farm and Industry Structure and Socioeconomic Conditions, Albany: The State University of New York Press.

Lobao LM, Rulli J. (1997). Public Policies, Economic Restructuring, and Regional and Local Outcomes: the Ohio River Valley. Working Paper Series, UK, 1997.

Massey D. (1995). Spatial Divisions of Labor: Social Structures and the Geography of Production. New York. Routledge.

Matsuoka J.K., Benson M. (1996). Economic Change, Family Cohesion, and Mental Health in a Rural Hawaii Community, Families in Society. 108-116. 
Mitchell P.B. (2004). Is Antidepressant Prescribing Associated With Suicide Rates? Psychiatric Times. 21:6.

Morell S., Taylor R., Slaytor E., Ford P. (1999). Urban and Rural Suicide Differentials in Migrants and the Austrailian-Born, New South Wales, Australia 1985-1994. Social Science and Medicine. 49:81-91.

National Institute of Mental Health. (2001). Older adults: depression and suicide facts. Accessed on September 27, 2002: http://www.nimh.nih.gov/publicat/elderlydepsuicide.cfm.

National Institute of Mental Health. Suicide Facts. http://www.nimh.nih.gov/research/suifact.htm, pp.1-2.

Nielsen F., Alderson A.S. (1997). The Kuznets Curve and The Great U-Turn: Income Inquality in U.S. Counties, 1970 to 1980. American Sociological Review. 62:12-33. Olfson M., Guardino M., Struening E., Schneier F.R., Hellman F., Klein D.F. (2000). Barriers to the Treatment of Social Anxiety. American Journal of Psychiatry. 157:4:521527.

Ostamo A., Lahelma E., Lonnqvist J. (2001). Transitions of Employment Status Among Suicide Attempters During a Severe Economic Recession, Social Science and Medicine. 52:1741-1750.

Preti A, Miotto P. (1999). Suicide and Unemployment in Italy. 1982-1994.

Journal of Epidemiology and Community Health. 53: 694-701.

Proenca M. (2001). History of Suicide. Accessed on September 27, 2002:

http://www.suicide-parasuicide.rumos.com/en/articles/suicide/history of suicide.htm

Rich C.L., Young D., Fowler R.C. (1986). San Diego Suicide Study. General Psychiatry. 43: 577-582.

Saunderson T.R., Langford I.H. (1996). A Study of the Geographical Distribution of Suicide Rates in England and Wales 1989-92 Using Empirical Bayes Estimates. Social Science and Medicine.43(4):489-502.

Sclar E.D. (1980). Community Economic Structure and Individual Well-Being: A Look Behind the Statistics. International Journal of Health Services. 10(4):563-79.

Smith, N. (1990). Uneven Development: Nature, Capital and the Production of Space. Second Edition. Oxford: Basil Blackwell.

Storper M. and Walker R. (1989). The Capitalist Imperative: Territory, Technology, and Industrial Growth. Oxford:Basil Blackwell. 
Tolbert C.M. and Sizer-Killian M.(1987). Labor Market Areas for the United States.U.S.D.A, Economic Research Service, Agriculture and Rural Economy Division.

U.S. Public Health Service. (1999). The Surgeon General's Call To Action To Prevent Suicide. Washinton, DC.

U.S. Department of Health and Human Services, Centers for Disease Control. (1997). Regional Variations in Suicide Rates, 1990-1994. Morbidity and Mortality Weekly Report. August 29, 1997.

Waitzman N.J., Smith K.R. (1998). Separate but Lethal: the Effects of Economic Segregation on Mortality in Metropolitan America. The Milbank Quarterly. 76(3): 341373.

Winkleby M.A., Cubbin C., Ahn D.K., Kraener H.C. (1999). Pathways by Which SES and Ethnicity Influence Cardiovascular Disease Risk Factors. In Adler, N.E., Marmot, M., McEwen, B.S. \& Stewart, J. (Eds.). Socioeconomic Status and Health in Industrialized Nations: Social, Psychological, and Biological Pathways. 896: 191-209. New York, NY: NY Academy of Sciences.

Weyerer S., Wiedenmann A. (1995). Economic Factors and the Rates of Suicides in Germany Between 1981 and 1989. Psychol. Rep. 76:1331 - 1341.

Zimmerman, S.L. (1988). State-Level Public Policy as a Predictor of Individual and Family Well-Being. Women and Health.12: 3-4:161- 188. 